\title{
Questioning the rater idiosyncrasy explanation for error variance by searching for multiple signals within the noise
}

Citation for published version (APA):

Gingerich, A. M. (2015). Questioning the rater idiosyncrasy explanation for error variance by searching for multiple signals within the noise. [Doctoral Thesis, Maastricht University]. Datawyse / Universitaire Pers Maastricht. https://doi.org/10.26481/dis.20150903ag

Document status and date:

Published: 01/01/2015

DOI:

10.26481/dis.20150903ag

Document Version:

Publisher's PDF, also known as Version of record

Please check the document version of this publication:

- A submitted manuscript is the version of the article upon submission and before peer-review. There can be important differences between the submitted version and the official published version of record.

People interested in the research are advised to contact the author for the final version of the publication, or visit the DOI to the publisher's website.

- The final author version and the galley proof are versions of the publication after peer review.

- The final published version features the final layout of the paper including the volume, issue and page numbers.

Link to publication

\footnotetext{
General rights rights.

- You may freely distribute the URL identifying the publication in the public portal. please follow below link for the End User Agreement:

www.umlib.nl/taverne-license

Take down policy

If you believe that this document breaches copyright please contact us at:

repository@maastrichtuniversity.nl

providing details and we will investigate your claim.
}

Copyright and moral rights for the publications made accessible in the public portal are retained by the authors and/or other copyright owners and it is a condition of accessing publications that users recognise and abide by the legal requirements associated with these

- Users may download and print one copy of any publication from the public portal for the purpose of private study or research.

- You may not further distribute the material or use it for any profit-making activity or commercial gain

If the publication is distributed under the terms of Article $25 \mathrm{fa}$ of the Dutch Copyright Act, indicated by the "Taverne" license above, 


\section{QUESTIONING THE RATER IDIOSYNCRASY EXPLANATION FOR ERROR VARIANCE}

BY SEARCHING FOR MULTIPLE SIGNALS WITHIN THE NOISE

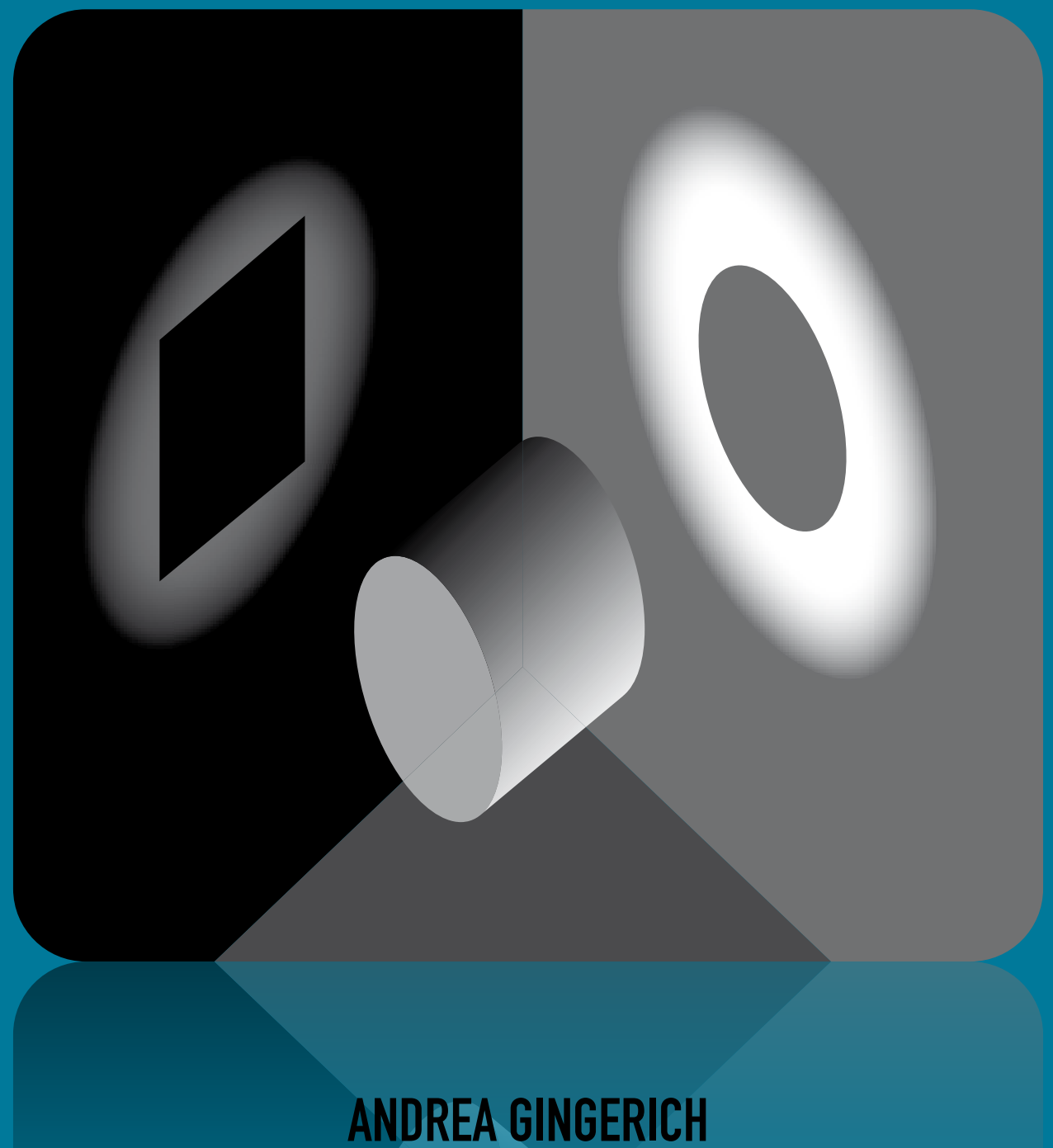


The research reported in this dissertation was carried out through

\section{DM Maastricht University in Learning!}

within the School of Health Professions Education

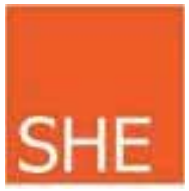

at the Northern Medical Program

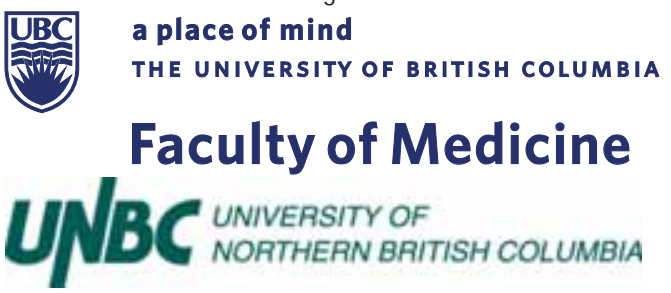

with funding for the review article 'Rater-based assessments as social judgments: Rethinking the etiology of rater errors' through a small grant from the Society of Directors of Research in Medical Education (a nonprofit organization [501c3]) and funding for all empirical research through a substantial Edward J. Stemmler, MD, Medical Education Research Fund grant from

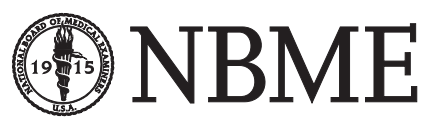

National Board of Medical Examiners

Front cover illustration

The image (author unknown) was chosen as an analogy for this program of research. It shows two shadows: one a circle and the other a square. From one perspective, someone would report observing a circular shadow and may infer the object casting it was a sphere. Viewed from a different perspective, another person would report observing a square-shaped shadow and might infer that the object casting it was a cube. Both people would be reporting on the same object and their observations would conflict. What we need, metaphorically, is an assessment system that will combine their reports in a way that will allow us to learn that the object casting the shadow is likely a cylinder.

Back cover illustration

Cornsweet edge optical illusion

Image courtesy of Purves, D. et al. (2002)."Why we see what we do." American Scientist 90(3): 236-243.

(c) copyright Andrea Gingerich, M aastricht 2015

ISBN 9789461594556

Printing: Datawyse | Universitaire Pers M aastricht 


\title{
Questioning the rater idiosyncrasy explanation for error variance by searching for multiple signals within the noise
}

\author{
DISSERTATION \\ to obtain the degree of Doctor at Maastricht University, \\ on the authority of the Rector M agnificus Prof.Dr. L.L.G. Soete, \\ in accordance with the decision of the Board of Deans, \\ to be defended in public on Thursday, September $3^{\text {rd }}, 2015$ at 14:00 hours \\ by
}

Andrea Gingerich

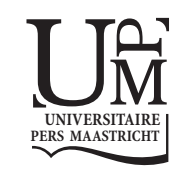




\section{Supervisors}

Prof. Dr. C.P.M . van der Vleuten

Prof. Dr. K.W. Eva, University of British Columbia

Prof. Dr. G. Regehr, University of British Columbia

\section{Assessment Committee}

Prof. Dr. S. Heeneman, chair

Dr. E.W. Driessen

Prof. Dr. J.J.G. van Merriënboer

Prof. Dr. L.W.T. Schuwirth, Flinders University

Prof. Dr. R.G. Williams, Indiana University 
To three wise men in the North: Hanh Huynh, Geoff Payne and Dave Snadden who dared to think outside of the box and then helped me to go over, under or around the boxes obscuring my path to completing this dissertation. 



\section{Table of Contents}

CHAPTER 1 Introduction

CHAPTER 2 Seeing the 'black box' differently:

Assessor cognition from three research perspectives

CHAPTER 3 Rater-based assessments as social judgments:

Rethinking the etiology of rater errors

CHAPTER 4 More consensus than idiosyncrasy:

Categorizing social judgments to examine variability in M ini-CEX ratings

CHAPTER 5 Comparing the ability of social judgment theories to explain rater variance in M ini-CEX assessments

CHAPTER 6 Consistently variable:

Multiple points of view for a clinical performance predict ratings

CHAPTER 7 Discussion

Summary

Samenvatting (Summary in Dutch)

Addendum: Valorization paragraph

Curriculum vitae

SHE dissertations series 

CHAPTER

Introduction 

Workplace-based assessments, objective structured clinical examinations, problem based learning tutorial assessments and simulation debriefing sessions are some of the important assessment opportunities in medical education curricula that rely on assessors observing a trainee's performance and making an assessment judgment. Raterbased assessments are used at all levels of training for both formative and summative purposes including high-stakes decisions by medical licensing bodies. ${ }^{1-3}$ They are valued because they allow the assessment of performance of skills and interactions with patients that are not well assessed using written examinations. ${ }^{4,5}$ Rater-based assessments are an integral tool in assessment programs and, as a result, they receive frequent study and review in the medical education literature. ${ }^{6-11}$ This research largely reveals psychometric weaknesses which are problematic for making defensible assessment decisions due to adverse effects on reliability. ${ }^{7,12,13}$ These measurement limitations, which are commonly labeled as high error variance, are often attributed to limitations of raters. ${ }^{13-22}$

An underlying assumption of rater-based assessments is that in a perfect world, under ideal training and assessment conditions, we would expect that different raters assessing the same performance under the same conditions should make the same observations, same interpretations and assign the same ratings. ${ }^{12}$ Therefore, in our imperfect world, consensus is used as a proxy for accuracy, and we assume that the overlapping part of judgments is the signal of interest. In Generalizability theory, for example, the desirable variance is labeled "Ratee" and refers to the differences attributable to the person(s) being assessed. ${ }^{23-25}$ Any variability outside of this Ratee variance is labeled as error in the measurement or noise. ${ }^{13,25,26}$ The error component can be further divided into variance components including a few which feature prominently in analyses of rater-based assessments in medical education. In particular, stable idiosyncratic rater variance components including rater-specific rating styles ${ }^{13,19,20,27}$ (e.g. leniency and severity patterns) and variance caused by the unique interaction between a particular rater and a traine $e^{17,18,28,29}$ can comprise substantial proportions of the error variance. Other error components not related to the rater, such as variance associated with context, ${ }^{30-33}$ can also be substantial.

Statistical "rater error" is not necessarily synonymous with raters committing errors. ${ }^{25,34-37}$ Nonetheless, in the discourse of rater-specific variance components, it is clear that the source of this variance -- especially when the ratings have been assigned for the same observed performance -- is understood to be the result of raters committing mistakes or omissions or being biased. ${ }^{14,38-40}$ This is the rater idiosyncrasy explanation that is referred to in this dissertation: the understanding that variance attributed to raters is caused by the shortcomings of raters. More specifically, it refers to rating variance that is attributable to the sample of raters who provide the ratings and is, therefore, seemingly unrelated to the trainee's competence. Given this understanding 
of rater error, efforts to improve the measurement outcomes of rater-based assessments have been directed at supporting physicians to work better within the assessment procedures through faculty development ${ }^{41}$ and through objectification of assessment strategies. ${ }^{42-45}$ Unfortunately, these solutions have had less success at improving measurement outcomes than anticipated. ${ }^{7,38,46-52}$

The inability of these solutions to sufficiently correct measurement errors in raterbased assessments may result from a flaw in the underlying assumption that different people ought to make the same interpretation based on the same data. Decades of research in psychology, however, suggests that people cannot interpret the same stimulus the same way. Rather, humans automatically interpret data, as soon as it is perceived, by filtering it through their own unique past experiences. ${ }^{53,54}$ As information is noticed in the environment, different parts of the human brain simultaneously analyze it, organize it, and construct it into something meaningful and understandable. ${ }^{53,55}$ From psychophysics ${ }^{56}$ to eyewitness testimony ${ }^{57}$ and from first impressions ${ }^{58}$ to wine connoisseurship, ${ }^{59}$ perception of the same stimuli does not always result in the same interpretation, judgment or evaluation. With respect to performance assessments, what this suggests is that variable interpretations might reflect different legitimate interpretations, which would require us to change our assumptions regarding the meaning of variance components that are typically labeled as error. For example, we could no longer assume that only the inter-rater consensus variance component necessarily represented the construct relevant variance. Therefore, current solutions that aim to improve inter-rater agreement or reliability and minimize rater error components may no longer be considered sufficient for the utility of rater-based assessments.

\section{BACKGROUND ON THIS RESEARCH PROGRAM}

The problem outlined above creates a challenge for the medical education community in that contemporary approaches to the study of assessment, which are largely based on psychometric models, allow one only to parcel out variance into different facets without any opportunity to determine whether or not "error" could actually represent meaningful differences of perspective. Demonstrating the utility of rater-based assessment is needed; but, the extent to which measurement limitations are by default attributed to the fallibility of human judgment (i.e., rater "error"), is the extent to which one is prevented from seeing whether or not some different opinions might be equally valid. This dissertation documents a line of research that investigates this problem from a different angle, challenging us to think differently about it and question what we think we know about it. It provokes us to re-examine our assumptions regarding rater-based assessments, and at least temporarily set aside some of those assumptions while novel ones are investigated. This line of research germinated out of a curi- 
osity regarding how multiple people could observe the same performance and make very different interpretations and judgments about what they saw. It is especially perplexing to see such variability when the people involved are well-intentioned, trained and conscientious. The timeliness of these ideas is evidenced by our program of research being one of several investigating inter-rater variation in recent years. ${ }^{60-64}$ Our research draws into health professional education the findings from an unrelated field (social cognition) where it has also been found that multiple people can form different impressions and social judgments of the same person $n^{65,66}$ as a way of understanding inter-rater variation in rater-based assessments.

Psychology, and more specifically social cognition, researchers have spent considerable time studying how people perceive and represent others in their minds..$^{5,67,68}$ Social categorization has been heavily investigated as part of the process for forming impressions about others. ${ }^{69}$ Several theories have been proposed to explain the underlying mechanisms of categorization including the use of pre-conceived labels ${ }^{70}$ (e.g. as in the use of stereotypes); judgments made on universal social dimensions ${ }^{71}$ (e.g. warmthcompetence model); and story-telling models ${ }^{65,66}$ (e.g. Person Model theory). Among the different conceptualizations of social categorization, we were initially most intrigued by research findings from the Person Model theory. In this theory, impressions are represented as stories spontaneously created about a target person as raters are exposed to each new piece of information about the individual. ${ }^{65,66}$ At first glance, a conceptualization of categorization with this much flexibility and room for idiosyncrasy has unsettling implications if a comparable process were to be involved with rater cognition in rater-based assessments. However, the study conducted by Mohr and Kenny (2006) exploring this model of impression formation suggests that there is more consistency in the impressions than might be imagined. When researchers asked 69 people to watch the same 4 minute video of a person in conversation and then write about what they thought of that person, instead of receiving 69 uniquely interpreted narratives, the narratives could be categorized into three prototypical stories. The stories were very different from one another in terms of content. Further, accounting for there being three impressions generated for the individual, rather than only one, explained a significant proportion of "error variance" in the social judgment ratings.

This research led us to question how much variance might be explained if we assumed that physician raters similarly formed one of a few different, but equally legitimate, impressions when observing a single trainee. To use an example from a very different context, imagine that three different raters interpreted the stimulus of a killer whale as belonging to one of three different categories: "dolphin", "endangered species," and "apex predator". All three categories are accurate and applicable to a killer whale but each is very different from one another, not only in terms of the features that are most pronounced in these characterizations, but also in terms of the impressions they gen- 
erate. It is conceivable that if these raters were then asked to assess the killer whale's overall "competence", the rater who invoked a more victim-like endangered species category may assign lower ratings than the rater who categorized it as a predator at the top of the food chain. Perhaps the rater who categorized a killer whale as the largest member of the dolphin family would give the highest competency ratings?

All three of these categories are legitimate, and if they were to be associated with different ratings it may not be appropriate to describe the resulting score differences as either "mistakes" made by raters or simply as statistical "error". Even though they are all rating a killer whale, when asked to assess its competence it is doubtful that they are all aligned in their target in a comparable way that multiple people guessing the weight of an ox are all basing their judgments on the same dimension. When judging the weight of an $\mathrm{ox}$, everyone has a similar concept of the tangible metric of weight and each is equally likely to guess a bit high or a bit low. Therefore, averaging across their responses produces a better answer than any one individual's response. ${ }^{72} \mathrm{~A}$ key aspect of these sorts of judgments is that weight is a tangible construct that is easily measured in numbers whereas competence is not--it is inferred and is inferred from a potentially complex interaction between many dimensions. ${ }^{43,44,73-75}$ It is doubtful that averaging the inferred competence of a dolphin, an endangered species and an apex predator would provide a better estimate of a killer whale's competence, but perhaps another mechanism for combining those inferences and categorizations might.

In sum, the underlying premise of this dissertation is that there may be more than one signal within the noise of variable assessment judgments and ratings. In other words, if raters are making different categorical judgments and forming different impressions of the same performance, it could result in multiple different points of consensus within their varied descriptions of the performance. By adopting the assumption that the majority of raters are trying to give us good assessment information and that they are capable of giving us good assessment information, when they give us variable or different or conflicting ratings and judgments, those differences may actually reflect valid points of view. This dissertation describes an exploratory line of research searching for multiple interpretations of the same performance and analyzing them to see if they best represent idiosyncratic views of individuals that reveal more about the personal biases of the raters than the trainee or if they represent multiple legitimate interpretations of the performance.

\section{RESEARCH DESIGN AND QUESTIONS}

The main purpose for this dissertation is to determine if it is possible to identify multiple, distinct assessment interpretations within the variable comments and ratings 
provided by raters. We focused on workplace-based assessment, in particular M ini-CEX assessments, for a number of reasons. The Mini-CEX is a commonly used and wellresearched assessment tool. ${ }^{6,7,76-79}$ Further, workplace-based assessment offers critical assessment opportunities and is a foundation for trainee's learning. ${ }^{5,80}$ It is an important assessment modality, but, because of its unpredictable nature, many typical techniques cannot be easily used to reduce its error variance and it could benefit from novel solutions. We used video-recorded clinical performances to ensure multiple raters observed the same clinical performances. The use of videos ensured that all participants who provided ratings for a particular trainee had observed exactly the same performance such that any differences in their ratings could not to be due to differences in the trainee. Although workplace-based assessments are usually conducted live and in-person, ratings based on videos have been found to be comparable to ratings based on live performances in recent studies. ${ }^{61,81-83}$

Psychometrics, in particular, assumes raters are aiming at the same target or construct when they are assessing the same ratee. To search for the possibility that multiple targets or signals are influencing rater-based assessment requires an analysis tool that allows for that possibility. To that end, we drew upon the social judgment literature to provide a framework and methodology to guide our search for multiple signals. ${ }^{65} \mathrm{Im}$ plementation into the medical education context required the use of sorting tasks called latent partition analysis ${ }^{84,85}$ and Q methodology. . $^{86,87}$

\section{Ethical considerations}

Our investigation of complex clinical assessment judgments required recruiting experienced physicians as raters. The primary ethical focus was on respectfully recruiting and collecting the perceptions of these individuals. In addition to abiding by the standard guidelines issued by the ethic boards, we conducted ample pilot testing to ensure we were respecting their time and making the best use of the data participants provided. This preparation included consulting with experts to ensure our design, data collection and analysis, were appropriate. We also took extra precautions to ensure responses remained safe, private and usable because our data were collected online.

\section{DISSERTATION OUTLINE INCLUDING MAIN AND SUB RESEARCH QUESTIONS}

This dissertation includes two theoretical papers that are structured as reviews of the literature. The first explores the constructions of rater variance from three different perspectives in an effort to fully articulate the ways in which this issue has been, and is 
being, approached in medical education. The third perspective offered in that paper represents the approach that is being pursued in this program of research.

The second literature review paper explores more deeply the theoretical underpinnings of this new perspective on rater variance by drawing on theories of impression formation from social cognition research. This second theoretical paper sets the stage for the empirical research studies of the dissertation.

The subsequent three chapters represent empirical research from two research studies. Methodologies from social cognition and social sciences research were used to search for multiple shared impressions within rating variability. The first of these research papers introduced the method of latent partition analysis to the medical education community and served as a "proof of concept" analysis for the work. The second research paper draws on additional data from the same data set and further investigates rater variance using this same methodology. The third research paper presents a triangulation of the findings using a new set of participants and a different methodology.

Research Questions

\section{Main research question 1}

- How have medical education researchers associated raters with "measurement error"?

\section{Sub questions}

- In what ways has assessor cognition been explored as a source of variability in performance assessment judgments?

- What else could variability in ratings for a single performance be if not rater idiosyncrasy?

\section{Main research question 2}

- How well suited is human cognition for the tasks asked of raters in our current rater-based assessment designs?

Sub questions

- How does the social cognition literature and its investigation of impression formation and social judgments stimulate us to re-think the sources of variability in rater-based assessment judgments?

- How reasonable is it to expect multiple raters to perceive, interpret, judge and rate the same performance in exactly the same way? 
Chapter 2 provides the foundation to address main research question la by describing the current state of assessor cognition research in medical education. It describes three distinct, but not mutually exclusive, perspectives on the origins and possible solutions to variability in assessment judgments. The first perspective asserts that assessors vary because they do not apply assessment criteria correctly, use varied frames of reference and make unjustified inferences. The second perspective asserts that variations arise due to fundamental limitations in human cognition that mean assessors are readily influenced by their immediate context. Both of these perspectives view variable ratings as evidence of raters' mistakes or cognitive limitations. The third perspective addresses questions $1 b$ and $2 a$ by asserting that experts are capable of making sense of highly complex and nuanced scenarios through inference and contextual sensitivity but may do so in different ways. It introduces the potential for variable ratings to represent legitimate experience-based interpretations. Together, these diverse literatures can be used to look for answers to question $2 \mathrm{~b}$.

Chapter 3 further addresses questions $1 \mathrm{~b}$ and $2 \mathrm{a}$ by delving deeper into the social judgment literature to discover raters may form categorical judgments about ratees as part of impression formation. The proposed mechanisms for social categorization are grouped into three theories: Nominal Labels, that posits impressions are formed by assigning a person to a pre-conceived group; Two-Dimensions, that posits social judgments are made by categorizing a person into one of four quadrants based on judgments of the person's warmth-coldness and competence-incompetence; and Person Models, that posits impressions are formed by spontaneously creating an ad hoc story about the person. Although social categorization could be extremely idiosyncratic, raters tend to consistently construct one of a few possible interpretations of each ratee. In addressing questions $2 a$ and $2 b$, it is proposed that if raters naturally form categorical judgments, an assessment system requiring ordinal or interval ratings may inadvertently introduce conversion errors due to translation techniques unique to each rater.

Both chapters 2 and 3 draw on diverse literatures to describe rater cognition and question the conventional thinking about rater error variance.

\section{Main research question 3}

- How can the search for multiple signals within the noise of rating error variance be conducted when the commonly used statistics assume only one signal?

\section{Sub questions}

- Can the methodology used by Mohr and Kenny (2006) in the social cognition literature, to discover that multiple people formed each of three different impressions for the same focal person, be translated into the clinical performance assessment domain? 
- What other methodologies are available to extend and triangulate potential findings of multiple signals?

\section{Main research question 4}

How could it be possible for different, conflicting or contradictory assessment judgments for the same performance to each contain legitimate assessment information?

\section{Sub questions}

- How many different interpretations can there be for the same performance and what makes each a distinct interpretation?

- How do the different interpretations correspond with the assigned ratings?

Chapter 4 specifically addresses research question 3a by presenting a conceptual replication of Mohr and Kenny's (2006) study from the social cognition literature. It also introduces the methodology of latent partition analysis to medical education. Questions $4 \mathrm{a}$ and $4 \mathrm{~b}$ are addressed when we find that variable assessment judgments partition into a finite number of distinct impressions for the same trainee with raters sharing similar impressions also assigning similar ratings.

Chapter 5 addresses research questions $3 a, 4 a$ and $4 b$ by using the same methodology and raw data introduced in Chapter 4 along with data that was collected but not presented in that chapter. The findings are extended to compare the ability of categories formed through three theories of social categorization, described in Chapter 3, to explain variance in the ratings. Each theory of social categorization identified clusters of consensus which could explain similar proportions of variance in the ratings. Examination of the cluster of consensus that were significant predictors of ratings suggested that raters see different aspects of the same performance as more salient than others, can disagree on the interpretation of the same aspect of a performance, and can form different social judgments to help explain why a trainee is performing in that particular manner at this particular time.

Chapter 6 specifically addressed research question 3b by functioning as a form of triangulation of the findings using a new dataset and a different methodology. The clusters of consensus identified in Chapter 5 were re-studied to address research questions $4 \mathrm{a}$ and $4 \mathrm{~b}$. Taken together, the findings from Chapters 4-6 support the suggestion that there may be multiple signals within the noise of inter-rater variability.

Chapter 7 synthesizes the results from all of the studies and discusses the implications for rater-based assessment.

This dissertation consists of papers written for scientific journals and, as a result, some repetition of information across chapters cannot be avoided. 


\section{REFERENCES}

1 Melnick DE. Licensing examinations in north america: Is external audit valuable? Medical Teacher 2009;31 (3):212-4.

2 Moonen-van Loon J, Overeem K, Donkers H, Van der Vleuten C, Driessen E. Composite reliability of a workplace-based assessment toolbox for postgraduate medical education. Advances in Health Sciences Education 2013;18 (5):1087-102.

3 Naeem N. Validity, reliability, feasibility, acceptability and educational impact of direct observation of procedural skills (DOPS). J Coll Physicians Surg Pak 2013;23 (1):77-82.

4 Fromme HB, Karani R, Downing SM. Direct observation in medical education: Review of the literature and evidence for validity. M ount Sinai Journal of M edicine 2009;76 (4):365-71.

5 Pangaro L, ten Cate 0. Frameworks for learner assessment in medicine: AMEE Guide No. 78. Medical Teacher 2013;35 (6):e1197-e210.

6 Pelgrim E, Kramer A, M okkink H, Van den Elsen L, Grol R, Van der Vleuten C. In-training assessment using direct observation of single-patient encounters: A literature review. Advances in Health Sciences Education 2011;16 (1):131-42.

7 Kogan JR, Holmboe ES, Hauer KE. Tools for direct observation and assessment of clinical skills of medical trainees: A systematic review. JAM A 2009;302 (12):1316-26.

8 Brannick MT, Erol-Korkmaz HT, Prewett M. A systematic review of the reliability of objective structured clinical examination scores. M edical Education 2011;45 (12):1181-9.

9 Jelovsek JE, Kow N, Diwadkar GB. Tools for the direct observation and assessment of psychomotor skills in medical trainees: A systematic review. Medical Education 2013;47 (7):650-73.

10 Cook DA, Brydges R, Zendejas B, Hamstra SJ, Hatala R. Technology-enhanced simulation to assess health professionals: A systematic review of validity evidence, research methods, and reporting quality. Academic Medicine 2013;88 (6):872-83.

11 Gillis AE, Morris MC, Ridgway PF. Communication skills assessment in the final postgraduate years to established practice: A systematic review. Postgraduate M edical Journal 2015;91 (1071):13-21.

12 Downing SM. Reliability: On the reproducibility of assessment data. Medical Education 2004;38 (9):1006-12.

13 M cGill D, van der Vleuten C, Clarke M. Supervisor assessment of clinical and professional competence of medical trainees: A reliability study using workplace data and a focused analytical literature review. Advances in Health Sciences Education 2011;16 (3):405-25.

14 Downing SM. Threats to the validity of clinical teaching assessments: What about rater error? Medical Education 2005;39 (4):353-5.

15 Kreiter CD, Ferguson KJ. Examining the generalizability of ratings across clerkships using a clinical evaluation form. Evaluation \& The Health Professions 2001;24 (1):36.

16 Pulito AR, Donnelly MB, Plymale M. Factors in faculty evaluation of medical students' performance. Medical Education 2007;41 (7):667-75.

17 van Barneveld $C$. The dependability of medical students' performance ratings as documented on intraining evaluations. Academic M edicine 2005;80 (3):309-12.

18 Margolis MJ, Clauser BE, Cuddy M M, Ciccone A, M ee J, Harik P et al. Use of the mini-clinical evaluation exercise to rate examinee performance on a multiple-station clinical skills examination: A validity study. Academic M edicine 2006;81 (10 Suppl):S56-S60.

19 Harasym PH, Woloschuk W, Cunning L. Undesired variance due to examiner stringency/leniency effect in communication skill scores assessed in osces. Advances in Health Sciences Education 2008;13 (5):617-32.

20 Alves de Lima A, Conde D, Costabel J, Corso J, Van der Vleuten C. A laboratory study on the reliability estimations of the mini-CEX. Advances In Health Sciences Education 2013;18 (1):5-13.

21 Hill F, Kendall K, Galbraith K, Crossley J. Implementing the undergraduate mini-CEX: A tailored approach at southampton university. Medical Education 2009;43 (4):326-34. 
22 Weller J, Jones A, M erry A, Jolly B, Saunders D. Investigation of trainee and specialist reactions to the mini-clinical evaluation exercise in anaesthesia: Implications for implementation. British journal of anaesthesia 2009;103 (4):524-30.

23 Crossley J, Davies H, Humphris G, Jolly B. Generalisability: A key to unlock professional assessment. Medical Education 2002;36 (10):972-8.

24 Kreiter CD, Ferguson K, Lee WC, Brennan RL, Densen P. A generalizability study of a new standardized rating form used to evaluate students' clinical clerkship performances. Academic Medicine 1998;73 (12):1294-8.

25 O'Neill TA, M cLarnon MJ, Carswell JJ. Variance components of job performance ratings. Human Performance 2015;28 (1):66-91.

26 Kreiter C. A comment on the continuing impact of case specificity. M edical Education 2008;42 (6):548-9.

27 Spielvogel R, Stednick Z, Beckett L, Latimore D. Sources of variability in medical student evaluations on the internal medicine clinical rotation. International Journal of M edical Education 2012;3:245-51.

28 Kreiter CD, Ferguson KJ. The empirical validity of straight-line responses on a clinical evaluation form. Academic M edicine 2002;77 (5):414-8.

29 Alves de Lima A, Barrero C, Baratta S, Castillo Costa Y, Bortman G, Carabajales J et al. Validity, reliability, feasibility and satisfaction of the mini-clinical evaluation exercise (mini-CEX) for cardiology residency training. Medical Teacher 2007;29 (8):785-90.

30 Eva KW. On the generality of specificity. Medical Education 2003;37 (7):587-8.

31 Norman G, Bordage G, Page G, Keane D. How specific is case specificity? Medical Education 2006;40 (7):618-23.

32 Wimmers PF, Cha-Chi F. The impact of case specificity and generalisable skills on clinical performance: A correlated traits-correlated methods approach. Medical Education 2008;42 (6):580-8.

33 Wimmers PF, Splinter TAW, Hancock GR, Schmidt HG. Clinical competence: General ability or casespecific? Advances In Health Sciences Education 2007;12 (3):299-314.

34 Funder DC. Errors and mistakes: Evaluating the accuracy of social judgment. Psychological Bulletin 1987;101 (1):75-90.

35 Murphy KR, Jako RA, Anhalt RL. Nature and consequences of halo error: A critical analysis. Journal of Applied Psychology 1993;78 (2):218-25.

36 Murphy KR, DeShon R. Interrater correlations do not estimate the reliability of job performance ratings. Personnel Psychology 2000;53 (4):873-900.

37 M urphy KR, Balzer WK. Rater errors and rating accuracy. Journal of Applied Psychology 1989;74 (4):619-24.

38 Williams RG, Klamen DA, M cGaghie WC. Cognitive, social and environmental sources of bias in clinical performance ratings. Teaching \& Learning in Medicine 2003;15 (4):270-92.

39 Albanese M. Challenges in using rater judgements in medical education. Journal of Evaluation in Clinical Practice 2000;6 (3):305-19.

40 Lance CE, Hoffman BJ, Gentry WA, Baranik LE. Rater source factors represent important subcomponents of the criterion construct space, not rater bias. Human Resource Management Review 2008;18 (4):223.

41 Holmboe ES, Ward DS, Reznick RK, Katsufrakis PJ, Leslie KM, Patel VL et al. Faculty development in assessment: The missing link in competency-based medical education. Academic Medicine 2011;86 (4):460-7.

42 Norman G, Vleuten C, Graaff E. Pitfalls in the pursuit of objectivity: Issues of validity, efficiency and acceptability. Medical Education 1991;25 (2):119-26.

43 Hodges B. Assessment in the post-psychometric era: Learning to love the subjective and collective. Medical Teacher 2013;35 (7):564-8.

44 Hodges B. M edical education and the maintenance of incompetence. Medical Teacher 2006;28 (8):690-6.

45 Eva KW, Hodges BD. Scylla or charybdis? Can we navigate between objectification and judgement in assessment? Medical Education 2012;46 (9):914-9.

46 Newble DI, Hoare J, Sheldrake PF. The selection and training of examiners for clinical examinations. Medical Education 1980;14 (5):345-9. 
47 Marshall VR, Ludbrook J. The relative importance of patient and examiner variability in a test of clinical skills. British Journal Of M edical Education 1972;6 (3):212-7.

48 Lurie SJ, M ooney CJ, Lyness JM. M easurement of the general competencies of the accreditation council for graduate medical education: A systematic review. Academic M edicine 2009;84 (3):301-9.

49 Cook DA, Dupras DM, Beckman TJ, Thomas KG, Pankratz VS. Effect of rater training on reliability and accuracy of mini-cex scores: A randomized, controlled trial. Journal Of General Internal Medicine 2009;24 (1):74-9.

50 Iramaneerat C, Yudkowsky R. Rater errors in a clinical skills assessment of medical students. Evaluation $\&$ The Health Professions 2007;30 (3):266-83.

51 Gray JD. Global rating scales in residency education. Academic M edicine 1996;71 (1):S55-S63.

52 Silber CG, Nasca TJ, Paskin DL, Eiger G, Robeson M, Veloski JJ. Do global rating forms enable program directors to assess the acgme competencies? Academic M edicine 2004;79 (6):549-56.

53 Aditya S, Aloimonos Y, Baral C, Fermuller C, Yang Y. Visual common-sense for scene understanding using perception, semantic parsing and reasoning. Association for the Advancement of Artificial Intelligence 2014.

54 Milner AD, Goodale MA. Two visual systems re-viewed. Neuropsychologia 2008;46 (3):774-85.

55 Malle BF. Time to give up the dogmas of attribution: An alternative theory of behavior explanation. In: Zanna M P, Olson JM, editors. Advances in experimental social psychology: Elsevier Inc.; 2011. p. 297-311.

56 Eagleman DM. Timeline: Visual illusions and neurobiology. Nature Reviews Neuroscience 2001;2 (12):920-6.

57 Waubert de Puiseau B, Aßfalg A, Erdfelder E, Bernstein DM . Extracting the truth from conflicting eyewitness reports: A formal modeling approach. Journal of Experimental Psychology: Applied 2012;18 (4):390-403.

58 Wood T. Exploring the role of first impressions in rater-based assessments. Advances in Health Sciences Education 2014;19 (3):409-27.

59 Parr WV, M ouret M, Blackmore S, Pelquest-Hunt T, Urdapilleta I. Representation of complexity in wine: Influence of expertise. Food Quality \& Preference 2011;22 (7):647-60.

60 Yeates P, M oreau M, Eva K. Are examiners' judgments in OSCE-style assessments influenced by contrast effects? Academic M edicine 2015.

61 Kogan JR, Conforti L, Bernabeo E, lobst W, Holmboe E. Opening the black box of clinical skills assessment via observation: A conceptual model. Medical Education 2011;45 (10):1048-60.

62 Govaerts MJB, van der Vleuten CPM, Schuwirth LWT, Muijtjens AMM. Broadening perspectives on clinical performance assessment: Rethinking the nature of in-training assessment. Advances in Health Sciences Education 2007;12 (2):239-60.

63 Crossley J, Jolly B. Making sense of work-based assessment: Ask the right questions, in the right way, about the right things, of the right people. Medical Education 2012;46 (1):28-37.

64 Tavares W, Eva KW. Exploring the impact of mental workload on rater-based assessments. Advances in Health Sciences Education 2013;18 (2):291-303.

65 Mohr CD, Kenny DA. The how and why of disagreement among perceivers: An exploration of person models. Journal of Experimental Social Psychology 2006;42 (3):337-49.

66 Park B, DeKay ML, Kraus S. Aggregating social behavior into person models: Perceiver-induced consistency. Journal of Personality and Social Psychology 1994;66 (3):437-59.

67 Hamilton DL, Driscoll DM, Worth LT. Cognitive organization of impressions: Effects of incongruency in complex representations. Journal of Personality and Social Psychology 1989;57 (6):925-39.

68 Todd AR, Molden DC, Ham J, Vonk R. The automatic and co-occurring activation of multiple social inferences. Journal of Experimental Social Psychology 2011;47:37-49. Epub 14 August 2010.

69 Macrae CN, Bodenhausen GV. Social cognition: Thinking categorically about others. Annual Review of Psychology 2000;51 (1):93-120.

70 Kunda Z, Thagard P. Forming impressions from stereotypes, traits, and behaviors: A parallel-constraintsatisfaction theory. Psychological Review 1996;103 (2):284-308.

71 Fiske ST, Cuddy AJC, Glick P. Universal dimensions of social cognition: Warmth and competence. Trends in Cognitive Sciences 2007;11 (2):77-83. 
72 Surowiecki J. The wisdom of crowds: Random House Digital, Inc.; 2005.

73 Lingard L. What we see and don't see when we look at 'competence': Notes on a god term. Advances in Health Sciences Education 2009;14 (5):625-8.

74 Epstein RM. Assessment in medical education. The New England Journal of M edicine 2007;356 (4):387-96.

75 Kreiter CD, Bergus GR. Case specificity: Empirical phenomenon or measurement artifact? Teaching \& Learning in Medicine 2007;19 (4):378-81.

76 Al Ansari A, Ali SK, Donnon T. The construct and criterion validity of the mini-cex: A meta-analysis of the published research. Academic M edicine 2013;88 (3):413-20.

77 Norcini JJ, Blank LL, Duffy FD, Fortna GS. The mini-CEX: A method for assessing clinical skills. Annals of Internal M edicine 2003;138 (6):476.

78 Cook DA, Beckman TJ. Does scale length matter? A comparison of nine- versus five-point rating scales for the mini-cex. Advances in Health Sciences Education 2009;14 (5):655-64.

79 Cook DA, Beckman TJ, Mandrekar JN, Pankratz VS. Internal structure of mini-CEX scores for internal medicine residents: Factor analysis and generalizability. Advances in Health Sciences Education 2010;15 (5):633-45.

80 Schuwirth LWT, Van der Vleuten CPM. Programmatic assessment: From assessment of learning to assessment for learning. M edical Teacher 2011;33 (6):478-85.

81 House JB, Dooley-Hash S, Kowalenko T, Sikavitsas A, Seeyave DM, Younger JG et al. Prospective comparison of live evaluation and video review in the evaluation of operator performance in a pediatric emergency airway simulation. Journal of Graduate M edical Education 2012;4 (3):312-6.

82 Dankbaar M EW, Stegers-Jager KM, Baarveld F, M errienboer JJGV, Norman GR, Rutten FL et al. Assessing the assessment in emergency care training. PLOS ONE 2014;9 (12):1-13.

83 Williams JB, M CDonough M A, Hilliard M W, Williams AL, Cuniowski PC, Gonzalez M G. Intermethod reliability of real-time versus delayed videotaped evaluation of a high-fidelity medical simulation septic shock scenario. Academic Emergency M edicine 2009;16 (9):887-93.

84 Miller DM, Wiley DE, Wolfe RG. Categorization methodology: An approach to the collection and analysis of certain classes of qualitative information. Multivariate Behavioral Research 1986;21 (2):135.

85 Wiley DE. Latent partition analysis. Psychometrika 1967;32 (2):183-93.

86 Stephenson W. The study of behavior: Q-technique and its methodology. Chicago, Illinois: University of Chicago Press; 1953. 376 p.

87 Watts S, Stenner P. Doing Q methodological research: Theory, method and interpretation. Thousand Oaks, California: Sage; 2012. 238 p. 
Seeing the 'black box' differently Assessor cognition from three research perspectives

Andrea Gingerich

Jennifer Kogan

Peter Yeates

Marjan Govaerts

Eric Holmboe

Published in: Medical Education 2014; 48; 1055-1068 


\section{ABSTRACT}

Context Performance assessments, such as workplace-based assessments, are a crucial component of assessment strategies in medical education. Persistent concerns about rater variability in performance assessments have produced a new field of study focusing on the cognitive processes used by raters, or more inclusively, by assessors.

Methods An international group of researchers met regularly to share and critique key findings in assessor cognition research. Through iterative discussions the prevailing approaches to assessor cognition research were identified and it was noted that each was based on nearly disparate theoretical frameworks and literatures. This paper aims to provide a conceptual review of the different perspectives used by researchers in this field by using the specific example of workplace-based assessment (WBA).

Results Three distinct, but not mutually exclusive, perspectives on the origins and possible solutions to variability in assessment judgements emerged from the discussions within the group of researchers: 1 . assessor as trainable - assessors vary because they do not apply assessment criteria correctly, use varied frames of reference and make unjustified inferences; 2 . assessor as fallible - variations arise due to fundamental limitations in human cognition that mean assessors are readily and haphazardly influenced by their immediate context; and 3. assessor as meaningfully idiosyncratic experts are capable of making sense of highly complex and nuanced scenarios through inference and contextual sensitivity which suggests assessor differences may represent legitimate experience-based interpretations.

Conclusions Although each of the perspectives discussed in this paper advances our understanding of assessor cognition and its impact on WBA, every perspective has its limitations. Following a discussion of areas of concordance and discordance across the perspectives, we propose a co-existent view in which researchers and practitioners utilise aspects of all three perspectives with the goal of advancing assessment quality and ultimately improving patient care. 


\section{CONTEXT}

The primary goal of medical education is to produce highly competent practitioners capable of improving the health and healthcare of their patients and their communities. ${ }^{1,2}$ M uch has been written about the shortcomings of the current medical education system in reaching this goal, ${ }^{3,4}$ especially around the quality of clinical performance assessment. ${ }^{5}$ One type of performance assessment, workplace-based assessment (WBA), incorporates the assessment of complex clinical tasks within day-to-day practice through direct observation of trainees authentically interacting with patients in real clinical settings. Direct observation provides information and data to inform judgements about trainee progress. WBA has become an essential component of medical education because, ultimately, clinical supervisors must be able to determine if a trainee can be entrusted with the tasks or activities critical to the profession. ${ }^{6}$

Despite the importance and necessity of their use, WBA and other performance assessments have measurement limitations. ${ }^{7-9}$ These limitations, such as low inter-rater reliability, are often attributed to flaws in assessors' judgements. ${ }^{10-12}$ In fact, when using psychometrics to analyze performance assessments, often a greater amount of variance in ratings can be accounted for by the assessors (i.e. rater variance) than the trainees (i.e. true score variance). ${ }^{13-15}$ Rater or assessor cognition research is a relatively new domain in medical education focusing on the investigation of assessors' cognitive processes and their impact on assessment quality. In this paper the term "assessor" will be used rather than "rater" to emphasize that assessment involves not only rating (numerical scores) but providing narrative comments, feedback and supervisory decisions. By better understanding the limitations and strengths of cognitive processes used by assessors, compatible modifications in assessment practices could be made to improve the defensibility of assessment decisions, the learning value of formative feedback exchanged with trainees, and ultimately contribute to increased public safety.

\section{METHODS}

An international group of researchers met regularly to share and critique key findings in assessor cognition research. Through iterative discussions the prevailing approaches to assessor cognition research were identified and it was noted that each was based on nearly disparate theoretical frameworks and literatures. This resulted in different and sometimes contrasting implications for optimizing assessment practices. Given the increasing importance of performance assessment within competency-based assessment, it seemed prudent to provide a conceptual review of the different perspectives used by researchers in this field. Using the specific example of WBA, each perspective is explored individually and then jointly to further our understanding of assessor cogni- 
tion. As such, this paper is not a systematic review of any of the literatures discussed nor is it meant to be a conclusive statement on the way assessor cognition research should progress.

\section{RESULTS}

There appear to be three distinct, though not mutually exclusive, perspectives on assessor cognition within the research community. The first perspective describes potentially controllable cognitive processes invoked during assessment and draws on components of behavioural learning theory to help frame an approach to reduce unwanted variability in assessors' assessments through faculty training. The second perspective draws on social psychology research and focuses on identifying the automatic and unavoidable bias of human cognition so that assessment systems can compensate for them. A third perspective draws from sociocultural theory and the expertise literature and proposes that variability in judgements could provide useful assessment information within a radically different assessment design. Although there is some conceptual overlap between the perspectives, there are striking differences in the fundamental assumptions being made and the theories being used. Importantly the first two perspectives assume that any given performance exhibits a singular "true" standard of performance; whilst they differ in their explanations of assessor variability, both perspectives view it as error. Conversely the third perspective argues that variability may arise due to multiple legitimately different truths, which may not represent error. It seems necessary to explicitly describe these three different perspectives on assessor cognition as their differences may have challenging implications for future assessment solutions and research. In an effort to best describe the distinctiveness of each perspective, slight oversimplification and polarization of the perspectives was necessary.

\section{Perspective 1: Assessor as trainable}

From this perspective, inter-assessor variability in WBA is seen as the result of assessors not "knowing" or correctly "applying" assessment criteria. Therefore, variability in assessment judgements reflects inaccuracy in the information provided by assessors and this variability needs to be minimized to improve the quality of assessment information. A viable solution to reduce variability in judgements and improve measurement outcomes in assessments is targeted training for assessors. This training would aim to improve consistency in assessment judgements by providing practice using relevant guidelines, performance criteria and an agreed upon frame of reference to assess performances. 
This perspective is partially grounded in behavioural learning theory which assumes that trainee learning has occurred when there are observable changes in the trainee's behaviours (or actions) which can be measured and evaluated. Learning tasks can be broken down into specific measurable behaviours ${ }^{16}$ and by identifying specific behavioural objectives, learners can know exactly what behaviours need to be performed. ${ }^{17}$, ${ }^{18}$ Assessment criteria are used to specify how learning will be evaluated ${ }^{17,18}$ and rigorous standards for evaluating the educational outcome can help ensure assessment accountability. ${ }^{16}$ Assessment then relies on deciding if the trainee met the objectives which can be determined by detecting the expected observable behaviour from the learner. Assessment measures (i.e. a scoring rubric) are criterion referenced in that learners are assessed by how well they do, not how well they rank among their peers. ${ }^{19,20}$

Applying this to WBA, when assessors observe and assess trainees with patients, they need to be able to identify trainees' "desired" and "undesired" behaviours (clinical skills). Because many core clinical skills have specific criteria by which quality care can be defined, ${ }^{21,}{ }^{22}$ assessors should be using these criteria as they observe and assess trainees. For example, best practices have been defined for many skills related to history taking, physical exam, and counselling. ${ }^{23-28}$ If the desired endpoint of medical education is based on these definitions of clinical care quality, ${ }^{29,}{ }^{30}$ then best practices for care quality should inform trainee assessment, and assessors should be using these quality metrics to assess clinical skills. ${ }^{31} \mathrm{~A}$ single stimulus, the interaction between a trainee and a patient, would then ideally result in more similar responses by assessors. However, assessors often fail to appropriately use quality metrics to assess clinical skills.

Research in WBA has revealed at least three key cognitive processes used by assessors that could adversely influence assessments. One is that assessors use variable frames of reference, or standards, against which they judge trainees' performance. ${ }^{32-35 ~ " U n-~}$ satisfactory," "satisfactory," and "superior" are common anchors on many assessment tools. ${ }^{36}$ How these anchors are interpreted is very variable. For example, some assessors use these scales normatively, defining "satisfactory" as what a trainee at a particular level of training would be expected to do, even if they are uncertain about what skills should be expected at a given stage of training or what constitutes competence. ${ }^{32,}{ }^{34}$ Another particularly prevalent frame of reference that assessors use is themselves. While observing trainees with patients, assessors commonly use their own skills as the comparison ("self" as frame of reference). ${ }^{32,}{ }^{37}$ This is problematic for assessment when practicing physicians' clinical skills are variable, or sometimes even deficient, in core skill domains such as history taking, physical exam, and counseling. ${ }^{38-}$ ${ }^{41}$ If our goal in assessment is to determine whether care meets quality standards (the observable outcome), assessors must know and be able to accurately assess for the 
presence or absence of skills that define high quality patient care. They may be less able to do this if their own clinical skills are insufficient. We know that some faculty cannot articulate what drives their assessment and can only provide a "gut" or "gestalt" rating. ${ }^{32}$ For many assessors, the criteria they use to assess trainees develop experientially and individuals subsequently end up focusing on different aspects of performance resulting in assessors having variable definitions of what determines quality. ${ }^{32,}$ As a consequence, it is rare for assessors to explicitly apply criteria of best practice when assessing clinical performances. ${ }^{32}$

A second potential source of measurement error is assessors making inferences during direct observation (deriving what seem to be logical conclusions from premises assumed to be true) rather than assessing observable behaviours. ${ }^{32,}{ }^{42}$ Assessors make inferences about trainees' knowledge, skills (competence), and attitudes (work-ethic, emotions, intentions, personality). ${ }^{32,43}$ Assessors do not recognize when they are making these inferences and do not validate them for accuracy. ${ }^{32}$ Unchecked inferences risk "distorting" the accurate assessment of the trainee, because the assessors' inferences cannot be observed and measured, leading to greater inter-assessor variability, and ultimately faulty assessment.

A third cognitive process used by assessors that could increase assessment variability is modifying assessment judgements to avoid unpleasant repercussions. For example, some faculty might artificially inflate a rating so that they do not have to have a conversation with a trainee about a marginal assessment, whereas others focus on their roles and responsibilities as coaches and do not shy away from lower ratings. ${ }^{32}$ Some may inflate assessments to be perceived as a popular or likable teacher, but this is not true of all assessors. ${ }^{32}$ There is also variability in how much assessors avoid stringent assessments to avert conversations with institutional leaders where they may be asked to defend their assessments. ${ }^{32,44,45}$ There are many stimuli within the culture of WBA that may lead assessors to variably synthesize what initially may have been somewhat similar observations of trainees into different assessment judgements.

From this perspective, the aforementioned sources of error could, in part, be addressed through faculty development (i.e. the assessor as trainable) and certain principles of behavioural learning theory can be invoked to support proposed "training solutions". Germane to behaviourism, in a competency-based training paradigm, competencies, milestones, and entrustable professional activities are articulated (with the caveat that the goals/objectives are not just behaviours but also knowledge and skills) and subsequently measured. ${ }^{46,47}$ If quality patient care is the assessment endpoint, then assessment of trainees should be based upon those competencies needed to achieve high quality care in unsupervised practice. ${ }^{29}$ To accomplish this, assessors would need to learn a criterion based approach to assessment where trainee perfor- 
mance is compared to pre-specified criteria that are ideally grounded in evidencebased best practices. This may entail opportunities for assessors to refresh or acquire the clinical skills they will need to assess in WBA. ${ }^{48}$ Preliminary research suggests that helping assessors have a criterion-referenced shared mental model may even mitigate some of the pressures related to giving constructive feedback.

Faculty development techniques such as performance dimension training would enable assessors to break down clinical skills into agreed upon observable behaviours and consistently apply assessment criteria. Training could also include reflection on the biases each assessor brings to the assessment tasks as well as learning to recognize when inferences are being used. The goal would not be to prevent inferences from being made but to help assessors develop awareness of when their judgements may be based on inferences rather than observed behaviours. Assessors could then make better judgements about the quality of clinical skills being performed.

The end result is that some of the cognitive processes typically used by assessors to make assessment judgements may contribute to suboptimal assessments. This situation creates problems for learners, assessors, and patients. Learners receive mixed messages during assessment and discrepant feedback which can interfere with their learning since there is inconsistency in what is or is not being reinforced. Assessors, in making inaccurate assessments of the trainee, may make poorly informed supervision decisions. This, in turn, is a potential threat to patient safety and care quality.

\section{Perspective 2: Assessor as fallible}

The "first perspective" relies on an inherent assumption that adequately-resourced assessors will function like well-tuned analytical machines, precisely observing and comparing performance against a defined standard. Logically, any difficulties with this approach should be improved through clearer frameworks or through training in more accurate observation. Yet decades of research tell us that these approaches make comparatively little difference. ${ }^{49}$ Why? A different body of literature challenges this "precise analytical machine" assumption. This second perspective sees assessor variability arising from fundamental limitations in human cognition. In short, low inter-rater reliability persists despite training, not because assessors are ill-prepared, but because human judgement is imperfect and will always be readily influenced.

Cognitive and social psychology assert that assessors cannot simply (passively) observe and capture performances. ${ }^{50}$ Human working memory and processing capacity is limited. ${ }^{51}$ Information is either lost very quickly, or must be processed and linked to a person's pre-existing knowledge structures to allow it to be retained and used. ${ }^{52}$ As a result, there can be no such thing as "objective" observation of performance. To retain 
and compare information long enough to give scores and feedback, humans necessarily interfere with what they observe. These cognitive processes are the source of many described biases, ${ }^{53}$ and (within this perspective) the origin of problems with judgement-based assessments.

Although numerous biases in cognition exist, some illustration is useful. To make information cognitively manageable, people activate "schemas": networks of related information. So, for example, the phrase "heart attack" might activate a web of information that contains: pathophysiological concepts; typical symptoms; likely investigation findings; and treatment algorithms. ${ }^{54}$ It might also activate a mental image of a "typical" heart attack patient. The notion of a "typical" patient, or person, arises from our tendency to categorise people ${ }^{55}$, which leaves us open to "representativeness bias $^{\prime \prime 56}$ : rather than effortfully process all available information, we tend to compare key features of a new person to a "typical" example of the quantity we are interested in (i.e typical heart attack patient or "typical" competent trainee). By judging the similarity of the new and "typical" people, we judge whether it is likely that the new person is indeed having a heart attack / is a competent trainee. This saves a lot of mental effort, but means we tend to ignore important information, and this can bias our judgements. This type of bias is well illustrated by the literature on stereotypes.

Once active, stereotypes (or the tendency for impressions of a person to be influenced by their membership of a group rather than their individual features), can distort which features individuals pay attention to, ${ }^{57}$ the judgements that they reach ${ }^{58}$ and their recall of what has occurred. ${ }^{59}$ The latter is particularly important: rather than "objectively" recalling what they have just observed, people may unconsciously "fill in the blanks" based on what their stereotypical beliefs suggest. ${ }^{60}$ This would be particularly important to WBA as it would distort not just scores, but also the feedback given to trainees.

Importantly, the influence of stereotypes is often not under conscious control: changes in context determine which stereotypes are activated ${ }^{61}$ and people are often unaware of the unconscious thoughts that influence either their cognition ${ }^{62}$ or behaviour. ${ }^{63}$ Emotions, ${ }^{64}$ time pressure, ${ }^{59}$ circadian rhythms, ${ }^{65}$ motivation, pre-existing levels of prejudice ${ }^{66}$ and individual cognitive preferences ${ }^{67}$ all influence the degree to which stereotypes influence individual decisions, making their influence haphazard and hard to predict. Instructions to avoid stereotyping can make their influence paradoxically worse ${ }^{68}$, which makes it unlikely that simple training will overcome the problem.

Whilst well demonstrated in social psychology, the extent to which stereotypes influence assessment-judgements in medical education is unknown. We do, however, know that senior doctors possess well developed stereotypes of the way that ethnic minority 
students may perform or behave ${ }^{69}$ whilst in other aspects of education, unconscious stereotyping of ethnic minorities can be seen to account for reduced academic achievement by these students. ${ }^{70}$ It has previously been shown that doctors judging performances of trainees are over-confident in their judgements (they are right less often than they think). ${ }^{71}$ Judgemental overconfidence is thought to typically arise due to representativeness bias ${ }^{56}$, and so suggests that these effects may well be at work in assessment judgements.

Whilst the influence of stereotypes on assessors' judgements remains to be elucidated, the influences of other biases are clearer. Humans are known to be poor at judging or scaling absolute quantities; judgements are easily influenced by contextual information, ${ }^{72}$ through processes known as assimilation or contrast effects. ${ }^{73}$ Recently Yeates et $\mathrm{al}^{34}$ showed that the scores given to intermediate performances in Mini-CEX assessments are influenced to a moderately large degree by the standard of immediately preceding performances, biasing scores away from the preceding performance. Follow up study suggested this effect can occur across a range of performance levels, is fairly robust and that assessors may lack insight into its operation. ${ }^{33}$

Other authors have theoretically considered ways that categorical thinking, ${ }^{55}$ cognitive load ${ }^{74,75}$ or first impressions ${ }^{76}$ might influence assessors' judgements in medical education. Although detailed empirical investigation of these claims is awaited, initial investigation has shown that examiners in OSCE exams experience higher mental workload than occurs in routine clinical work. ${ }^{77}$ Consequently there is much reason to suggest that flaws in human cognition that have been thoroughly described in other arenas are likely to influence assessor cognition in medical education.

Having noted the often unconscious and uncontrollable nature of these limitations in human judgement, we must face the possibility that they cannot easily be overcome through either training or more detailed assessment frameworks. In fact, as making more detailed checklists could increase the cognitive load experienced by assessors, this approach could potentially (paradoxically) worsen the very problem it hopes to improve. $^{75}$

It would be easy, therefore, to conclude that this perspective demands a nihilistic view of judgement-based assessments: judgement is flawed, and cannot be fixed. Not so. Instead, it suggests that progress may exist within a toolbox of possible cognitive interventions. For example, although (as mentioned earlier) asking people to avoid stereotyping can paradoxically worsen the influence of stereotypes, an alternative approach may be more effective. Recent research indicates that people can be induced to adopt an "egalitarian motivation" prior to making judgements of a person. ${ }^{78,79}$ This reduced the cognitive activation of stereotypes ${ }^{78,79}$ and lessened the influence of stereotypes 
on behavioural intentions and inter-personal interactions. ${ }^{79}$ It might therefore be that improvements in judgements can be achieved by first elucidating the effect of cognitive influences on judgements, and secondly finding corresponding cognitive tools to counteract these effects.

Needless to say, much further work is required before any claims can be made about the potential benefits of these approaches. Even if these interventions are successful, they are unlikely to completely overcome contextual influences on judgements. ${ }^{74}$ One possible implication of this perspective would be to seek ways to replace human judgement with algorithmic measurement. Recent research has shown that a computer-learning algorithm can separate novice and expert laparoscopic surgeons with reasonable accuracy, by measuring and analysing their hand movements. No human judgement was involved. ${ }^{80}$ Perhaps further developments of this sort will gradually replace human judgement. This second perspective views assessor variations as the product of fundamental limitations in human cognition. Recognising this requires the medical education community to seek a different set of solutions than our traditional approaches have supplied.

\section{Perspective 3: Assessor as meaningfully idiosyncratic}

In the previous two perspectives, variability in assessors' judgements is described as being problematic for measuring competency, for making assessment decisions and for giving feedback. Quite reasonably then, the proposed solutions aim to increase the reliability of assessors' judgements. In the third perspective, the view of assessor variability is radically different. One of its fundamental questions is: What if variability, at least in part, comes from assessors each forming relevant and legitimate but different, and sometimes conflicting, interpretations? This perspective examines potential sources of idiosyncrasy within assessor cognition that could provide meaningful assessment information but also lead to variability, assessor disagreement and low interrater reliability.

In the unstandardized reality of WBA, variance attributable to the idiosyncrasies of assessors is only outmatched by variance attributable to context specificity. ${ }^{81-83}$ From a psychometric measurement standpoint, neither of these sources of variance reveal anything about the trainee's competence and are generally assumed to contribute to measurement error. Viewed from situated cognition theory and socio-cultural (learning) theories, however, context-specific variation is not "error". According to these theories, context is not an inert or interchangeable detail separate from a trainee's performance but instead is viewed as enabling and constraining the trainee's ability to perform any intended or required skills. ${ }^{84-86}$ This is because context is understood to encompass all the dynamic interactions between everyone and everything within an 
environment, and not just be a label for the physical location. ${ }^{84,85,87,88}$ Based on this understanding of context, trainees would not have full control over the events within a clinical encounter and their competence would instead be shaped by, revealed within, and linked to that unique context. ${ }^{89,90}$

Viewpoints such as these make it more difficult to think of context as something to be disregarded or averaged across. They also call into question the idea of competence as something that resides solely within each trainee and remains stable across different places, patients and time. ${ }^{91}$ On the contrary, competence has been described as being socially constructed and needing to be demonstrated and perceived by others. ${ }^{92-94}$ The idea of perceiving others' competence is especially important for WBA because many of the key constructs that need to be assessed are not directly observable. ${ }^{95}$ Instead, constructs such as patient-centeredness, professionalism, humanism and many others must be inferred from observable demonstrations. ${ }^{89,93}$ Inferences are also required for making judgements of responsibility, praise and blame ${ }^{96-99}$ that are essential to clinical supervision decisions. If we assume that trainees' clinical performance is constructed through dynamic interactions with contexts, then there is a need for contextualized interpretations of those performances. Consequently, a WBA designed to accommodate this would require an instrument with the sensitivity to detect unpredictable changes in performance across contexts. The instrument would also need sufficient specificity to pick out key features of a performance amidst a barrage of potentially useful data. In addition, it would need the wisdom to make useful inferences and extrapolations from observed events. Fortuitously or not, such an instrument is already being used. Expert assessors could perform these tasks by making social inferences and may be essential for high quality WBA designs.

With this in mind, it may be informative to refer to discussions about expert judgement in clinical diagnosis. Research increasingly suggests that assessor expertise resembles diagnostic expertise in the clinical domain to a remarkable extent. ${ }^{43,100,101}$ Experienced clinicians use rapid, automatic pattern recognition to form diagnostic impressions; they very rapidly cluster sets of information into meaningful patterns, enabling fast and accurate diagnostic reasoning. ${ }^{102}$ They do not use detailed checklists with signs and symptoms based on textbook knowledge as novices would do, and more than that, they use information reflecting (subtle) variations in the context of the patient encounter. ${ }^{103}$ The cognitive processing used by experts heavily relies on identification and interpretation of relevant contextual cues. "In fact, that's the main business of human brains-to take a complex situation and to put one's finger on what matters in it, to distill from an initial welter of sensations and ideas what a situation really is all about. To spot the gist." ${ }^{104(\text { 2277) }}$ In addition, experts can recognize anomalies that violate expectancies; note the significance of the situation beyond the immediate events; identify what events have already taken place based on the current situation; 
and form expectations of events that will likely happen based on the current situation. ${ }^{105-107}$ Human cognition is superb at filtering through unlimited bits of incoming data to discern relevant cues and make sense of situations.

In WBA, research findings indicate that experienced assessors are similarly able to note situation-specific cues in the assessment task; link task-specific cues to task-specific performance requirements and performance assessment; explicitly link specific aspects of trainee performance to patient behaviours and the outcome of the consultation, and form more comprehensive interpretations of performance. ${ }^{42,}{ }^{43}$ Even when experienced clinical assessors are engaged in complex tasks, often under time pressures and with conflicting, as well as ill-defined goals, they seem to be capable of identifying cues in trainees' performances that correlate with future performances. ${ }^{100}$ They spot the gist.

Using humans as the assessment instrument adds additional complexity, though. Assessor expertise, as with any professional expertise, develops through immersion within specific contexts. ${ }^{108}$ Since each assessor's expertise will have been influenced by different contexts and shaped by unique experiences, different mental models of general performance, task-specific performance and person schemas could be expected with each assessor inevitably developing a unique cognitive filter. ${ }^{42,43}$ When interpreting performance in context, assessors will give meaning to their observations by using their past experiences and understanding of their social, cultural and contextual surroundings. Consequently, assessors may spot different "gists" or underlying concepts within a complex performance and construct different interpretations for them. ${ }^{89}, 109$ Or, as stated by Delandshere:

'Judges' values, experiences, and interests are what makes them capable of interpreting complex performances, but it will never be possible to eliminate those attributes that make them different, even with extensive training and "calibration"." 110(p16)

Variations in assessor judgements may very well represent variations in the way performance can be understood, experienced and interpreted.

From this perspective, differences in assessor judgements are not something to eliminate. This perspective does not deny that expert reasoning in performance judgements may be flawed-- comparable to errors in experts' diagnostic reasoning. ${ }^{111}$ However, rather than reflecting suboptimal judgements, inconsistencies between assessors' interpretations may very well reflect the complexity of the performance and the inherently "subjective" interpretation of that performance filtered through the assessor's understanding. If differences in assessment judgements were to come from differ- 
ences in the way the trainee's performance can be perceived and experienced by others, then the inconsistencies between assessor's interpretations might be complementary and equally valid. Assessor disagreement may look less like error, for example, if many interpretations were collected and considered pieces of a composition that thoroughly described the trainee's perceived competence. ${ }^{112}$ There could be significant value in the aggregated information if it could reveal specific, context-dependent patterns of performance and performance interpretations. ${ }^{93}$ Even contradictory judgements could be informative if judgements were collected purposefully until some type of information saturation was reached. ${ }^{113} \mathrm{~A}$ key difference in using saturation, rather than reliability, to analyze assessors' judgements is the power to capture pockets of repeated interpretations that may differ from the majority interpretation yet represent important variants of how that resident's behaviour can be perceived.

There are certainly other implications for WBA design. If experienced assessors are viewed as potentially important assessment instruments for WBA, then it would be important to cultivate expertise in assessors through ongoing feedback and deliberate practice with making assessment judgements. Solutions aimed to minimize assessor variability, such as checklists and reducing tasks into observable subcomponents, would best be avoided as they may interfere with assessors making expert judgements. ${ }^{91,114,115}$ Assessors would likely need to provide some form of narrative assessment information to help reveal the context-dependence of their interpretations. As for trainees, since they might receive conflicting assessment information from assessors, guided reflection could help them reconcile how others can interpret their behaviour differently than how it was intended. These conversations could be incorporated into an assessment culture focusing on deliberate practice for continual improvement of patient care and outcomes.

In the third perspective, and similar to the second perspective, ideas for why it is unreasonable to expect different assessors to interpret the same trainee's performance in exactly the same way are shared. In contrast to the second perspective, variability has been described as a potentially useful source of assessment information stemming from assessors differently developing expertise and using expert judgement. WBA is filled with unpredictable assessment situations where assessors are continuously challenged to identify critical features of context-dependent performances. Experts may be well suited for this task but the inferences and extrapolations they use to interpret the performance could also introduce variability into their judgements. To harness their insights, radically new assessment analyses, designs and culture may be needed. Even if it were possible for assessors to be objective, this perspective would argue that it is not desirable to eliminate these differences as when compiled they could contribute to a more comprehensive understanding of the trainee's abilities. 


\section{DISCUSSION}

It is important to recognize that for the foreseeable future, workplace-based assessment will be highly dependent on the judgement of humans. Few would deny that the primary goal of medical education is to produce a highly competent healthcare workforce to care for patients and populations and that WBA is a critical component of clinical training. The three perspectives on assessor cognition, as discussed above, not only highlight a number of difficulties with WBA but, more importantly, challenge some of our preconceptions of assessment and cognition. When considered separately, each proposes a reasonable and logical view of assessor cognition. However, when considered simultaneously, it might seem initially that the three perspectives are irreconcilable. Instead of summarizing each perspective, we will take the opportunity to highlight important commonalities that were not previously discussed before noting some points of divergence. We recognize this represents a synthesis developed through literature review and an iterative group process. Accordingly, it is not meant to cover all possible perspectives or serve as a systematic review of the literature. Despite the challenges highlighted in this paper, we believe that WBA can be improved by integrating the areas of concordance and discordance amongst the three perspectives.

\section{Areas of Concordance}

Several areas of concordance deserve elaboration. First, all three perspectives require assessors to actually observe trainees interacting with patients and all recognize the current quantity and frequency of observationally-based assessment of undergraduate and post-graduate medical trainees is less than ideal. This is a serious deficiency in assessment programs and it requires immediate attention. ${ }^{36,116-124}$ Regardless of the perspective on assessor cognition, institutions must create clinical and medical education systems that permit, promote and sustain direct observation of trainees. Hence, the first step to improving WBA requires institutions to support and ensure faculty actually do it.

A second area of concordance between the three perspectives is the need for faculty to achieve and maintain their own clinical competence, while concomitantly developing expertise as an assessor. An impediment to assessing the quality of specific skills performed by a trainee is an assessor's lack of awareness of the specific skills required to competently perform that task. Therefore, faculty development for assessors may need to include training for their own clinical skills development in addition to training for how to assess those skills. 
Finally, there are two mechanisms common in each perspective that could be useful to help maximize the strengths and minimize the weaknesses of assessor cognition. One is robust sampling of tasks for each trainee assessed by an equally robust sample of assessors to improve the reliability, validity, quality and the defensibility of assessment decisions. The other is facilitated group discussions among assessors and assessment decision makers that provide an opportunity to synthesize all available assessment data to create a clearer composite picture of a trainee's overall performance. ${ }^{125}$ Group discussions allow both consistent and variable judgements to be explored and better understood. ${ }^{126}$

\section{Areas of Discordance}

There are also areas of discordance, or incompatibilities, between the three perspectives that cannot be ignored. For example, whether there exists one or multiple "truths", the goals of faculty development, the utility of making inferences and the pursuit of reliability have been previously discussed. Rather than trying to overcome the discordances and fully integrate the different perspectives into a unified theory, it may be useful to identify circumstances where the strengths of a particular perspective may be especially advantageous.

A simple football (soccer) analogy might help to illustrate how different perspectives on assessor cognition could be purposefully matched to fundamentally different assessment situations to improve WBA. A football player must place the ball into the net in order to score a goal and anything outside the boundary of the net is a miss. Delivery of healthcare is similarly bounded; there are not limitless ways for trainees to provide safe, effective, patient-centered care. Some clinical tasks have tighter boundaries, or a smaller "net". For example, insertion of central venous catheters and safe management of mechanical ventilators to prevent pneumonia should be performed within the boundaries specified by the latest evidence-based medicine or procedural checklists. Variance from the standards in these cases should be limited. Correspondingly, it would be advantageous for assessor judgements of these performances to have less variability. There are situations, however, where determining the quality of the trainee's performance is dependent on a larger number of contextual factors such as patients' medical conditions, needs and culture, and system factors. For example, although there are guidelines for delivering bad news (e.g. the SPIKES ${ }^{127}$ framework), an appropriate performance under a specific combination of factors may not be appropriate given a different combination of factors. In other words, the boundary zone (i.e. size of the net) is wider for breaking bad news as compared to central venous catheter insertion, but neither is infinite. For clinical encounters that can be highly influenced by contextual factors, an assessment system that can accommodate variability and expertise in assessors' judgements may be appropriate and valuable. 


\section{CHAPTER 2}

\section{Moving Forward}

As the emerging field of "assessor cognition" research grows, these perspectives will help to align and situate research, signposting ways to discuss discordant (even contradictory) empirical findings to inform and develop assessment practice. Our goal should not be to accept inherent limitations in assessor cognition as an excuse to avoid improving assessment design. Instead, we should critically reflect on and strategically incorporate both the concordant and discordant views presented by each of these perspectives to enhance the quality of our assessments.

All three perspectives will also need to account for rapidly changing clinical care delivery models, a critical contextual variable, that will substantially impact medical education. Learning and clinical care now occurs increasingly through inter-professional teams, and this will affect how we think about the assessment of individuals. Patients are entrusting faculty and programs to perform supervision and assessment in a manner that effectively meets their needs in this new context. Furthermore, it is likely that judgements of competence will be done through group process, meaning groups will make inferences based on others' observations and ratings. In the end, regardless of what perspective of assessor cognition is emphasized or utilized, and how that perspective is used, the ultimate outcome must be the same: the delivery of safe, effective, patient-centred care.

Contributions: All authors were involved in developing the conceptual framework and made substantive contributions to writing and editing the entire paper. Each author took the lead on different sections of the paper: JK for Assessor as Trainable; PY for Assessor as Fallible; AG and MG for Assessor as M eaningfully Idiosyncratic; and EH for the discussion.

Funding: The authors are grateful for the in-kind support provided by the American Board of Internal Medicine used to cover the costs of conference calls and other collaboration expenses.

Competing Interests: Eric Holmboe receives royalties from Mosby-Elsevier for a textbook on assessment.

Acknowledgements: The authors wish to thank Lisa Conforti from the ABIM for assisting with the logistics required for a successful international collaboration; and Glenn Regehr for providing helpful comments on a previous draft. 
Previous presentations: The authors discussed ideas from this paper in symposiums presented at the AAMC RIM E conference in Philadelphia, PA (November 2013) and the Ottawa conference in Ottawa, ON (April 2014). 


\section{REFERENCES}

1 McGaghie WC, Lipson L. Competency-based curriculum development in medical education: An introduction: World Health Organization Geneva; 1978.

2 Frenk J, Chen L, Bhutta ZA et al. Health professionals for a new century: Transforming education to strengthen health systems in an interdependent world. Lancet 2010;376 (9756):1923-58.

3 Hodges BD. A tea-steeping or i-doc model for medical education? Acad M ed 2010;85 (9):S34-S44.

4 Irby DM , Cooke M, O'Brien BC. Calls for reform of medical education by the Carnegie Foundation for the advancement of teaching: 1910 and 2010. Acad Med 2010;85 (2):220-7.

5 van der Vleuten CPM, Schuwirth LWT. Assessing professional competence: From methods to programmes. Med Educ 2005;39 (3):309-17.

6 ten Cate TJO, Snell L, Carraccio C. M edical competence: The interplay between individual ability and the health care environment. M ed Teach 2010;32 (8):669-75.

7 Lurie SJ, M ooney C), Lyness JM. M easurement of the general competencies of the accreditation council for graduate medical education: A systematic review. Acad M ed 2009;84 (3):301-9.

8 Albanese M. Rating education quality: Factors in the erosion of professional standards. Acad Med 1999;74 (6):652-8.

9 Williams RG, Klamen DA, McGaghie WC. Cognitive, social and environmental sources of bias in clinical performance ratings. Teach Learn M ed 2003;15 (4):270-92.

10 Elliot DL, Hickam DH. Evaluation of physical examination skills. Reliability of faculty observers and patient instructors. JAM A 1987;258 (23):3405-8.

11 Noel GL, Herbers JE, Caplow M P, Cooper GS, Pangaro LN, Harvey J. How well do internal medicine faculty members evaluate the clinical skills of residents? Ann Intern M ed 1992;117 (9):757-65.

12 Herbers JE, Jr., Noel GL, Cooper GS, Harvey J, Pangaro LN, Weaver MJ. How accurate are faculty evaluations of clinical competence? J Gen Intern M ed 1989;4 (3):202-8.

13 Cook DA, Beckman TJ, Mandrekar JN, Pankratz VS. Internal structure of Mini-CEX scores for internal medicine residents: Factor analysis and generalizability. Adv Health Sci Educ 2010;15 (5):633-45.

14 Margolis MJ, Clauser BE, Cuddy M M et al. Use of the mini-clinical evaluation exercise to rate examinee performance on a multiple-station clinical skills examination: A validity study. Acad Med 2006;81 (10 Suppl):S56-S60.

15 Hill F, Kendall K, Galbraith K, Crossley J. Implementing the undergraduate M ini-CEX: A tailored approach at southampton university. Med Educ 2009;43 (4):326-34.

16 Tyler R. Basic principles of curriculum and instruction. Chicago: The University of Chicago Press; 1949.

17 Ertmer PA, Newby TJ. Behaviorism, cognitivism, constructivism: Comparing critical features from a design perspective. Perform Improve Quarterly 1993;6 (4):50-72.

18 Saettler P. The evolution of American educational technology. Englewood, CO: Libraries Unlimited, Inc.; 1990.

19 Smith P, Ragan T. Instructional design. 2nd ed. New York: John Wiley \& Sons, Inc.; 1999.

20 Torre DM, Daley BJ, Sebastian JL, Elnicki DM. Overview of current learning theories for medical educators. Am J Med 2006;119:903-7.

21 Institute of M edicine. Crossing the quality chasm: A new health system for the 21st century. Washington, DC: 2001.

22 World Health Organization. Quality of care: A process form aking strategic choices in health systems 2006 November 22, 2013. Available from: http://www/who.int/management/quality/assurance/Quality Care_B.Def.pdf.

23 Lyles JS, Dwamena FC, Lein C, Smith RC. Evidence-based patient-centered interviewing. J Clin Outcomes Manage 2001;8 (7):28-34.

24 Braddock CH, III, Edwards KA, Hasenberg NM, Laidley TL, Levinson W. Informed decision making in outpatient practice: Time to get back to basics. JAM A 1999;282 (24):2313-20. 
25 Murray CJ, Frenk J. Health metrics and evaluation: Strengthening the science. Lancet 2008;371 (9619):1191-9.

26 Ptacek JT, Eberhardt TL. Breaking bad news. A review of the literature. JAM A 1996;276 (6):496-502.

27 Searight R. Realistic approaches to counseling in the office setting. Am Fam Physician 2009;79 (4):27784.

28 M cGee S. Evidence-based physical diagnosis. St. Louis, M O: Saunders Elsevier; 2007.

29 Sklar DP, Lee R. Commentary: What if high-quality care drove medical education? A multiattribute approach. Acad M ed 2010;85 (9):1401-4.

30 Asch DA, Nicholson S, Srinivas S, Herrin J, Epstein AJ. Evaluating obstetrical residency programs using patient outcomes. JAM A 2009;302 (12):1277-83.

31 Haan CK, Edwards FH, Poole B, Godley M, Genuardi FJ, Zenni EA. A model to begin to use clinical outcomes in medical education. Acad M ed 2008:83 (6):574-80.

32 Kogan JR, Conforti L, Bernabeo E, lobst W, Holmboe E. Opening the black box of clinical skills assessment via observation: A conceptual model. Med Educ 2011;45 (10):1048-60.

33 Yeates P, O'Neill P, Mann K, Eva K. Seeing the same thing differently: Mechanisms that contribute to assessor differences in directly-observed performance assessments. Adv Health Sci Educ 2013;18 (3):325-41.

34 Yeates P, O'Neill P, Mann K, Eva KW. Effect of exposure to good vs poor medical trainee performance on attending physician ratings of subsequent performances. JAM A 2012;308 (21):2226-32.

35 Yeates $\mathrm{P}, \mathrm{O}$ 'Neill P, Mann K, W Eva K. 'You're certainly relatively competent': Assessor bias due to recent experiences. Med Educ 2013;47 (9):910-22.

36 Kogan JR, Holmboe ES, Hauer KE. Tools for direct observation and assessment of clinical skills of medical trainees: A systematic review. JAM A 2009;302 (12):1316-26.

37 Kogan JR, Hess BJ, Conforti LN, Holmboe ES. What drives faculty ratings of residents' clinical skills? The impact of faculty's own clinical skills. Acad M ed 2010;85 (10 Suppl):S25-S8.

38 Vukanovic-Criley JM, Criley S, Warde CM et al. Competency in cardiac examination skills in medical students, trainees, physicians, and faculty: A multicenter study. Arch Intern M ed 2006;166 (6):610-6.

39 Paauw DS, Wenrich MD, Curtis JR, Carline JD, Ramsey PG. Ability of primary care physicians to recognize physical findings associated with hiv infection. JAM A 1995;274 (17):1380-2.

40 Ramsey PG, Wenrich MD. Use of peer ratings to evaluate physician performance. JAMA 1993;269 (13):1655-60.

41 Braddock CH, 3rd, Fihn SD, Levinson W, Jonsen AR, Pearlman RA. How doctors and patients discuss routine clinical decisions. Informed decision making in the outpatient setting. J Gen Intern M ed 1997;12 (6):339-45.

42 Govaerts MJB, de Wiel M WJv, van der Vleuten CPM. Quality of feedback following performance assessments: Does assessor expertise matter? Eur J Train Dev 2013;37 (1):105-25.

43 Govaerts MJB, Schuwirth L, Van der Vleuten CP, M uijtjens AM M. Workplace-based assessment: Effects of rater expertise. Adv Health Sci Educ 2011;16 (2):151-65.

44 Dudek NL, Marks MB, Regehr G. Failure to fail: The perspectives of clinical supervisors. Acad Med 2005;80 (10):S84-S7.

45 Cleland JA, Knight LV, Rees CE, Tracey S, Bond CM. Is it me or is it them? Factors that influence the passing of underperforming students. Med Educ 2008;42:800-9.

46 Nasca TJ, Brigham T, Philibert I, Flynn TC. The next gme accreditation system - rationale and benefits. New Engl J Med 2012;366 (11):1051-6.

47 Carraccio CL, Englander R. From Flexner to competencies: Reflections on a decade and the journey ahead. Acad M ed 2013;88 (8):1067-73.

48 Frankel RM, Eddins-Folensbee F, Inui TS. Crossing the patient-centered divide: Transforming health care quality through enhanced faculty development. Acad M ed 2011;86 (4):445-52.

49 Landy FJ, Farr JL. Performance rating. Psychol Bull 1980;87 (1):72-107.

50 Ilgen DR, Barnes-Farrell JL, M cKellin DB. Performance appraisal process research in the 1980s: What has it contributed to appraisals in use? Organ Behav Hum Dec 1993;54 (3):321-68. 
51 Baddeley A. The magical number seven: Still magical after all these years? Psychol Rev 1994;101 (2):353.

52 van M erriënboer JJG, Sweller J. Cognitive load theory in health professional education: Design principles and strategies. Med Educ 2010;44 (1):85-93.

53 Macrae CN, Bodenhausen GV. Social cognition: Categorical person perception. Brit J Psychol 2001;92 (Pt 1):239-55.

54 Schmidt HG. Foundations of problem-based learning: Some explanatory notes. Med Educ 1993;27 (5):422-32.

55 Gingerich A, Regehr G, Eva KW. Rater-based assessments as social judgments: Rethinking the etiology of rater errors. Acad M ed 2011;86 (10):S1-S7

56 Tversky A, Kahneman D. Judgment under uncertainty: Heuristics and biases: Science; 1974.

57 Bodenhausen GV, Wyer JRS. Effects of stereotypes on decision making and information-processing strategies. J Pers Soc Psychol 1985;48 (2):267-82.

58 Bodenhausen GV. Stereotypic biases in social decision making and memory: Testing process models of stereotype use. J Pers Soc Psychol 1988;55 (5):726-37.

59 Dijksterhuis A, van Knippenberg A. Memory for stereotype-consistent and stereotype-inconsistent information as a function of processing pace. Eur J Soc Psychol 1995;25 (6):689-93.

60 MacRae CN, Schloerscheidt AM, Bodenhausen GV, Milne AB. Creating memory illusions: Expectancybased processing and the generation of false memories. M emory 2002;10 (1):63-80.

61 Macrae CN, Bodenhausen GV, Milne AB. The dissection of selection in person perception: Inhibitory processes in social stereotyping. J Pers Soc Psychol 1995;69 (3):397-407.

62 Nisbett RE, Wilson TD. Telling more than we can know: Verbal reports on mental processes. Psychol Rev 1977;84 (3):231-59.

63 Bargh JA, Chartrand TL. The unbearable automaticity of being. Am Psychol 1999;54 (7):462-79.

64 Bodenhausen GV, Sheppard LA, Kramer GP. Negative affect and social judgement: The differential impact of anger and sadness. Eur J Soc Psychol 1994;24 (1):45-62.

65 Bodenhausen GV. Stereotypes as judgmental heuristics: Evidence of circadian variations in discrimination. Psychol Sci 1990;1 (5):319-22.

66 Kunda Z, Spencer SJ. When do stereotypes come to mind and when do they color judgment? A goal-based theoretical framework for stereotype activation and application. Psychol Bull 2003;129 (4):522-44.

67 Crawford MT, Skowronski JJ. When motivated thought leads to heightened bias: High need for cognition can enhance the impact of stereotypes on memory. Pers Soc Psychol Bull 1998;24 (10):1075-88.

68 Macrae CN, Bodenhausen GV, Milne AB, Jetten J. Out of mind but back in sight: Stereotypes on the rebound. J Pers Soc Psychol 1994;67 (5):808-17.

69 Woolf K, Cave J, Greenhalgh T, Dacre J. Ethnic stereotypes and the underachievement of uk medical students from ethnic minorities: Qualitative study. BMJ (Int Ed) 2008;337 (7670):611-5.

70 van den Bergh L, Denessen E, Hornstra L, Voeten M, Holland RW. The implicit prejudiced attitudes of teachers: Relations to teacher expectations and the ethnic achievement gap. Am Educ Res J 2010;47 (2):497-527.

71 Tweed M, Ingham C. Observed consultation: Confidence and accuracy of assessors. Adv Health Sci Educ 2010;15 (1):31-43.

72 Stewart N, Brown GDA, Chater N. Absolute identification by relative judgment. Psychol Rev 2005;112 (4):881-911.

73 Mussweiler T. Comparison processes in social judgment: Mechanisms and consequences. Psychol Rev 2003;110 (3):472-89.

74 Wood TJ. Mental workload as a tool for understanding dual processes in rater-based assessments. Adv Health Sci Educ 2013;18 (3):523-5.

75 Tavares W, Eva KW. Exploring the impact of mental workload on rater-based assessments. Adv Health Sci Educ 2013;18 (2):291-303.

76 Wood TJ. Exploring the role of first impressions in rater-based assessments. Adv Health Sci Educ 2013.

77 Byrne A, Tweed N, Halligan C. A pilot study of the mental workload of objective structured clinical examination examiners. M ed Educ 2014;48 (3):262-7. 
78 M oskowitz GB, Li P. Egalitarian goals trigger stereotype inhibition: A proactive form of stereotype control. J Exp Soc Psychol 2011;47 (1):103-16.

79 Todd AR, Bodenhausen GV, Richeson JA, Galinsky AD. Perspective taking combats automatic expressions of racial bias. J Pers Soc Psychol 2011;100 (6):1027.

80 Watson RA. Use of a machine learning algorithm to classify expertise: Analysis of hand motion patterns during a simulated surgical task. Acad M ed 2014.

81 Colliver JA. Educational theory and medical education practice: A cautionary note for medical school faculty. Acad M ed 2002;77 (12):1217-20.

82 Baig LA, Violato C, Crutcher RA. Assessing clinical communication skills in physicians: Are the skills context specific or generalizable. BM C M ed Educ 2009;9 (1):22.

83 Keller L, Mazor KM, Swaminathan H, Pugnaire M P. An investigation of the impacts of different generalizability study designs on estimates of variance components and generalizability coefficients. Acad M ed 2000;75 (10):S21-S4.

84 Durning SJ, Artino AR, Jr., Pangaro LN, van der Vleuten C, Schuwirth L. Redefining context in the clinical encounter: Implications for research and training in medical education. Acad M ed 2010;85 (5):894-901.

85 Durning SJ, Artino AR. Situativity theory: A perspective on how participants and the environment can interact: AM EE Guide no. 52. Med Teach 2011;33 (3):188-99.

86 Richter Lagha RA, Boscardin CK, May W, Fung C-C. A comparison of two standard-setting approaches in high-stakes clinical performance assessment using generalizability theory. Acad M ed 2012;87 (8):1077-82.

87 Hager P, (Editor). Theories of workplace learning. Los Angeles, CA: Sage Publications; 2011.

88 Engeström $Y$, Sannino A. Studies of expansive learning: Foundations, findings and future challenges. Educ Res Rev 2010;5 (1):1-24.

89 Kuper A, Reeves S, Albert M, Hodges BD. Assessment: Do we need to broaden our methodological horizons? Med Educ 2007;41 (12):1121-3.

90 Ginsburg S, Bernabeo E, Ross KM, Holmboe ES. "It depends": Results of a qualitative study investigating how practicing internists approach professional dilemmas. Acad M ed 2012;87 (12):1685-93.

91 Hodges B. Assessment in the post-psychometric era: Learning to love the subjective and collective. Med Teach 2013;35 (7):564-8.

92 Lingard L. What we see and don't see when we look at 'competence': Notes on a god term. Adv Health Sci Educ 2009;14 (5):625-8.

93 Delandshere G, Petrosky AR. Assessment of complex performances: Limitations of key measurement assumptions. Educ Res 1998;27 (2):14-24.

94 Hodges B. Medical education and the maintenance of incompetence. M ed Teach 2006;28 (8):690-6.

95 Pangaro L, ten Cate O. Frameworks for learner assessment in medicine: AM EE Guide no. 78. M ed Teach 2013;35 (6):e1197-e210.

96 Read SJ, Jones DK, Miller LC. Traits as goal-based categories: The importance of goals in the coherence of dispositional categories. J Pers Soc Psychol 1990;58 (6):1048-61.

97 Reeder GD, Kumar S, Hesson-M cInnis M, Trafimow D. Inferences about the morality of an aggressor: The role of perceived motive. J Pers Soc Psychol 2002;83 (4):789-803.

98 Malle BF, Pearce GE. Attention to behavioral events during interaction: Two actor-observer gaps and three attempts to close them. J Pers Soc Psychol 2001;81 (2):278-94.

99 Weiner B. Inferences of responsibility and social motivation. In: Zanna M P, editor. Advances in experimental social psychology, vol 27. San Diego, CA US: Academic Press; 1995. p. 1-47.

100 Berendonk C, Stalmeijer RE, Schuwirth LWT. Expertise in performance assessment: Assessors' perspectives. Adv Health Sci Educ 2013;18 (4):559-71.

101 Govaerts MJB, Wiel M WJ, Schuwirth LWT, Vleuten CPM, M uijtjens AM M. Workplace-based assessment: Raters' performance theories and constructs. Adv Health Sci Educ 2013;18 (3):375-96.

102 Gruppen LD, Frohna AZ. Clinical reasoning. In: Norman GR, van der Vleuten CPM, Newble DI, editors. International handbook of research in medical education. Dordrecht: Kluwer Academic Publishers; 2002. p. 205-30. 
103 Durning SJ, Artino AR, Boulet JR, Dorrance K, van der Vleuten C, Schuwirth L. The impact of selected contextual factors on experts' clinical reasoning performance (does context impact clinical reasoning performance in experts?). Adv Health Sci Educ 2012;17 (1):65-79.

104 Hofstadter D. I am a strange loop. New York, NY US: Basic Books; 2007.

105 Klein G. Streetlights and shadows: Searching for the keys to adaptive decision making. Cambridge, MA: MIT Press; 2009.

106 Chi MTH, Feltovich PJ, Glaser R. Categorization and representation of physics problems by experts and novices*. Cognitive Sci 1981;5 (2):121-52.

107 Norman GR, Tugwell P, Feightner JW, M uzzin LJ, Jacoby LL. Knowledge and clinical problem-solving. M ed Educ 1985;19 (5):344-56.

108 Webster-Wright A. Reframing professional development through understanding authentic professional learning. Rev Educ Res 2009;79 (2):702-39.

109 Gipps C. Socio-cultural aspects of assessment. Revi Res Educ 1999;24:355-92.

110 Delandshere G, Petrosky AR. Capturing teachers' knowledge: Performance assessment a) and poststructuralist epistemology, b) from a post-structuralist perspective, c) and post-structuralism, d) none of the above. Educ Res 1994;23 (5):11-8.

111 Elstein AS, Schwarz A. Clinical problem solving and diagnostic decision making: Selective review of the cognitive literature. BMJ 2002;324 (7339): 729-732.

112 Schuwirth LW, van der Vleuten CP. Assessing competence. In: Hodges BD, Lingard LA, editors. The question of competence: Reconsidering medical education in the twenty-first century. First ed. Ithaca and London: ILR Press-Cornell University Press; 2012. p. 113-30.

113 Ross S, Poth CN, Donoff M et al. Competency-based achievement system: Using formative feedback to teach and assess family medicine residents' skills. Canadian Fam Physician 2011;57 (9):e323-30.

114 Kahneman D, Klein G. Strategic decisions: When can you trust your gut? [Interview]: McKinsey \& Company, Inc.; 2010 [cited 2013-10-28]; 58-67]. Available from: http://www.mckinsey.com/insights/ strategy/strategic_decisions_when_can_you_trust_your_gut.

115 Crossley J, Jolly B. Making sense of work-based assessment: Ask the right questions, in the right way, about the right things, of the right people. Med Educ 2012;46 (1):28-37.

116 Nutter D, Whitcomb ME. The AAM C project on the clinical education of medical students. 2008 December 16, 2013. Available from: https:// www.aamc.org/download/68522/data/clinicalskillsnutter.pdf

117 Daelmans HEM, Hoogenboom RJI, Donker AJM, Scherpbier AJJA, Stehouwer CDA, van der Vleuten CPM . Effectiveness of clinical rotations as a learning environment for achieving competences. Med Teach 2004;26 (4):305-12.

118 Holmboe ES. Faculty and the observation of trainees' clinical skills: Problems and opportunities. Acad Med 2004;79 (1):16-22.

119 Bindal N, Goodyear H, Bindal T, Wall D. Dops assessment: A study to evaluate the experience and opinions of trainees and assessors. Med Teach 2013;35 (6):e1230-e4.

120 Bindal T, Wall D, Goodyear HM. Trainee doctors' views on workplace-based assessments: Are they just a tick box exercise? M ed Teach 2011;33 (11):919-27.

121 Weston PSJ, Smith CA. The use of M ini-CEX in UK foundation training six years following its introduction: Lessons still to be learned and the benefit of formal teaching regarding its utility. Med Teach 2014;36 (2):155-63.

122 M cKavanagh P, Smyth A, Carragher A. Hospital consultants and workplace based assessments: How foundation doctors view these educational interactions? Postgrad M ed J 2012;88 (1037):119-24.

123 Sabey A, Harris M. Training in hospitals: What do gp specialist trainees think of workplace-based assessments? Educ Primary Care 2011;22 (2):90-9.

124 Tokode OM, Dennick R. A qualitative study of foundation doctors' experiences with M ini-CEX in the UK. Int J Med Educ 2013;4:83-92.

125 Pangaro L. A new vocabulary and other innovations for improving descriptive in-training evaluations. Acad Med 1999;74 (11):1203-7.

126 Surowiecki J. The wisdom of crowds: Random House Digital, Inc.; 2005. 
127 Baile WF, Buckman R, Lenzi R, Glober G, Beale EA, Kudelka AP. SPIKES -- a six-step protocol for delivering bad news: Application to the patient with cancer. Oncologist 2000;5 (4):302-11. 



\section{CHAPTER}

\section{Rater-based assessments as social judgments Rethinking the etiology of rater errors}

Andrea Gingerich

Glenn Regehr

Kevin W. Eva

Published in: Academic M edicine 2011; 86: S1-S7 


\section{ABSTRACT}

Problem Statement and Background Measurement errors are a limitation of using rater-based assessments that are commonly attributed to rater errors. Solutions targeting rater subjectivity have been largely unsuccessful.

Methodology This critical review examines investigations of rater idiosyncrasy from impression formation literatures to ask new questions for the parallel problem in raterbased assessments.

Synthesis of Findings Raters may form categorical judgments about ratees as part of impression formation. Although categorization can be idiosyncratic, raters tend to consistently construct one of a few possible interpretations of each ratee. If raters naturally form categorical judgments, an assessment system requiring ordinal or interval ratings may inadvertently introduce conversion errors due to translation techniques unique to each rater.

Conclusions Potential implications of raters forming differing categorizations of ratees combined with the use of rating scales to collect categorical judgments on measurement outcomes in rater-based assessments are explored. 


\section{BACKGROUND}

Medical education has long struggled to find a way to take advantage of human observation to inform assessment of its professionals and trainees. Rater-based assessments are used because they allow students to be observed performing complex tasks corresponding to higher levels of competency. ${ }^{1,2}$ Common examples include objective structured clinical examinations (OSCE), ${ }^{3}$ small group tutorial assessments ${ }^{4}$ and workplace assessments ${ }^{5}$. Unfortunately, rater-based assessments generally demonstrate psychometric weaknesses ${ }^{6-9}$ including measurement errors of leniency, ${ }_{1}^{10}$ undifferentiation, ${ }_{11}^{11}$ range restriction, ${ }^{12}$ bias $^{13}$ and unreliability. ${ }^{14}$ One of the biggest threats to the reproducibility of clinical ratings, low inter-rater reliability, ${ }_{15,16}$ has been found to occur even when different raters view the same performance. ${ }^{17-20}$ In a dramatic example, 19 of 20 OSCE stations each had 1-8 discrepancies where at least one rater made a positive evaluative comment about the presence or absence of a specific observable behaviour, while another rater made a negative evaluative comment regarding the exact same behaviour. ${ }^{21}$

While actual ratee performance differences attributable to context or case specificity are acknowledged to play a critical role in the complexities of rater-based assessment, ${ }^{22}$ its effects are well understood and accounted for in current assessment systems. Causes of variability in ratings, given by multiple raters for the same performance within the same context, are more uncertain with considerable debate currently taking place about whether or not such variability can be overcome. ${ }^{23-25}$ The challenge is illustrated well by Marshall and Ludbrook who stated, "the judgment that an examiner makes of a candidate in the setting of the conventional test of clinical skills is an entirely personal one. ${ }^{\prime 2(p 215)}$ This assumption of raters being idiosyncratic has led to the development of solutions to help raters be more objective. Medical education researchers have redesigned rating scales, ${ }^{27}$ forms, ${ }^{11}$ and systems ${ }^{28}$ to help deter subjective biases and support rater judgments during assessments, but these solutions have had limited success. ${ }^{6,29,30}$ With raters identified as the problem, rater training has been the most persistently proposed solution. ${ }^{31}$ Rater training's meagre improvement of measurement outcomes, however, has provoked some researchers to suspect medical raters are impervious to training, 7,32 by suggesting that "some examiners are inherently consistent raters and others less so. The former do not need training and the latter are not improved by training." $33($ (p349)

Given the apparent intractability of this problem using our standard frameworks, it might be worth exploring other approaches to understand the manner in which people represent and make determinations about others. For example, a handful of medical education researchers have called attention to the importance of considering raters' social cognitive processes and corresponding implications concerning measurement of 
performance assessments. These authors have stressed the need to see raters as active information processors using judgment, reasoning and decision making strategies to assess ratees. ${ }^{34}$ They have also highlighted a complex interaction of impression formation, interpretation, memory recall and judgment in assigning ratings. ${ }^{21}$ And several have described potential incongruences between assessment procedures, psychometric measurement principles and human rater capabilities. ${ }^{2,35,36}$

The approach being explored by these authors is highly reminiscent of the impression formation literature, a large research domain within social cognition focused on understanding how individuals make judgments of others in social settings. ${ }^{37}$ Impressions are formed as part of knowing another person. They are constructed from factual information, inferences and evaluative reactions regarding the target person. ${ }^{37}$ It has been suggested that impressions are used to organize information into a structure of knowledge about the person ${ }^{38}$ in order to interact with them. ${ }^{39}$ Social cognition researchers are interested in the specific cognitive processes used by people to think about the social world. They investigate how social information is encoded; stored and retrieved from memory; structured and represented as knowledge; and the processes used to form judgments and make decisions. ${ }^{40}$

Interestingly, the idiosyncrasy of raters has also been of interest to impression formation researchers. ${ }^{41}$ In that literature, it is well established that different raters will often form different impressions of the same ratee even when given the exact same information. ${ }^{42,43}$ In fact, the descriptions made by a single rater about multiple others have been found to be more similar than the descriptions made by multiple raters about a single ratee. ${ }^{44}$ Typically, the largest portion of variance in personality trait ratings is not attributable to differences perceived between the ratees but differences uniquely contained within the relationship between each rater and ratee. ${ }^{42,45}$ These parallel findings between the rater-based assessment literature and the impression formation literature suggest that social cognitive explorations of this phenomenon could be informative in better understanding the cognitive processes used by raters within the social context of rater-based assessments. ${ }^{21}$ In turn, such better understanding could inform new solutions for the limitations of these techniques. ${ }^{35}$

\section{METHOD}

This paper represents a synthesis of related research domains focused on understanding the source of variance in social judgments. Although the measurement limitations in rater-based assessments undoubtedly stem from many complex factors, this paper explores the perplexing origins of rater variance when raters observe the same act. MEDLINE, ERIC and PsycINFO were used to search for articles investigating social 
judgment processes including impression formation and associated socio-cognitive processes. This paper is necessarily non-systematic and non-exhaustive in order to present a preliminary understanding of vast literatures investigating problems analogous to those with rater-based assessments. Accordingly, the intent is to stimulate different ways of asking questions about the limitations of rater-based assessments prior to negotiating potential solutions. Due to space restrictions, the papers cited are a representative sample of larger bodies of research and interested readers may want to consult their respective reference lists.

\section{RESULTS}

Within psychology literatures, the act of perceiving other people (i.e. forming impressions), is commonly described as a categorization task though differences exist in the way in which these cognitive processes are thought to be enacted. ${ }^{46,47}$ Based on iterative readings of the social cognition literature, three themes emerged that encapsulate the differing conceptions of categorization as used in forming impressions of other people. These themes included the conceptualization of impression formation as the construction of Person M odels, impression formation as a nominal categorization process, and impression formation as a dimensionally based categorization process. Each of these concepts will be elaborated, and potential implications for rater-based assessment in medical education will be highlighted, in the following sections.

\section{Impression formation as idiosyncratic yet convergent Person Models}

Social judgments have been found to be idiosyncratic and fallible under certain conditions. ${ }^{48}$ Psychology researchers have studied numerous variables that provide some understanding of why this is the case. For example, raters' mood and emotions at the time of the judgment can have an influence. ${ }^{49}$ If the ratee reminds the rater of a significant other, the ratee can be perceived to share similar characteristics. ${ }^{50}$ If the rater has recently been exposed to a description of the ratee, ambiguous behaviour can be interpreted as being consistent with that description. ${ }^{51,52}$ Thus, there exists an implicit understanding that impressions are subject to variables and contextual factors beyond the ratee herself.

Despite this expectation of rater idiosyncrasy in impression formation, however, there exists evidence that impressions will often be quite consistent across raters. One line of research, for example, has demonstrated that when raters were asked to write descriptions of a ratee based on their impressions, all descriptions for that ratee could be grouped into three representative stories (or "Person M odels") about that individual. ${ }^{42,45}$ The Models are ad hoc descriptions of the ratee based on the rater's impres- 
sions formed from the information available. Importantly, while many stories can be generated, stories pertaining to any one individual tend to fall into one of three Models though the same three Models are not relevant to every individual. To elaborate, in one study, ${ }^{45} 69$ participants viewed the same four minute video of a ratee having a conversation with a friend and then with a family member. Participants provided a written description of what they thought about the ratee. Naive participants subsequently reviewed all the descriptions and independently sorted them into groups based on similarity or shared meaning. Their groupings showed high agreement, and cluster analyses confirmed that, for each ratee, there were three distinct ways in which (s)he was described. Consider these three descriptions ${ }^{(p 341)}$ :

M odel 1 ( $67.6 \%$ of descriptions): [Ratee E] is energetic, friendly, and expressive, although she is more outgoing with her friend than her mother. She seems to be a kind and considerate person who enjoys talking to others. She laughs a lot and has many ideas.

Model 2 (15.5\% of descriptions): [Ratee E] is insecure and nervous. She seems distracted at times, and she has trouble making decisions. She plays with her pen a lot and keeps bringing up a trip she was supposed to go on last year.

Model 3 (16.9\% of descriptions): [Ratee E] has to dominate the conversation. She is rude and obnoxious and seems insensitive to other people. She doesn't even say bless you when her friend sneezes. She seems self-centred and barely lets her friend talk.

Consistent with this example, for each ratee in the study the majority of participants had a tendency to describe the ratee using a particular Person Model. In each case, however, two other, sometimes vastly different, descriptions were also consistently given. Thus while judgments are idiosyncratic, they are not infinitely so. It has been suggested that different combinations and prioritization of the pieces of information resulted in the different explanatory stories. ${ }^{42}$ In a follow-up study, ${ }^{45}$ the Person M odels corresponded with ratings of liking and positive-negative evaluation such that raters using Model 1 viewed the ratee positively and liked her whereas raters using Models 2 or 3 viewed her negatively and disliked her. The Person Models, therefore, were found to account for a substantial portion of the variance in impressions attributed to the unique relationship between the rater and the ratee-the variance often described as noise resulting from the idiosyncrasy of the rater. ${ }^{45}$

Impressions, and ratings, have often been regarded as personal to the rater and easily biased by various factors. ${ }^{7,53}$ If raters are forming Person Models as part of constructing a coherent impression about a ratee from the information they are receiving, and if there generally exist about three Person Models that are used for every ratee, this 
could help explain decreased inter-rater reliability in rater-based assessments while still yielding a sense of relative cohesion and coherence for each rater. And, it would lead to questioning whether and how the three possible, but highly divergent, M odels could ever be reconciled into a uniform set of ratings for an individual student. Before exploring these questions, however, it may be useful to examine some other social judgment conceptualizations.

\section{Impression formation as a nominal categorization process}

The Person Model shares many characteristics with theories that focus on the use of social categories as a way to decipher and integrate information about a ratee. $47,53,54$ Here the focus is not on the ad hoc construction of narratives around a ratee's behaviour, but rather, the focus is on raters' tendencies to lump ratees into pre-existing schemas. Categories are thought to be valuable in that they enable raters to apply preexisting knowledge to help understand incoming information about a person. While there are clear and readily recognized dangers in over-generalization (such as stereotypes), there are apparent benefits to categorization as well. ${ }^{46}$ With the use of categories, cognitive resources do not need to be used in order to monitor a ratee's category consistent behaviour. Instead, the rater only needs to note any category inconsistent behaviours. ${ }^{55}$ Categorization of the ratee also allows the rater to go beyond the given information to infer other expected details consistent with typical category members. ${ }^{56}$ This can be useful to better understand the individual ratees, to make predictions about how they will behave, and to decide how best to behave when interacting with them. ${ }^{47}$ Consistent with the Person Model theories of impression formation, category-based knowledge is thought to act as a framework to provide possible explanations for why a ratee might display particular behaviours in a given situation. Accordingly, it has been suggested that categories could be thought of as a type of shorthand to explain what a group of people are like and why. ${ }^{57}$

Although the social categorization literature suggests that these categories can exist pre-formed in long-term memory, ${ }^{46}$ social categorizations of a person are thought to be flexible because any individual can be categorized in multiple ways. ${ }^{58}$ Consistent with the findings described above, this literature has found context to be important in determining which category of the many possibilities will be applied to the person. ${ }^{51,59}$ For example, a man carrying a baby in a grocery store may be categorized as a Dad but in a hospital as a Nurse. Researchers in this area have been particularly concerned with the question of how controllable category activation is. Some researchers argue it is automatic and not controllable, ${ }^{60}$ others have suggested that it is "conditionally automatic" ${ }^{61,62}$ or consciously controllable. ${ }^{63}$ Interestingly, there is evidence to suggest that intentionally trying to adjust social judgments to counteract categorization-based assumptions or trying to suppress categorical thinking can cause the categorizations to 
have more adverse influence on impressions. ${ }^{64}$ This has been repeatedly demonstrated, for example, with studies where raters who were trying to avoid the use of stereotypes ended up demonstrating more stereotypic thinking in subsequent trials ${ }^{65}$ and more stereotyped memories of the ratee.$^{66}$ This suggests that good intentions and the motivation to avoid categorizing people may not be completely possible and, when attempted, may not result in improved judgments.

If we were to accept that raters may be categorizing ratees as part of perceiving and forming an impression of them, this could have important implications for rater-based assessment. Perhaps the most intriguing implication is the resemblance of categories to nominal rather than ordinal or interval data. As a level of measurement, the nominal scale "classifies objects into categories based on some characteristic of the object. ${ }^{\text {67(p15) }}$ Nominal variables have categories but do not have an inherent, logical order, a true zero, or an equal interval between the categories. Assessment forms often require ordinal responses such as the selection of an ordered descriptive value on a behaviourally-anchored scale, or interval responses such as the selection of a numerical value on a Likert-type rating scale. If raters are judging ratees by perceiving them as belonging to a particular category, then how do they translate that categorical judgment into a rating scale value?

\section{Impression formation as dimensionally-based categorizations}

In contrast to the literature focussing on nominal categorizations of individuals, a third conceptualization of categorization counter-intuitively involves judgments made on dimensional scales. As is described more thoroughly in the following, people can appear to be placed into categories based on dichotomized judgments on two underlying dimensions. An extensive literature consistently identifies two orthogonal dimensions underlying social judgments that can account for the majority of variance in impression formation. In all studies, one of the dimensions refers to socially desirable or undesirable traits that directly impact upon others. It includes positive traits such as friendly or honest and negative traits such as cold or deceitful. The second dimension has more variability across studies and refers to traits that tend to more directly influence the individual's success. ${ }^{68,69}$ It tends to include positive traits such as intelligent or ambitious and negative traits such as indecisive or inefficient. These dimensions have been given various labels, likely attributable, in part, to differing domains having been studied: warmth/competence, ${ }^{69,70}$ communion/agency, ${ }^{68,71}$ social/intellectual, ${ }^{72}$ other-profitability/self-profitability, ${ }^{73}$ morality/competence ${ }^{74}$ and social desirability/ social utility. ${ }^{75}$ Although the choice of labels for each of the dimensions may imply researchers from different domains have identified very different dimensions, the researchers agree there is a common overlap of traits and behaviours. ${ }^{68-70,75,76}$ 
Interestingly, despite the speculation that there are two continuous, scaled dimensions underlying the process of social judgment, many researchers in the social judgment literature suggest that these two orthogonal dimensions are dichotomized into high versus low value judgments. When the two dimensions are crossed, therefore, the result is four potential combinations and it has been proposed that individuals and groups are categorized in one of these four clusters. ${ }^{77}$ Researchers have shown that the stereotyped groups described in the preceding section can be categorized into each cluster based on rater judgments of warmth/competence dimensions and that each cluster is associated with emotional and behavioural responses in the rater. ${ }^{78}$ More specifically, in North America, groups judged high on warmth and competence, such as the middleclass, invoke the emotions of pride and admiration and lead to behaviours of wanting to help and associate with them. Groups judged low on warmth and high on competence, such as the stereotypically gluttonous rich, elicit envy and willingness to associate but also to attack under certain conditions. Groups judged high on warmth and low on competence, including stereotypes for the elderly and disabled, elicit pity and willingness to help but also to avoid. Low judgements of both warmth and competence, including stereotypes for the homeless and drug-addicted, invoke the emotions of disgust and contempt and lead to behaviours of wanting to attack and to avoid.

The fundamental nature of two dimensions underlying social judgments has been explained using an evolutionary perspective. It has been proposed that successfully determining whether strangers are potential friends or enemies, based on their perceived intentions and also on whether they are capable of achieving those intentions, would provide a survival advantage. ${ }^{79}$ As such, persons categorized as having cold or immoral intentions and high competence receive more strongly negative impression ratings than those categorized as having immoral intentions and low competence. ${ }^{80}$ This occurs despite the immoral-incompetent categorization resulting from two negative dimensional judgments and the immoral-competent categorization resulting from the combination of a positive and a negative dimensional judgment. Categorizations based on dimensional judgments, therefore, do not purely reflect an algebraic combination of values judged on two orthogonal dimensions.

The finding that two dimensions can account for variance in impression formation is especially intriguing because two dimensions have also been found to underlie raterbased assessments in medical education. ${ }^{11,81,82}$ Factor analysis of rating forms designed to assess clinical competence often identifies two underlying factors regardless of the number of items or the number of dimensions included on the form. Of the two factors that explain the majority of variance in ratings, one tends to refer to Knowledge and the other to Interpersonal skills. The knowledge dimension seems analogous to the competence dimension in social judgments and the interpersonal skills dimension 
appears comparable to the warmth dimension. As such, medical raters could be using the cognitive processes, previously described using the example of stereotyped groups in North America, to classify ratees into one of the four clusters with consequent emotions and reactions. If two fundamental dimensions reflect the cognitive judgments made by people in forming impressions of others it may be useful to better understand how raters make judgments on these two dimensions and what factors influence judgments on either dimension. It may also be important to examine the dimensions more closely to determine if they are in fact continuous or dichotomized; to look for additional dimensional axes; and to confirm that these two dimensions are truly orthogonal.

On the other hand, it is worth noting that the two dimensions were revealed through the use of rating scales and factor analysis or multidimensional scaling. It is not clear, therefore, whether these dimensions represent the actual cognitive processes used by raters or are artefacts of the rating process used to capture the judgments. Thus, although these dimensions are potentially useful in understanding the judgments reported on rating scales, it remains to be seen whether they meaningfully reflect the underlying cognitions that generated the ratings in the first place or whether they emerge from the data because ratings scales were used to record the judgments.

\section{DISCUSSION}

The need for medical education to use rater-based assessments in determining the competence of its trainees and professionals combined with difficultly in resolving the psychometric limitations of these ratings has resulted in raters commonly being blamed for the limitations of this assessment approach. ${ }^{31}$ While case specificity has been shown to play a very important role, rater variability (based on idiosyncrasies of opinion, defiance or ineptitude) has also been seen as a source of construct irrelevant error ${ }^{16,25}$ with less clear understanding of how to overcome the challenge it creates. Solutions targeted at bolstering rater objectivity and ability have had little impact on reducing these measurement errors, ${ }^{7}$ and hence, perhaps the time has come to consider an alternate conception of rater "error". Through better understanding of how raters make judgments during the assessment process, we may be able to tease apart error attributable to human biases and error unintentionally imposed by assessment systems that are incongruent with innate human cognition. If we were to start with the premise that raters in rater-based assessments use the same cognitive processes as raters in social judgments, then what would the implications be for assessment and how would it change the way we talk about assessment? 
Psychologists have shown that, in making social judgments, people have a propensity to categorize other people. In the impression formation literature, there appears to be at least three different conceptualizations of this categorization process. The Person Model literature presents an adaptable type of categorization based on the construction of stories, as needed, to describe specific individuals. ${ }^{42,45}$ In contrast, the categorization literature suggests that categories can be pre-formed constructs that exist in the long-term memory and are applied when activated. ${ }^{46}$ And a third conceptualization is the concept of cluster-based categorization that results from dichotomous judgments on two dimensions. ${ }^{77,78}$ Regardless of these differences in conceptualization, there is general agreement in the impression formation literature that such categorizations allow information about a typical category member to be applied to the new person, thereby reducing the cognitive resources needed to monitor the person's behaviour, allowing for predictions of how they will behave, and providing options for how best to interact with them. ${ }^{46}$ If this is the basic process underlying raters' decisions in medical education, it has several implications for our conceptualization of rater error.

First, the categorization of the person can happen spontaneously and without awareness $^{60}$ and there may be poor control over these processes even when they are made explicit. ${ }^{64}$ This could directly impede efforts to modify the influence of categorization on assessments through rater training. Further, although there is evidence of these categorizations being surprisingly consistent across raters, there is nonetheless room for rater idiosyncrasy, or at least subgroups that consistently use a different Person Model in understanding a particular individual's behaviour. ${ }^{45}$ If we were to take this categorization model as the underlying process by which raters were assessing ratees, therefore, it would radically alter our understanding of the source of rater differences and the ways in which we might imagine trying to address it. It is not that raters are scaling the behaviours differently, but rather that they are placing ratees in different nominal categories.

Second, in the vast majority of rater-based assessments in medical education, the standard forms require ratings on a pre-determined list of performance domains, roles and/or competencies. These theoretically constructed assessment dimensions may not correspond with the categorizations that result from our innate cognitive processes and they may not be universally applicable to all ratee categorizations. It is possible, therefore, that rater error might stem from an assessment system that asks raters to carry out judgment tasks that are incongruent with the cognitive processes used by humans to perform judgments. If we were to accept the process of categorization of ratees during assessments, then what are the potential ramifications for analyzing rater-based assessments? If raters are forming nominal judgments but assessment forms require ordinal or interval ratings, how do they translate that categorical judgment into a rating scale value? Could raters using different conversion systems explain 
a portion of rater error? Could conversion miscalculations be a source of rater error? How much influence could an unreliable or idiosyncratic rater judgment to rating scale conversion process have on the measurement outcomes of rater-based assessments?

The idea that people categorize others as a way of perceiving and understanding who they are and what their significance may be in a social environment is, in and of itself, not a radical concept. Its potential implications for rater-based assessments, on the other hand, are profound. First, it suggests that measurement errors may be partially a function of raters making somewhat consistent, but different, categorizations. If this is true, assessment systems may need to accommodate the categorization process, and faculty development efforts would look very different if we are to improve the quality of assessments. Second, measurement errors may reflect conversion errors stemming from idiosyncratic or erroneous translation of these nominal judgments into the ordinal or interval judgments we demand of our raters. The statistical benefits of interval variables over nominal variables are enormous. But if this is how human raters form judgments and make assessments, then this inconvenient reality may need to be faced head-on. Thus, the third implication is that there may exist a more efficient, accurate and reliable rater-based assessment system that incorporates categorical judgment processes.

As we consider where to go from here, it is clear that, while immediate solutions are not available, a research agenda informed by the concept of an innate human inclination towards categorization of people during impression formation would lead to a very different set of questions regarding our assessment systems. Are rater-based assessments suffering from a "lost in translation" problem as they require ordinal judgments to be derived from a nominal categorization process? If raters are trying to provide nominal data, how might we codify these categorizations directly rather than asking our raters to translate their categorical assessments into universally applied scaled dimensions with ordered degrees of competence? How could such a categorical assessment system be analyzed and compared across raters? What would be required to compile and interpret various nominal judgments to determine the competency of individual students? How would the resulting assessment be communicated to students in a comprehensible and usable form? How could assessment decisions based on nominal data be defended during appeals and litigation?

It is with good intentions that steps have been taken to make rater-based assessments more consistent through increasingly structured dimensional assessment tools. Changes to rating scales, assessment procedures and rater training have been based on solid reasoning and rigorous study. It is important to have psychometrically sound assessments that are defensible, useful and meaningful. But the outcomes from this dedicated work have not entirely met expectations. It may be time to take a completely dif- 
ferent look at what raters have been asked to do. The skills of observation, perception, judgment and decision making have evolved in humans to benefit social interactions and ultimately survival. It is highly likely the rater-based assessment environment triggers the use of these innate social cognitive processes. An assessment process that best utilizes the advantages of social cognitive processes while minimizing the disadvantages may provide improved results.

Funding: Financial support for the preparation of this paper was generously provided by a grant from the Society of Directors of Research in M edical Education (a non-profit organization [501c3]); website: <www.sdrme.org >

Ethical approval: Not applicable.

Other disclosures: None. 


\section{REFERENCES}

1 Fromme HB, Karani R, Downing SM. Direct Observation in Medical Education: Review of the Literature and Evidence for Validity. Mt Sinai J M ed. 2009;76(4):365-371.

2 van der Vleuten CPM, Schuwirth LWT. Assessing Professional Competence: From Methods to Programmes. Med Ed. 2005;39(3):309-317.

3 Turner JL, Dankoski ME. Objective Structured Clinical Exams: A Critical Review. Fam Med. 2008;40(8): 574-578.

4 Eva KW. Assessing Tutorial-Based Assessment. Adv in Health Sci Ed. 2001;6:243-257.

5 Norcini J, Burch V. Workplace-Based Assessment as an Educational Tool: Amee Guide No. 31. Med Teach. 2007;29(9/10):855-871.

6 Lurie SJ, M ooney CJ, Lyness JM. M easurement of the General Competencies of the Accreditation Council for Graduate Medical Education: A Systematic Review. Acad M ed. 2009;84(3):301-309.

7 Williams RG, Klamen DA, M cGaghie WC. Cognitive, Social and Environmental Sources of Bias in Clinical Performance Ratings. Teach Learn M ed. 2003 Fall2003;15(4):270-292.

8 Kassebaum DG, Eaglen RH. Shortcomings in the Evaluation of Students' Clinical Skills and Behaviours in Medical School. Acad M ed. 1999;74(7):841-849.

9 Albanese M. Rating Education Quality: Factors in the Erosion of Professional Standards. Acad M ed. 1999 June;74(6):652-658.

10 Cacamese SM, Elnicki M, Speer AJ. Grade Inflation and the Internal M edicine Subinternship: A National Survey of Clerkship Directors. Teach Learn M ed. 2007;19(4):343-346.

11 Silber CG, Nasca TJ, Paskin DL, Eiger G, Robeson M, Veloski JJ. Do Global Rating Forms Enable Program Directors to Assess the Acgme Competencies? Acad Med. 2004;79(6):549-556.

12 Hatala R, Norman G. In-Training Evaluation During an Internal Medicine Clerkship. Acad Med. 1999 October;74(10):S118-S120.

13 van Barneveld C. The Dependability of Medical Students' Performance Ratings as Documented on inTraining Evaluations. Acad M ed. 2005;80(3):309-312.

14 Clauser BE, Clyman SG. Components of Rater Error in a Complex Performance Assessment. J Ed Meas. 1999 Spring99;36(1):29-45.

15 Downing SM. Reliability: On the Reproducibility of Assessment Data. M ed Ed. 2004;38(9):1006-1012.

16 Downing SM. Threats to the Validity of Clinical Teaching Assessments: What About Rater Error? M ed Ed. 2005;39(4):353-355.

17 Clauser BE, et al. Scoring a Performance-Based Assessment by M odeling the Judgments of Experts. J Ed Meas. 1995;32(4):397-415.

18 Elliot DL, Hickam DH. Evaluation of Physical Examination Skills. Reliability of Faculty Observers and Patient Instructors. JAM A. 1987;258(23):3405-3408.

19 Noel GL, Herbers JE, Caplow MP, Cooper GS, Pangaro LN, Harvey J. How Well Do Internal Medicine Faculty M embers Evaluate the Clinical Skills of Residents? Ann Int M ed. 1992;117(9):757-765.

20 Clauser BE, Harik P, Clyman SG. The Generalizability of Scores for a Performance Assessment Scored with a Computer-Automated Scoring System. J Ed M eas. 2000;37(3):245-261.

21 M azor KM, Zanetti M L, Alper EJ, Hatem D, Barrett SV, M eterko V, et al. Assessing Professionalism in the Context of an Objective Structured Clinical Examination: An in-Depth Study of the Rating Process. M ed Ed. 2007;41(4):331-340.

22 Eva KW. On the Generality of Specificity. Med Ed. 2003;37(7):587-588.

23 Holmboe ES, Ward DS, Reznick RK, Katsufrakis PJ, Leslie KM, Patel VL, et al. Faculty Development in Assessment: The M issing Link in Competency-Based Medical Education. Acad M ed. 2011;86(4):460-467.

24 Lurie SJ, M ooney CJ, Lyness JM. Commentary: Pitfalls in Assessment of Competency-Based Educational Objectives. Acad M ed. 2011;86(4):412-414.

25 Clauser BE, Harik P, M argolis MJ, M ee J, Swygert K, Rebbecchi T. The Generalizability of Documentation Scores from the Usmle Step 2 Clinical Skills Examination. Acad M ed. 2008;83(10 Suppl):S41-S44. 
26 Marshall VR, Ludbrook J. The Relative Importance of Patient and Examiner Variability in a Test of Clinical Skills. Brit J M ed Ed. 1972;6(3):212-217.

27 Gray JD. Global Rating Scales in Residency Education. Acad Med. 1996 January Supplement;71(1):S55S63.

28 Littlefield JH, DaRosa DA, Paukert J, Williams RG, Klamen DL, Schoolfield JD. Improving Resident Performance Assessment Data: Numeric Precision and Narrative Specificity. Acad M ed. 2005;80(5):489-495.

29 Wood L, Hassell A, Whitehouse A, Bullock A, Wall D. A Literature Review of Multi-Source Feedback Systems within and without Health Services, Leading to 10 Tips for Their Successful Design. M ed Teach. 2006;28(7):185-191.

30 Kogan JR, Holmboe ES, Hauer KE. Tools for Direct Observation and Assessment of Clinical Skills of Medical Trainees: A Systematic Review. JAM A. 2009;302(12):1316-1326.

31 Green ML, Holmboe E. Perspective: The Acgme Toolbox: Half Empty or Half Full? Acad Med. 2010;85(5):787-790.

32 Cook DA, Dupras DM, Beckman TJ, Thomas KG, Pankratz VS. Effect of Rater Training on Reliability and Accuracy of M ini-Cex Scores: A Randomized, Controlled Trial. J Gen Int M ed. 2009;24(1):74-79.

33 Newble DI, Hoare J, Sheldrake PF. The Selection and Training of Examiners for Clinical Examinations. Med Ed. 1980;14(5):345-349.

34 Govaerts MJB, Schuwirth L, Van der Vleuten CP, M uijtjens AM M. Workplace-Based Assessment: Effects of Rater Expertise. Adv in Health Sci Ed. 2010;Online First(16 September 2010).

35 Govaerts MJB, van der Vleuten CPM, Schuwirth LWT, Muijtjens AMM. Broadening Perspectives on Clinical Performance Assessment: Rethinking the Nature of in-Training Assessment. Adv in Health Sci Ed. 2007;12(2):239-260.

36 Lurie SJ, Mooney CJ, Lyness JM . In Reply Letters to Editor How Should the Acgme Core Competencies Be Measured? Acad M ed. 2009;84(9):1173.

37 Hamilton DL, Driscoll DM, Worth LT. Cognitive Organization of Impressions: Effects of Incongruency in Complex Representations. J Pers Soc Psych. 1989;57(6):925-939.

38 Lingle JH, Geva N, Ostrom TM, Leippe MR. Thematic Effects of Person Judgments on Impression Organization. J Pers Soc Psych. 1979;37(5):674-687.

39 Leyens J-P, Fiske ST. Impression Formation: From Recitals to Symphonie Fantastique. In: Devine PG, Hamilton DL, Ostrom TM (eds). Social Cognition: Impact on Social Psychology. San Diego, CA US: Academic Press, 1994:39-75.

40 Bless H, Fiedler K, Strack F. Social Cognition: How Individuals Construct Social Reality. New York, NY US: Psychology Press; 2004. 235 p.

41 Kenny DA. Person: A General M odel of Interpersonal Perception. Personality \& Social Psychology Review (Lawrence Erlbaum Associates). 2004;8(3):265-280.

42 Park B, DeKay ML, Kraus S. Aggregating Social Behavior into Person Models: Perceiver-Induced Consistency. Journal of Personality and Social Psychology. 1994;66(3):437-459.

43 Kenny DA. Interpersonal Perception: A Social Relations Analysis. New York, NY US: Guilford Press; 1994.

44 Bourne E. Can We Describe an Individual's Personality? Agreement on Stereotype Versus Individual Attributes. J Pers Soc Psych. 1977;35(12):863-872.

45 Mohr CD, Kenny DA. The How and Why of Disagreement among Perceivers: An Exploration of Person Models. J Exp Soc Psych. 2006;42(3):337-349.

46 Macrae CN, Bodenhausen GV. Social Cognition: Thinking Categorically About Others. Ann Rev Psych. 2000;51(1):93-120.

47 Fiske ST. Social Cognition and Social Perception. Ann Rev Psych. 1993;44:155-194.

48 Nisbett RE, Ross L. Human Inference: Strategies and Shortcomings of Social Judgment. Inglewood Cliffs, NJ: Prentice Hall; 1980.

49 Forgas JP. The Role of Emotion in Social Judgements: An Introductory Review and an Affect Infusion Model (Aim). Eur J Soc Psych. 1994;24(1):1-24.

50 Andersen SM, Cole SW. "Do I Know You?": The Role of Significant Others in General Social Perception. J Pers Soc Psych. 1990;59(3):384-399. 
51 Smith ER, Collins EC. Contextualizing Person Perception: Distributed Social Cognition. Psych Rev. 2009;116(2):343-364.

52 Higgins ET, Rholes WS, Jones CR. Category Accessibility and Impression Formation. J Exp Soc Psych. 1977;13(2):141-154.

53 Skowronski JJ, Carlston DE. Negativity and Extremity Biases in Impression Formation: A Review of Explanations. Psych Bull. 1989;105(1):131-142.

54 Kunda Z, Thagard P. Forming Impressions from Stereotypes, Traits, and Behaviors: A Parallel-ConstraintSatisfaction Theory. Psych Rev. 1996;103(2):284-308.

55 Macrae CN, Milne AB, Bodenhausen GV. Stereotypes as Energy-Saving Devices: A Peek inside the Cognitive Toolbox. J Pers Soc Psych. 1994;66(1):37-47.

56 Sherman JW, Lee AY, Bessenoff GR, Frost LA. Stereotype Efficiency Reconsidered: Encoding Flexibility under Cognitive Load. J Pers Soc Psych. 1998;75(3):589-606.

57 Wittenbrink B, Park B, Judd CM, Sedikides C, Schopler J, Insko CA. The Role of Stereotypic Knowledge in the Construal of Person Models. Ch. 8 In: Intergroup Cognition and Intergroup Behavior. Mahwah, NJ US: Lawrence Erlbaum Associates Publishers, 1998:177-202.

58 Stangor C, Lynch L, Duan C, Glas B. Categorization of Individuals on the Basis of Multiple Social Features. J Pers Soc Psych. 1992;62(2):207-218.

59 Stapel DA, Koomen W. Social Categorization and Perceptual Judgment of Size: When Perception Is Social. J Pers Soc Psych. 1997;73(6):1177-1190.

60 Bargh JA, Ferguson MJ. Beyond Behaviorism: On the Automaticity of Higher Mental Processes. Psych Bull. 2000;126(6):925-945.

61 Monteith MJ, Sherman JW, Devine PG. Suppression as a Stereotype Control Strategy. Pers Soc Psych Rev. 1998;2(1):63-82.

62 Gilbert DT, Hixon JG. The Trouble of Thinking: Activation and Application of Stereotypic Beliefs. J Pers Soc Psych. 1991;60(4):509-517.

63 Blair IV, Banaji MR. Automatic and Controlled Processes in Stereotype Priming. J Pers Soc Psych. 1996;70(6):1142-1163.

64 Wegner DM . Ironic Processes of M ental Control. Psych Rev. 1994;101(1):34-52.

65 Macrae CN, Bodenhausen GV, Milne AB, Jetten J. Out of Mind but Back in Sight: Stereotypes on the Rebound. J Pers Soc Psych. 1994;67(5):808-817.

66 Sherman JW, Stroessner SJ. Stereotype Suppression and Recognition Memory for Stereotypical and Nonstereotypical Information. Soc Cog. 1997 Fall97;15(3):205.

67 Hurlbert RT. Comprehending Behavioral Statistics. 4th ed. Toronto, Ontario: Thomson Wadsworth; 2006. $566 \mathrm{p}$.

68 Abele AE, Wojciszke B. Agency and Communion from the Perspective of Self Versus Others. J Pers Soc Psych. 2007;93(5):751-763.

69 Fiske ST, Cuddy AJC, Glick P. Universal Dimensions of Social Cognition: Warmth and Competence. Trends Cog Sci. 2007;11(2):77-83.

70 Judd CM, James-Hawkins L, Yzerbyt V, Kashima Y. Fundamental Dimensions of Social Judgment: Understanding the Relations between Judgments of Competence and Warmth. J Pers Soc Psych. 2005;89(6):899-913.

71 Ybarra O, Chan E, Park H, Burnstein E, M onin B, Stanik C. Life's Recurring Challenges and the Fundamental Dimensions: An Integration and Its Implications for Cultural Differences and Similarities. Eur J Soc Psych. 2008;38:1083-1092.

72 Rosenberg S, Nelson C, Vivekananthan PS. A Multidimensional Approach to the Structure of Personality Impressions. J Pers Soc Psych. 1968;9(4):283-294.

73 Peeters G. Evaluative Meanings of Adjectives in Vitro and in Context: Some Theoretical Implications and Practical Consequences of Positive-Negative Asymmetry and Behavioral-Adaptive Concepts of Evaluation. Psych Bel. 1992;32(2):211-231.

74 Wojciszke B. Affective Concomitants of Information on Morality and Competence. Eur Psych. 2005;10(1):60-70. 


\section{RATER-BASED ASSESSM ENTS AS SOCIAL JUDGM ENTS}

75 Beauvois J-Lo, Dubois N. Lay Psychology and the Social Value of Persons. Soc Pers Psych Comp. 2009;3(6):1082-1095.

76 Abele AE, Cuddy AJC, Judd CM, Yzerbyt VY. Fundamental Dimensions of Social Judgment. Eur J Soc Psych. 2008;38(7):1063-1065.

77 Cuddy AJC, Fiske ST, Glick P. The Bias Map: Behaviors from Intergroup Affect and Stereotypes. J Pers Soc Psych. 2007;92(4):631-648.

78 Fiske ST, Cuddy AJC, Glick P, Xu J. A M odel of (Often M ixed) Stereotype Content: Competence and Warmth Respectively Follow from Perceived Status and Competition. J Pers Soc Psych. 2002;82(6):878-902.

79 Wojciszke B, Bazinska R, Jaworski M. On the Dominance of Moral Categories in Impression Formation. Pers Soc Psych Bull. 1998;24(12):1251-.

80 Wojciszke B. Multiple M eanings of Behavior: Construing Actions in Terms of Competence or M orality. J Pers Soc Psych. 1994;67(2):222-232.

81 Ramsey PG, Wenrich M D. Use of Peer Ratings to Evaluate Physician Performance. JAM A. 1993;269(13): 1655-1660.

82 Nasca TJ, Gonnella JS, Hojat M, Veloski J, Erdmann JB, Robeson M, et al. Conceptualization and Measurement of Clinical Competence of Residents: A Brief Rating Form and Its Psychometric Properties. Med Teach. 2002;24(3):299-303. 



\section{CHAPTER}

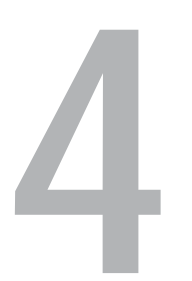

\section{More consensus than idiosyncrasy Categorizing social judgments to examine variability in M ini-CEX ratings}

\section{Andrea Gingerich}

Cees van der Vleuten

Kevin W. Eva

Glenn Regehr

Published in: Academic M edicine 2014; 89; 1510-1519 


\section{ABSTRACT}

Purpose Social judgment research suggests that rater unreliability in performance assessments arises from raters' differing inferences about the performer and the underlying reasons for the performance observed. These varying social judgments are not entirely idiosyncratic, but tend to partition into a finite number of distinct subgroups, suggesting some "signal" in the "noise" of inter-rater variability. The authors investigated the proportion of variance in M ini-CEX ratings attributable to such partitions of raters' social judgments about residents.

Method In 2012 and 2013, physicians reviewed video-recorded patient encounters for 7 residents, completed a Mini-CEX, and described their social judgments of the residents. Additional participants sorted these descriptions, which were analyzed using latent partition analysis (LPA). The best-fitting set of partitions for each resident served as an independent variable in a one-way ANOVA to determine the proportion of variance explained in M ini-CEX ratings.

Results Forty-eight physicians rated at least 1 resident (34 assessed all 7). The seven sets of social judgments were sorted by 14 participants. Across residents, 2 to 5 partitions (mode $=4$ ) provided a good LPA fit, suggesting that subgroups of raters were making similar social judgments, while different causal explanations for each resident's performance existed across subgroups. The partitions accounted for $9-57 \%$ of the variance in $\mathrm{M}$ ini-CEX ratings across residents (mean $=32 \%$ ).

Conclusions These findings suggest that multiple "signals" do exist within the "noise" of inter-rater variability in performance-based assessment. It may be valuable to understand and exploit these multiple signals rather than try to eliminate them. 


\section{PURPOSE}

Relying on clinical supervisors to observe and assess trainees' clinical performances has been an essential component of assessment in medical education. One of the limitations of this form of assessment is excessive variability in the ratings and judgments provided by supervisors. In fact, variance attributed to the idiosyncratic ratings of the supervisors often exceeds the variance accounted for by differences in trainees. ${ }^{1-3}$ From a psychometric perspective, this can be problematic, as it is not unusual for the majority of clinical rating variances to be considered unusable "error."

We have raised the possibility in a previous article ${ }^{7}$ that variability in clinical ratings could be introduced through the cognitive processes used in making social judgments (i.e., inferences about the performer and the underlying reasons for the performance observed). Recent research ${ }^{8,9}$ suggests supervisors do make such inferences during clinical assessments. However, the relationship between the formation of these social judgments about a trainee and supervisors' impressions regarding that trainee's clinical competence has not yet been specified. ${ }^{10}$

There are an infinite number of social judgments that could be made, ${ }^{11}$ raising concerns that as many social judgments could be formed about an individual as there are people providing judgments. Mohr and Kenny ${ }^{12}$ have found, however, that social judgments are much less idiosyncratic than that statement implies. They asked 69 study participants to view a brief video recording of a target person and to offer descriptions of that target person. The resulting descriptions included a wide variety of social judgments, yet that array of impressions could be easily organized into three coherent categories of description that were not only distinct from each other, but actually represented conflicting social inferences and personality attributions. This finding replicated across six different targets, although for each target there was a different set of distinct categories of social judgments. This finding was supportive of earlier work ${ }^{13,14}$ that proposed that people spontaneously create a narrative account of a target person that typically includes causal explanations for the observed behaviors. Importantly, these causal explanations and attributions were able to account for variance in numeric ratings of the target individual that would normally be attributed to rater idiosyncrasy. ${ }^{12,13}$

Mohr and Kenny's method, therefore, offers an opportunity to explore variability in clinical performance assessments and to examine the extent to which such variability reflects different social judgments. If such clustering of disparate social judgments does exist within subgroups of raters observing the same performance, it raises the possibility that there may be multiple "signals" in the "noise" of rater variability that are not currently being recognized, much less understood. This would, in turn, raise 
questions about whether these multiple signals should be treated as error to be eliminated or information to be exploited as we construct our assessment of a trainee's competence. The first step, however, is determining the extent to which these multiple signals do exist and to establish methods to effectively document their impact on rater assessments.

The primary purpose of our study, therefore, was to explore the utility of Mohr and Kenny's ${ }^{12}$ methodology to understand rater idiosyncrasy in clinical performance assessment. The specific research question was, "What proportion of variance in clinical competence ratings can be explained by raters' development of one of a few distinct social impressions about the performer?" We attempted to match M ohr and Kenny's ${ }^{12}$ conditions as closely as possible in the context of clinical performance assessment. It was necessary, however, to make some modifications to their methodology by using latent partition analysis (LPA) as a statistical method to identify the common categorizations of social judgments made by physician raters, as will be explained below. Thus, a secondary purpose of the study was to introduce LPA as a statistical method to the medical education literature.

\section{METHOD}

The first component of this study involved the selection of videos of clinical performances and the development of an online system to present the videos and collect data from physicians. Data collection and analysis then proceeded in four phases.

- In Phase 1 physicians assessed the video-recorded clinical performances by providing M ini-CEX ratings and narrative responses in the online data collection system.

- In Phase 2 additional participants (who were naïve to the videos, the clinical ratings, and the purpose of the study) reviewed and sorted the physicians' narrative responses for each clinical performance into piles based on the similarity of the social judgments being described.

- Phase 3 involved statistical analyses of the sorted piles using LPA to determine whether the narrative responses could sensibly be grouped into categories and then help define the number and composition of categories that best grouped the descriptions of social judgments for each clinical performance.

- In Phase 4, for each clinical performance, we treated the categories generated by LPA as the independent variable in a one-way ANOVA to determine the amount of variance that could be explained in the overall clinical competence ratings on the Mini-CEX. 


\section{MATERIALS GENERATION}

To identify an appropriate set of video performances to be assessed by raters in the study, we collected video recordings of clinical trainees interacting with patients that had been developed and used by other medical education researchers, ${ }^{8}$ along with videos that had been posted to YouTube for educational purposes. From these, we selected for pilot testing 11 videos representing a range of primary-care-related topics. Each video depicted one trainee and one patient (no examiner present) and plausibly represented a second-year internal medicine resident (6 were scripted at this level, ${ }^{8} 4$ were produced as study aids for medical licencing exams, and 1 was a practice session with a standardized patient for an undergraduate OSCE).

We then piloted the 11 videos to select the most appropriate set of stimuli for the study. Pilot participants were known by us to have an interest in medical education research along with experience in assessment administration, design, and/or with assessing residents' clinical skills. Eighteen participants, consisting of 15 physicians, a standardized patient trainer, an experienced standardized patient, and a clinical psychologist, were asked to review, score, and comment on the videos and provide feedback on their experience with these three tasks during four rounds of pilot testing. Based on their responses, 7 videos (3.5-7 minutes in length) representing a spectrum of competencies and interpersonal skill levels were selected as stimuli for Phase 1 (see Table 1). Participants from the pilot were not eligible to contribute responses in the subsequent phases of this study.

\section{Phase 1: Data collection from physicians}

Participants. Emergency, internal, and family medicine physicians associated with the University of British Columbia and the University of Toronto Faculties of M edicine who had experience assessing residents were invited to participate after we received approval from the respective research ethics boards. 
Table 1: Overview of Content of Seven Videos Used to the Collect M ini-CEX Ratings and Open-Text Responses of 48 Physician Participants from Two Canadian M edical Schools, $2013^{\text {a }}$

\begin{tabular}{|c|c|c|c|c|c|}
\hline Video & $\begin{array}{l}\text { Resident's } \\
\text { characteristics }\end{array}$ & $\begin{array}{l}\text { Patient's } \\
\text { characteristics }\end{array}$ & Clinical topic & $\begin{array}{l}\text { Level of medical } \\
\text { expertise }^{b}\end{array}$ & $\begin{array}{l}\text { Level of } \\
\text { interpersonal skills }\end{array}$ \\
\hline 1 & Caucasian woman & Caucasian woman & Respiratory history & Superior & $\begin{array}{l}\text { Satisfactory } \\
\text { (low) }\end{array}$ \\
\hline 2 & Caucasian woman & Caucasian man & $\begin{array}{l}\text { Depression history and } \\
\text { management }\end{array}$ & Satisfactory & $\begin{array}{l}\text { Satisfactory } \\
\text { (high) }\end{array}$ \\
\hline 3 & Caucasian man & Caucasian woman & $\begin{array}{l}\text { Terminal melanoma } \\
\text { diagnosis }\end{array}$ & Superior & Superior \\
\hline 4 & $\begin{array}{l}\text { Non-Caucasian } \\
\text { man }\end{array}$ & Caucasian man & $\begin{array}{l}\text { Painful urination history } \\
\text { and management }\end{array}$ & $\begin{array}{l}\text { Satisfactory } \\
\text { (high) }\end{array}$ & Satisfactory \\
\hline 5 & Caucasian man & Caucasian woman & $\begin{array}{l}\text { Terminal lung cancer } \\
\text { diagnosis }\end{array}$ & $\begin{array}{l}\text { Unsatisfactory } \\
\text { (high) }\end{array}$ & $\begin{array}{l}\text { Unsatisfactory } \\
\text { (high) }\end{array}$ \\
\hline 6 & Caucasian man & Black man & $\begin{array}{l}\text { Back pain history and } \\
\text { management }\end{array}$ & $\begin{array}{l}\text { Unsatisfactory } \\
\text { (low) }\end{array}$ & $\begin{array}{l}\text { Unsatisfactory } \\
\text { (low) }\end{array}$ \\
\hline 7 & Caucasian man & Caucasian man & Chest pain history & Unsatisfactory & Superior \\
\hline
\end{tabular}

a Each video portrayed a resident's encounter with a patient. The physicians' responses to the videos were used to understand rater idiosyncrasy in clinical performance assessment.

${ }^{b}$ The physicians used a 9-point M ini-CEX scale (1-2-3 unsatisfactory; 4-5-6 satisfactory; 7-8-9 superior). The levels of each resident's medical expertise and interpersonal skills are estimates made by the study investigators based on the scripts for the performance (if available) and the ratings collected during the pilot testing of the videos. The terms "low" and "high" are offered for comparison purposes across videos. For example, satisfactory (low) indicates the ratings were closer to 4 than to 6 in the satisfactory range.

Procedure. Physicians who responded to our recruitment requests were directed to the online data collection system. After they provided informed consent to participate, they received this prompt for the first video:

In the following video you will be shown a portion of a clinical encounter between a second-year internal medicine resident and a patient. Please watch the video a single time and, based on the information it contains, answer the questions that follow.

The same template was used for all seven videos.

Measures. After viewing each video, physicians completed M ini-CEX ratings using the form commonly applied. ${ }^{15}$ It consisted of 7 dimensions (medical interviewing skills, physical exam skills, humanistic qualities/professionalism, clinical judgment, counseling skills, organization/ efficiency, and overall clinical competence) with 9-point scales (1-2-3 unsatisfactory; 4-5-6 satisfactory; 7-8-9 superior). This was followed by three open-text questions: 
1. Please comment on this resident's clinical competence (about 1 paragraph). Include any specific behaviours, clinical skills, errors, omissions or other criteria that influenced your ratings.

2. Based on your experience, how would you complete this statement? "Oh, I know this type of resident. They're the type that [fill in the blank]..."

3. Now we would like you to be subjective and speculate about what type of person this resident may be. Please take a moment to imagine how someone might perceive this resident's personality, state of mind, intentions, or beliefs. Feel free to include your own first impressions in this description.

The three questions were designed to elicit responses consistent with each of three different conceptualizations of social categorization outlined in a previous article. ${ }^{7}$ Only responses to the third question were presented to sorters in Phase 2 (see below) because that is the question (after modifications made through pilot testing to ensure that participants' focus remained on the social judgments) used by M ohr and Kenny to elicit social judgments. ${ }^{12,16}$

Phase 2: Sorting of physicians' social judgment descriptions

Participants. We posted notices in the medical building at the University of Northern British Columbia to recruit 14 research participants to be sorters after receiving approval from the research ethics board. Because the sorting task required only reading comprehension skill, participants were required to be over the age of 18 and fluent in English, but clinical knowledge was not necessary.

Materials. Every open-text response to Question 3 was printed on a separate slip of paper. For each video, the slips of paper were randomly compiled into stacks.

Procedure. Each participant was given the stack of responses for a single video and asked to freely sort them into piles according to these sorting instructions:

Take a slip of paper from the stack, read the description, and place it on the table. Now read the description on the next slip of paper. If this description is part of the same story about the resident as that first description, then place it in the same pile. If this description is part of a different story about the resident, then start a new pile. Continue doing this for all the descriptions. You can use as many piles as you like and you can rearrange them as often as you'd like.

This process was repeated for each video. To counteract learning and order effects, half of the sorters worked through videos 1 to 7 and the other half worked through videos 7 to 1 . 
In the Mohr and Kenny report, ${ }^{12}$ a pair of sorters independently created piles and summarized the descriptions represented by each pile before meeting to reach consensus about the ideal number of piles and their respective meanings. It was necessary for us to deviate from this procedure when our first pair of sorters could not reach consensus. Each sorter had carefully constructed a different number of piles and each was committed to those constructions' being the best representations of the responses. As a result, the decision was made not to force participants to reach an agreement on the ideal number of piles. Instead, the remaining sorters completed the task without any interaction with other participants, and the composition of each of the 14 sorters' piles and their accompanying summaries were recorded. This technique is known as an "F sort" in LPA methodology. ${ }^{17,18}$

\section{Phase 3: LPA}

The decision to record sorters' independently generated piles meant we needed a data summarization technique to identify any common and underlying division points. LPA is a categorization methodology developed to study classes of qualitative information. ${ }^{17}$ It hypothesizes that there exists a set of latent partitions, or common underlying categorizations, for a group of items. It is assumed to be more probable for individual sorters to place items from the same latent (or underlying) category into the same pile. ${ }^{18}$ LPA allows empirical investigation of the content elements, number, and size of latent categories, as well as quantification of the relationships among the latent categories. ${ }^{18}$ It is important to note that in LPA methodology, disagreement between sorters regarding the ideal number or composition of piles in the $F$ sort is expected. As such, the lack of consensus we observed is not considered to be an indication of flawed sorting but representative of the multiple ways in which items can be categorized. For example, if sorters were asked to divide a set of objects into piles, some might group them only by size, others only by function, and others by both size and function. Although the individual $F$ sorts might look very different from one another, LPA calculations can still reveal what items were more often grouped together.

The first step in LPA is to tabulate each sorter's piles by creating a matrix with the items (the physicians' responses to Question 3 in this instance) listed as both row and column headings. Each cell is filled in by asking "Did this sorter put these two responses into the same pile?" Yes $=1$, No $=0$. LPA calculates averages across all of the sorter matrices to determine the proportion of sorters who placed each pair of responses into the same pile and determine which responses are consistently sorted together. Subsequent LPA calculations ${ }^{17,18}$ use these values to detect patterns in the sorting behavior across the participants. Responses that are consistently combined into the same pile are considered to form a latent category. ${ }^{18}$ 
The mathematical technique of LPA has some computational similarities to factor analysis, although LPA is appropriate for categorical data and produces categorical structures, whereas factor analysis is used for scale data and produces dimensional structures. ${ }^{18}$ Analogous to factor analysis, the researcher can specify a range of partitions to be made. As part of determining the ideal number of partitions (i.e. categories) that summarize the responses, two output matrices are produced to indicate how well each requested number of categories fit the data. A "phi matrix" specifies the content or composition of the latent categories. It provides values to specify how strongly each item belongs to each latent category. The "omega matrix" quantifies how cohesive each category is and how much it overlaps or gets confused with all the other categories in a given set. This matrix shows the probability of items being placed into their assigned category and the probability of them also being placed into another category within the set (i.e., the "confusion" probability). ${ }^{18}$

Similar to factor analysis, LPA does not indicate the set of categories that provides the best model. These phi and omega matrices provide numerical parameters to indicate how well each set of categories fits the data, but often there are multiple sets that fit reasonably well. Ultimately, as in factor analysis, the researcher must review the content of the items to determine which set of categories offers the most meaningful groupings. ${ }^{18}$ We used these procedures to determine the best-fitting set of categories for each video, with each physician's response thereby being assigned to one of the categories. RStudio was used to interface with $R$ version 3.0.1 (Boston, M assachusetts) ${ }^{19}$ to conduct the LPA. Phases 2 and 3 were completed; the sorters and the researchers (who made the final LPA decisions) were blinded to the M ini-CEX ratings provided by the physician participants.

\section{Phase 4: Analysis of variance}

For each video, the assignment of each response to a category was then used as an independent variable in a one-way ANOVA to determine the proportion of variance explained (partial eta ${ }^{2}$ ) in the "overall clinical competence" ratings assigned using the Mini-CEX scale. IBM SPSS Statistics 21 (Armonk, NY) was used for ANOVA calculations.

This study was approved by the Behavioural Research Ethics Board at the University of British Columbia, the Health Sciences Research Ethics Board at the University of Toronto, and the Research Ethics Board at the University of Northern British Columbia. 


\section{RESULTS}

\section{Phase 1: Data collection from physicians}

A total of 48 physicians reviewed, scored, and commented on at least one video, and 34 physicians completed these tasks for all seven videos. They received (or had donated to a charity on their behalf) a $\$ 100$ honorarium. Considerable variability in Mini-CEX ratings was observed (see Table 2), consistent with findings of a previous study ${ }^{20}$ that used four of the same videos. Seven responses ( $2.6 \%$ of all responses) to the social judgment question were blank (0-2/video) and, hence, could not be used in the F-sort. There was no obvious systematic pattern to the missing data.

\section{Phase 2: F-sort outcomes}

As planned, 14 individuals with diverse backgrounds, including university employees and assorted students (undergraduate, graduate, medical), were recruited to be sorters. Each sorter performed the seven F-sorts in 2-3 hours and received a $\$ 75$ honorarium. The sorting task was completed in groups of 2-4 people working independently at a large table. Dialogue between sorters was minimal and did not influence the sorting task. No relationship between the sorter's background and proficiency in completing the F-sort was observed.

As shown in Table 3, most sorters used 3-4 similarly labeled piles to group the responses for most videos (range 2-11 piles). The resemblance between piles constructed by different sorters can be seen in Table 4 where, using Video 6 as an example, the abbreviated summaries provided by each sorter for their own piles of physicians' descriptions of social judgments are shown.

Table 2: Descriptive Statistics for the M ini-CEX Overall Clinical Competence Ratings of Residents Featured in Seven Videos, Made by 48 Physician Participants from Two Canadian Medical Schools, $2013^{\text {a }}$

\begin{tabular}{|c|c|c|c|c|c|c|c|}
\hline \multirow[t]{2}{*}{ Video } & \multirow{2}{*}{$\begin{array}{l}\text { Number of } \\
\text { physician } \\
\text { participants }\end{array}$} & \multirow{2}{*}{$\begin{array}{l}\text { Number of } \\
\text { responses used in } \\
\text { F sort }\end{array}$} & \multicolumn{5}{|c|}{$\begin{array}{l}\text { Descriptive statistics for overall clinical competence ratings } \\
\text { based on items used in the F sort }\end{array}$} \\
\hline & & & $\begin{array}{l}\text { Lowest } \\
\text { rating }\end{array}$ & $\begin{array}{l}\text { Highest } \\
\text { rating }\end{array}$ & Mean & Median & Mode \\
\hline 1 & 48 & 46 & 1 & 7 & 4.0 & 4 & 4 \\
\hline 2 & 44 & 43 & 3 & 9 & 6.4 & 7 & 7 \\
\hline 3 & 39 & 38 & 4 & 9 & 6.8 & 7 & 6 \\
\hline 4 & 39 & 37 & 2 & 7 & 4.6 & 5 & 5 \\
\hline 5 & 36 & 36 & 2 & 6 & 3.6 & 3 & 3 \\
\hline 6 & 34 & 34 & 1 & 8 & 2.8 & 2 & 2 \\
\hline 7 & 35 & 34 & 1 & 9 & 4.8 & 4.5 & 4 \\
\hline
\end{tabular}


a Each video portrayed a resident's encounter with a patient. The overall clinical competence ratings were based on the items used in the F sort (the responses to stimulus question 3 about what kind of person the resident might be) for each video. These and other physicians' responses to the videos were used to understand rater idiosyncrasy in clinical performance assessment. As the table indicates, the ratings showed considerable variability.

Table 3: Number of Piles, Generated by Each of 14 Sorters, to Categorize Physicians' Responses to Question 3 into Similar Stories About Residents Featured in Seven Videos, Two Canadian M edical Schools, 2013. ${ }^{2}$

\begin{tabular}{lccccccc}
\hline \multirow{2}{*}{$\begin{array}{l}\text { Sorter } \\
\text { (sorter session) }\end{array}$} & \multicolumn{7}{l}{ Number of piles, by video number } \\
\cline { 2 - 8 } & $\# 1$ & $\# 2$ & $\# 3$ & $\# 4$ & $\# 5$ & $\# 6$ & $\# 7$ \\
\hline A (1) & 3 & 2 & 4 & 5 & 3 & 4 & 6 \\
B (1) & 4 & 3 & 4 & 5 & 5 & 4 & 4 \\
C (2) & 3 & 3 & 2 & 4 & 5 & 4 & 3 \\
D (2) & 3 & 2 & 3 & 4 & 3 & 3 & 3 \\
E (3) & 3 & 3 & 5 & 4 & 4 & 3 & 4 \\
F (3) & 5 & 2 & 5 & 5 & 4 & 4 & 3 \\
G (4) & 4 & 4 & 4 & 3 & 3 & 3 & 4 \\
H (4) & 3 & 5 & 4 & 4 & 4 & 3 & 4 \\
J (4) & 2 & 3 & 3 & 4 & 4 & 4 & 5 \\
K (4) & 3 & 3 & 3 & 2 & 3 & 5 & 4 \\
L (5) & 9 & 6 & 4 & 6 & 3 & 4 & 7 \\
M (5) & 6 & 9 & 6 & 8 & 8 & 7 & 7 \\
N (5) & 9 & 7 & 5 & 3 & 4 & 3 & 4 \\
P (5) & 11 & 10 & 9 & 10 & 7 & 6 & 8 \\
\hline
\end{tabular}

${ }^{a}$ Each video portrayed a resident's encounter with a patient. Question 3 asked the physicians' views on what kind of person the resident might be as part of an investigation into rater idiosyncrasy in clinical performance assessment. The physicians' responses to the videos were sorted into piles by a total of 14 additional participants in 5 separate sessions. As the table indicates, most sorters used 3-4 piles to group the responses for most videos (range 2-11 piles). 


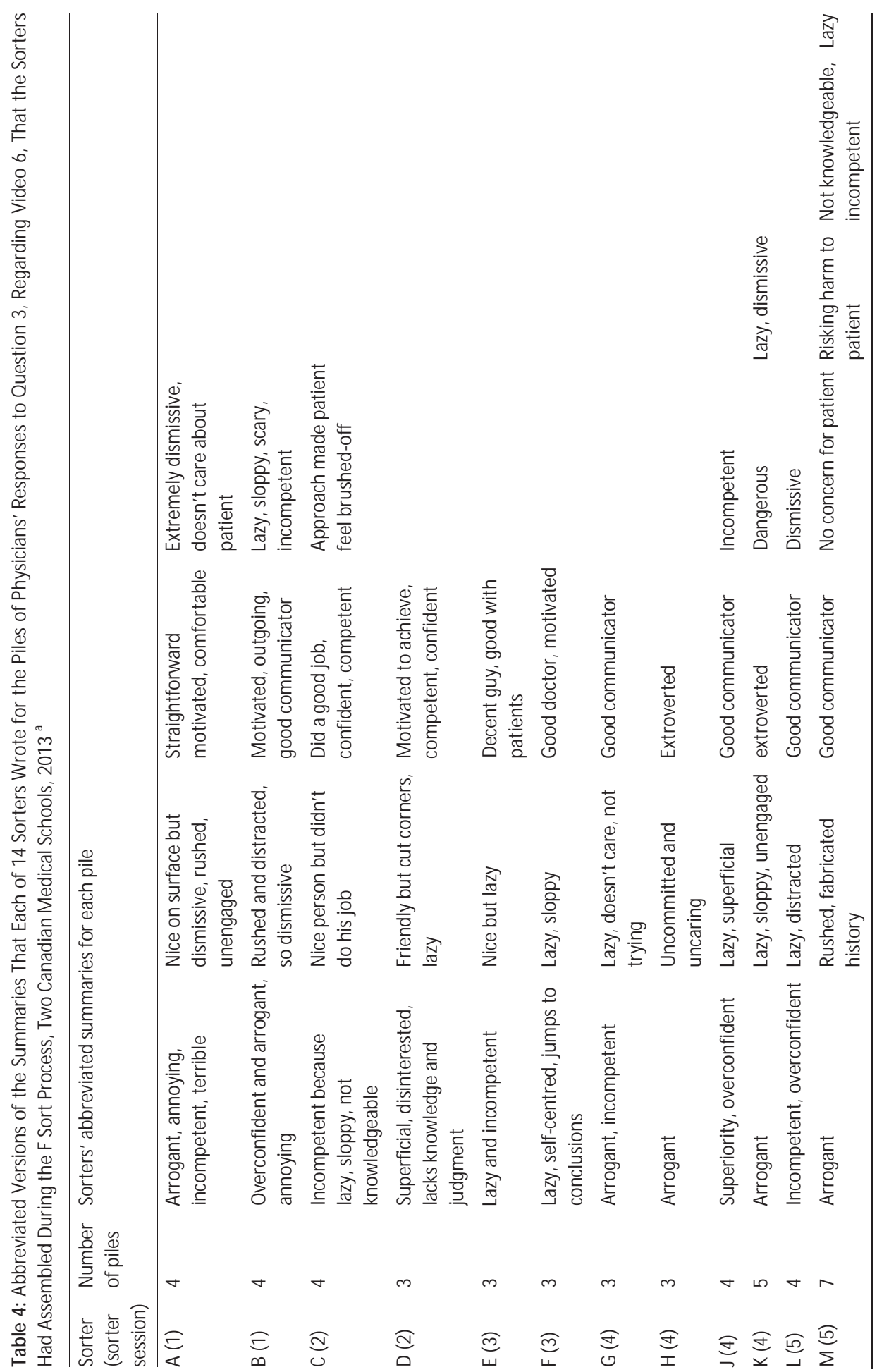


MORE CONSENSUS THAN IDIOSYNCRASY

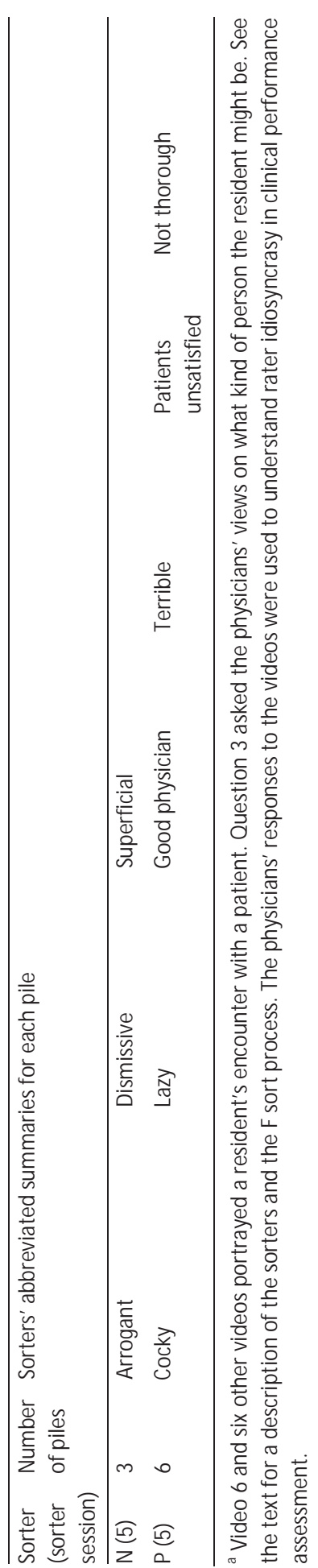


Sorters used piles to group together responses containing similar descriptor words, such as words describing personality traits. Responses using the words "arrogant" or "overconfident" to describe the resident in video 6 were often put into the same pile, but a different pile was used for responses using the descriptor "lazy." Notably, the content of the descriptions in one pile often conflicted with the content of the descriptions included in another pile within the same set (e.g., "dismissive" versus "good communicator").

\section{Phase 3: LPA}

Overview: For none of the performances of the seven observed residents did physician participants describe a single common social impression. However, even when asked to provide very subjective and potentially idiosyncratic information, the number of distinct social judgments was small relative to the number of raters contributing descriptions. In other words, there was more consensus in the social judgments and impressions than there was idiosyncrasy.

Since LPA results will be unfamiliar to many readers, we describe below the interpretation of the key output for one video in detail (see Figure 1 for an overview) before providing a summary of the findings for the remaining videos.

In Video 6, the resident presented with poor clinical skills and poor interpersonal skills. The young male patient described a 3-week history of low back pain radiating down one leg that was unresolved with pain medication. The resident's history was not thorough; he displayed closed body language, and assured the patient that this was a straightforward case of a common problem that would improve on its own with time. Although this performance received a large range of ratings, from $1-8$, over $75 \%$ of physicians rated it as unsatisfactory.

When the physicians' social judgment descriptions were divided into two categories, the phi matrix (not shown) indicated that four responses did not belong to either of the resulting categories and one barely fit into both. Again, by way of analogy, this is equivalent to a factor analysis illustrating 2 factors with 5 items that load suboptimally. The omega matrix indicated that both categories were somewhat cohesive (shown in Figure 1, near the bottom of the 2-partition column, as the bolded values .54 and .61 on the diagonal of the omega matrix). Review of the descriptive content of the responses, when grouped together in a 2-partition model, revealed there were contradictory statements included within each of the two categories. For example, Category 2 contained descriptions of the resident going "beyond expectations to help" the patient as well as "not attempt[ing] the most basic of medical skills." This indicates a poor fit. 
When a 3-partition model was specified (see Figure 1, column 2), the cohesion of the categories (again, illustrated by the bolded numbers on the diagonal of the omega matrix) was largely unchanged. Categories 1 and 2 overlapped with one another (shown in Figure 1 by the off-diagonal value of 28 in the $2^{\text {nd }}$ matrix), while Category 3 was distinct. Category 3 was composed of six responses, five being those that did not fit well in the 2-partition model. These six responses described the resident as friendly, helpful, and competent. Category 1 items described him as lazy and dismissive and Category 2 items described him as arrogant and careless.

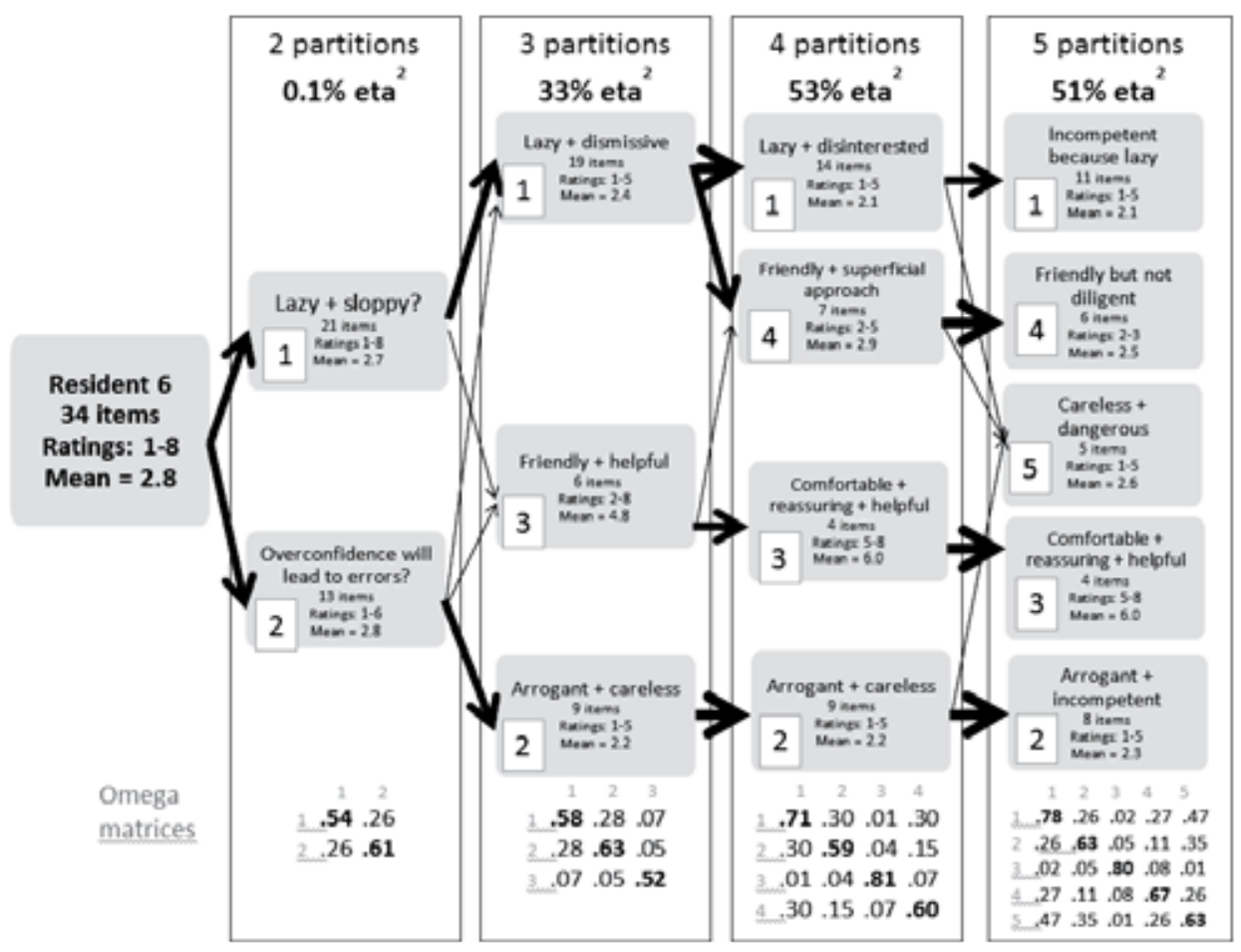

Figure 1 Schematic representation of latent partition analysis (LPA) output for one video (Video 6). In this study, physicians were invited to review videos of 7 residents' encounters with patients, complete a M iniCEX, and describe their social judgments of the resident. For Video 6, physicians provided 34 descriptions of social judgments and these items were sorted by 14 additional participants into piles based on semantic similarities. These piles were analyzed using LPA to indicate underlying categories that grouped the items. The four columns represent each of the 2-5 partition models that were specified. For example, in the second column, when the 34 items were partitioned into three categories, the column shows the number of items assigned to each category and a brief summary of their content along with the range and mean of their associated "overall clinical competence" Mini-CEX ratings. Moving between columns, it is possible to see how the assignment of items to categories changes (with the thickness of the arrows roughly depicting the quantity of items that were re-assigned) across models 2-5. The variance explained (eta $\left.{ }^{2}\right)$ in "overall clinical competence" Mini-CEX ratings-when items' category assignment is used as the independent variable in separate one-way ANOVAs for each partition model-is shown. Each partition model is accompanied by its LPA omega matrix, which quantifies the probability of items being assigned to their indicated category (the 
bolded diagonal of the matrix) and also to an alternate category (the off-diagonal of the matrix). See the text for more details regarding LPA and the interpretation of the output of Video 6.

When specifying a 4-partition model (see Figure 1, column 3), cohesion generally increased. Category 1 overlapped with Categories 2 and 4. Within each category, some responses loaded strongly only onto that one category. Based on these responses, it was determined that Categories 1, 2, and 4 all described an element of laziness but each provided a different explanation for it. More specifically, Category 1 suggested the laziness was an inherent characteristic of the resident or a deliberate choice of action, Category 2 inferred arrogance or overconfidence as a reason for his dismissing the concerns, and Category 4 described his behavior as a habit of using a superficial approach to patient care (see Table 5).

Table 5: Best-Fitting Partition M odels for Each of Seven Videos With a Corresponding Summary of the Identified Categories Within Each Model and a Representative Quote Taken From a Sorted Response, Two Canadian Medical Schools, $2013^{\text {a }}$

\begin{tabular}{|c|c|c|c|c|c|}
\hline Video & Model and its categories & $\begin{array}{l}\text { No. of } \\
\text { items in } \\
\text { category }\end{array}$ & Representative quote & M ean & $\begin{array}{l}\text { Partial } \\
\text { eta }^{2}\end{array}$ \\
\hline \multirow[t]{2}{*}{1} & $\begin{array}{l}\text { 1. Has good intention to do task } \\
\text { well but her goal had unintended } \\
\text { adverse effects on patient care }\end{array}$ & 31 & $\begin{array}{l}\text { "She may be more concerned with } \\
\text { presenting a full story for the sake of } \\
\text { impressing an attending, than actually } \\
\text { being concerned about the patient's } \\
\text { emotional well-being." }\end{array}$ & 4.3 & $9 \%^{b}$ \\
\hline & $\begin{array}{l}\text { 2. Is disinterested, has poor } \\
\text { intentions and no goals }\end{array}$ & 15 & $\begin{array}{l}\text { "very disinterested and didn't really } \\
\text { care about being there" }\end{array}$ & 3.4 & \\
\hline \multirow[t]{4}{*}{2} & $\begin{array}{l}\text { 1. Compassionate person doing a } \\
\text { competent job }\end{array}$ & 22 & $\begin{array}{l}\text { "This resident seems very calm and } \\
\text { caring with an easy interview } \\
\text { style...genuinely interested in helping } \\
\text { this patient." }\end{array}$ & 7.0 & $41 \%^{b}$ \\
\hline & $\begin{array}{l}\text { 2. Good person with specific } \\
\text { clinical management skills to } \\
\text { improve }\end{array}$ & 11 & $\begin{array}{l}\text { "Generally pleasant though } \\
\text { sometimes jumps to conclusions } \\
\text { without all the evidence." }\end{array}$ & 4.7 & \\
\hline & 3. Paternalistic style & 4 & $\begin{array}{l}\text { "She would like to be in charge and } \\
\text { dictate on patients what to do." }\end{array}$ & 5.3 & \\
\hline & 4. Likeable and respected & 6 & $\begin{array}{l}\text { "A positive, energetic and empathetic } \\
\text { person. Well respected by peers and } \\
\text { patients." }\end{array}$ & 8.0 & \\
\hline \multirow[t]{2}{*}{3} & 1. Compassionate person & 13 & $\begin{array}{l}\text { "This resident appears to be calm, } \\
\text { compassionate and competent." }\end{array}$ & 7.4 & $38 \%{ }^{b}$ \\
\hline & 2. Distant person & 6 & $\begin{array}{l}\text { "Academic person who cares more } \\
\text { about staging and study outcomes } \\
\text { than understanding the patient and } \\
\text { their emotions." }\end{array}$ & 5.3 & \\
\hline
\end{tabular}




\begin{tabular}{|c|c|c|c|c|c|}
\hline Video & Model and its categories & $\begin{array}{l}\text { No. of } \\
\text { items in } \\
\text { category }\end{array}$ & Representative quote & Mean & $\begin{array}{l}\text { Partial } \\
\text { eta }^{2}\end{array}$ \\
\hline & $\begin{array}{l}\text { 3. Underprepared for the } \\
\text { encounter }\end{array}$ & 3 & $\begin{array}{l}\text { "I hope he learns more about the } \\
\text { subject by the time he sees her } \\
\text { [again]." }\end{array}$ & 5.7 & \\
\hline & $\begin{array}{l}\text { 4. Uncomfortable due to } \\
\text { inexperience in this task }\end{array}$ & 7 & $\begin{array}{l}\text { "This resident strikes me as one that } \\
\text { hasn't broken as much bad news." }\end{array}$ & 6.6 & \\
\hline & 5. Good person & 9 & "Good person" & 7.6 & \\
\hline \multirow[t]{4}{*}{4} & 1. Uncomfortable with this topic & 14 & $\begin{array}{l}\text { "He came across as uncomfortable } \\
\text { with taking a sexual history." }\end{array}$ & 4.3 & $12 \%$ \\
\hline & $\begin{array}{l}\text { 2. Judgmental and overconfident } \\
\text { person }\end{array}$ & 9 & $\begin{array}{l}\text { "Somewhat self-centered and } \\
\text { judgemental." }\end{array}$ & 4.0 & \\
\hline & 3. Distant person & 6 & "This resident seems a bit distant." & 5.2 & \\
\hline & 4. Efficient approach & 8 & "Effective and efficient." & 5.4 & \\
\hline \multirow[t]{4}{*}{5} & 1. Lazy and uncaring person & 14 & $\begin{array}{l}\text { "The resident refused to listen [to] } \\
\text { the patient. He kept on ignoring all } \\
\text { the clues as [if] the patient did not } \\
\text { exist in the room and he was dictating } \\
\text { a report. He was not sorry at all." }\end{array}$ & 3.0 & $14 \%$ \\
\hline & 2. Lacks training in this task & 6 & $\begin{array}{l}\text { "Good person. Inadequate training on } \\
\text { this." }\end{array}$ & 3.7 & \\
\hline & 3. Distant person & 6 & $\begin{array}{l}\text { "Competent physician, but keeps } \\
\text { patients at a distance. Gets along with } \\
\text { colleagues, but no deep friendships." }\end{array}$ & 4.0 & \\
\hline & $\begin{array}{l}\text { 4. Not developmentally ready for } \\
\text { this task }\end{array}$ & 10 & $\begin{array}{l}\text { "Has yet to experience life on his } \\
\text { own. Not willing to validate the } \\
\text { emotions of the patient and her } \\
\text { concerns because he is likely } \\
\text { incapable of it. This is not something } \\
\text { we can really teach, it comes with } \\
\text { time and maturity." }\end{array}$ & 4.1 & \\
\hline \multirow[t]{4}{*}{6} & $\begin{array}{l}\text { 1. Lazy, disinterested, } \\
\text { incompetent }\end{array}$ & 14 & $\begin{array}{l}\text { "The resident seems unconcerned, } \\
\text { disinterested, and dismissive. He } \\
\text { seems lazy and unwilling to address } \\
\text { the patient's concerns." }\end{array}$ & 2.1 & $53 \%{ }^{b}$ \\
\hline & 2. Lazy, disinterested, arrogant & 9 & $\begin{array}{l}\text { "The resident was very arrogant. He } \\
\text { had his mind on other things, perhaps } \\
\text { golfing. He had no intention of } \\
\text { helping this patient." }\end{array}$ & 2.2 & \\
\hline & $\begin{array}{l}\text { 3. Reassuring, helpful, } \\
\text { comfortable communicating with } \\
\text { people }\end{array}$ & 4 & $\begin{array}{l}\text { "This resident is confident and } \\
\text { comfortable with communicating } \\
\text { with people." }\end{array}$ & 6.0 & \\
\hline & $\begin{array}{l}\text { 4. Lacks attention to detail or } \\
\text { uses a superficial approach to the } \\
\text { task }\end{array}$ & 7 & $\begin{array}{l}\text { "He is not detail oriented, and is not } \\
\text { as diligent as he should be." }\end{array}$ & 2.9 & \\
\hline
\end{tabular}




\begin{tabular}{|c|c|c|c|c|c|}
\hline Video & Model and its categories & $\begin{array}{l}\text { No. of } \\
\text { items in } \\
\text { category }\end{array}$ & Representative quote & Mean & $\begin{array}{l}\text { Partia } \\
\text { eta }^{2}\end{array}$ \\
\hline \multirow[t]{2}{*}{7} & $\begin{array}{l}\text { 1. Nice guy, genuinely interested } \\
\text { in patient's welfare and is trying } \\
\text { hard but did an inadequate } \\
\text { history and missed the diagnosis } \\
\text { either because he is not too } \\
\text { bright or has not learned the } \\
\text { skills yet. }\end{array}$ & 19 & $\begin{array}{l}\text { "He seems pretty nice and pleasant, } \\
\text { easy to get along with. Still a bit } \\
\text { haphazard in his approach, so } \\
\text { perhaps not the brightest student." }\end{array}$ & 3.6 & $57 \%^{b}$ \\
\hline & $\begin{array}{l}\text { 2. Friendly, eager to help the } \\
\text { patient, competent, thorough } \\
\text { history }\end{array}$ & 15 & $\begin{array}{l}\text { "I would guess he is good-natured, } \\
\text { pleasant, competent, self-confident." }\end{array}$ & 6.3 & \\
\hline
\end{tabular}

\footnotetext{
${ }^{a}$ Each video portrayed a resident's encounter with a patient. Physicians completed Mini-CEX ratings and described social judgments for each resident. The social judgment descriptions were sorted by additional participants into piles based on semantic similarities. These piles were analyzed using latent partition analysis to determine the composition and cohesion of any latent categories. The best-fitting partition models for each video are summarized in this table by providing a brief synopsis of descriptions contained in each category, the number of items assigned to each category, a quote extracted from a description assigned to each category, the mean of ratings associated with the descriptions within each category, and the variance explained $\left(\right.$ eta $\left.^{2}\right)$ in overall clinical competence Mini-CEX ratings when category assignment is used as the independent variable in separate one-way ANOVAs. See the text for an explanation of how the categories and models were created; see Figure 1 for an example of a set of partition models for Video 6.

${ }^{\mathrm{b}} \mathrm{P}<.05$.
}

Within each of these categories there were also responses that loaded onto a secondary category in addition to their primary category. By reviewing the content of these items, we could identify the concept overlapping both categories. For example, the concept of being "disinterested" overlapped between Categories 1 and 2. Between Categories 1 and 4, the shared concept was "not being diligent." Category 3 remained distinct and contained four of the responses that did not fit in the 2-partition model. These responses described a very different resident: one that was reassuring and helpful and comfortable communicating with people. Without going into detail, the 5partition model (see Figure 1, column 4) did not fit well. Category 5 (careless and dangerous) was redundant with Category 1 (incompetent because lazy). As such, the 4partition model was determined to have the best fit.

The same process was used to interpret the LPA outputs for all seven videos. The bestfitting models are summarized in Table 5 . We will briefly discuss a few findings that were shared across multiple videos. In describing Video 6 above, we saw how LPA revealed three different explanations for perceived laziness. This finding of categories containing different explanations or inferred reasons for the resident's performance occurred in multiple videos. For example, in Video 3, three of the five categories were composed of responses describing the resident and his performance as awkward or hesitant, but each of the three categories had a distinct explanation for it: (1) not pre- 
paring well enough for the task, (2) feeling uncomfortable due to inexperience with the difficult task, or (3) being a distant person.

Again in Video 4, nearly all of the physicians commented that the resident did not fully connect with or understand the patient. But, when grouped into the four categories specified by LPA, there are four different proposed reasons for it: (1) uncomfortable with this sensitive topic, (2) a judgmental and overconfident person, (3) focused on task efficiency, or (4) a distant person.

Comparable explanations appear in the categories for Video 5 as reasons for a suboptimal performance by an unempathetic resident: (1) a lazy person, (2) lacks training in this difficult task, (3) not developmentally ready for this task, or (4) a distant person. Of note, although all three videos had the same category "distant person," these responses were not provided by the same subgroup of raters (17 such responses were provided by 13 different physicians).

In summary, upon inspection of all seven sets of categories identified by LPA, each category is a coherent collection of descriptions of social judgments. The categories resemble impressions and often contain inferred reasons for the resident's performance, known as causal explanations. More than one impression was described for every resident, and the descriptions of the social judgments for the same resident often contained conflicting information. Despite asking over 34 physicians to provide descriptions of social judgments, LPA helped determine there were only two to five social impressions described for each resident.

\section{Phase 4: Analysis of variance}

The categorical (i.e., partition) assignments of each physician's responses resulting from Phase 3 were used as the independent variable in a one-way ANOVA to determine the amount of variance in the "overall clinical competence" rating from the M ini CEX that was accounted for by the categories. As shown in Table 5, the partial eta ${ }^{2}$ ranged widely from 9 to $57 \%$ with a mean of $32 \%$ across videos. Using Video 6 as the example again, grouping physicians' ratings into the four categories explained $53 \%$ of the variance in overall clinical competence ratings $\left[F(3,30)=11.34, P<.05, \eta_{P}^{2}=.531\right]$. The set of categories for five of the seven videos had mean ratings that were significantly different from each other (see Table 5), and a Bonferroni correction was used to make post-hoc comparisons. For video 7 , the content of significantly different categories seem to differ in the description of the resident's competence (Category $1 \mathrm{com}$ pared to Category 2). However, for Videos 1 and 3, the significantly different categories differed in terms of the social judgments being made about the resident. For example, in Video 3 the physicians who described the resident's personality as distant 
and detached (Category 2) gave significantly lower ratings than did the physicians who described him as a warm person (Category 1) or as a good person (Category 5). For Video 1 , every rater described the resident's performance as coldly efficient. The category where her perceived motive was described as a goal of productivity (Category 1) had significantly higher ratings than the category where her behavior was attributed to loss of interest in the task (Category 2). Videos 2 and 6 had categories with content that differed in both descriptions of competence and social judgments.

\section{DISCUSSION}

In our study, dozens of physicians were asked to perform a potentially idiosyncratic task: describe the social judgments that could be made while assessing a videorecorded clinical performance. The social judgments that were described could be grouped based on their similarity into a discrete set of categories resembling social impressions. Consistent with the social cognition literature, more than one impression was described for every resident, and the content across the various categories for the same resident contained not merely different but, in fact, conflicting social judgments and causal explanations. Importantly, however, the social judgment descriptions were not unique to individual raters and were replicated across many raters. Thus, despite a possibility for each physician participant to describe unique social judgments, LPA helped determine there were as few as two and no more than five distinct social impressions described for each resident. Thus we were able to conceptually replicate the main finding from Mohr and Kenny. ${ }^{12}$ The difference between the categories within the set for each performance often focused on a different inferred reason for the resident's performance, known as a causal explanation, and this finding is also consistent with those of past research. ${ }^{13,14}$

More importantly, in terms of assessment implications, there was a tendency for subgroups of physicians who had described similar social judgments to have also given more similar performance ratings. Accounting for these different social judgments for the same resident often explained significant variance in Mini-CEX ratings across the seven performances (9-57\%). Given that multiple physicians collectively described only a small but distinct number of social judgments and that those differing judgments were often associated with different ratings, perhaps some of the "error" variance in ratings is systematic and relevant. In other words, if multiple physicians describe the same social judgments, maybe there is something within the performance that could be noticed by others, such as patients. If multiple, distinct and often conflicting judgments are described for the same performance but such judgments are described by multiple people, could that consensus possibly represent multiple "signals" about the resident rather than "noise" from the rater? 


\section{Limitations}

These descriptions came in response to an explicit request for social judgments, a request that runs counter to pro-forma Mini-CEX procedures. Previous research, ${ }^{8,9}$ however, has also found social inferences mixed with clinical assessment judgments, suggesting they do naturally co-occur. It must also be noted that the design of this study does not allow causation to be determined. For example, although responses can be grouped together, and accounting for these different groupings can explain some rating variance, we cannot determine whether anything within those groupings caused the different ratings.

Similarly, we cannot determine the accuracy of any of the social judgments, categories, and/or impressions due to the lack of a comparable standard. As noted previously, some modifications were needed to transfer the methodological procedures from a social cognition context to a clinical assessment context. In particular, we required the methodology of LPA because the sorters could not reach consensus on the ideal number of categories describing each resident. However, when utilized, this analysis did enable the identification and discrimination of internally consistent groupings of social judgments with statistical and conceptual coherence. In contrast to M ohr and Kenny's finding that three categories were consistently the ideal number to best represent the impressions being made, the exact number of categories varied between performances in our study. This could be due to the conflation of clinical competency judgments with social judgments, the use of a smaller dataset, or the modifications made to the original methodology. Despite these limitations, our results support previous research that people form one of a finite number of impressions when perceiving others. ${ }^{12,13}$

\section{Next steps}

It has been common to assume that different judgments of the same performance reflect rater biases and thus should be treated as error variance. If consensus within multiple divergent judgments is consistently found, it will be important to investigate the legitimacy of the multiple judgments. If multiple legitimate judgments are possible, it may be necessary to support trainees to critically reflect on and integrate divergent pieces of feedback and to be aware that their performance can justifiably be perceived differently by different subgroups of people. In addition, this study investigated only one conceptualization of social categorization, but three have been previously described. ${ }^{7}$ Further analysis of all three must be done to directly compare their capacity to explain variability in ratings.

In conclusion, social judgments and impressions made by raters are typically viewed as sources of idiosyncrasy and, therefore, construct irrelevant variability in performance 


\section{CHAPTER 4}

ratings contributing to the "noise" in the measurement. However, our findings that idiosyncratic judgments tend to be finite in number and replicable across multiple raters suggest that multiple "signals" do exist within the "noise" of inter-rater variability in performance-based assessment. It may be valuable to understand and exploit these multiple signals rather than try to eliminate them.

Acknowledgments: The authors wish to thank Jennifer Kogan, MD, for her generosity in sharing her videos, the authors of the YouTube videos for giving permission to use their posts, Richard Wolfe, PhD, for sharing his LPA program for R, Scott Allen, PhD for his instructions on how to use R, Jimmie Leppink, M Sc, LLM, M Sc, PhD, for his methodological guidance, Shiphra Ginsburg, MD, Med, for her assistance with the data collection from Toronto, and the Survey Research Lab at the University of Northern British Columbia for their persistence in developing the data collection system.

Funding/Support: This study was funded by a National Board of Medical Examiners (NBM E) Edward J. Stemmler, M D, Medical Education Research Fund Grant.

Ethical approval: This study was approved by the Behavioural Research Ethics Board at the University of British Columbia, the Health Sciences Research Ethics Board at the University of Toronto, and the Research Ethics Board at the University of Northern British Columbia.

Previous presentations: Findings from this study were presented at the 2014 Ottawa Conference, April 28, 2014, Ottawa, Ontario, Canada; and the 2014 AM EE Conference, September 1, 2014, M ilan, Italy.

Disclaimer: The project does not necessarily reflect NBME policy, and NBME support provides no official endorsement. 


\section{REFERENCES}

1 Margolis MJ, Clauser BE, Cuddy M M , et al. Use of the mini-clinical evaluation exercise to rate examinee performance on a multiple-station clinical skills examination: A validity study. Acad Med. 2006;81(10 Suppl):S56-S60.

2 Harasym PH, Woloschuk W, Cunning L. Undesired variance due to examiner stringency/leniency effect in communication skill scores assessed in OSCEs. Adv Health Sci Educ. 2008;13:617-632.

3 Cook DA, Beckman TJ, Mandrekar JN, Pankratz VS. Internal structure of mini-CEX scores for internal medicine residents: Factor analysis and generalizability. Adv Health Sci Educ 2010;15:633-645.

4 van Barneveld $C$. The dependability of medical students' performance ratings as documented on intraining evaluations. Acad Med. 2005;80:309-312.

5 Kreiter $C D$, Ferguson $\mathrm{KJ}$. Examining the generalizability of ratings across clerkships using a clinical evaluation form. Eval Health Prof. 2001;24:36.

6 M cGill D, van der Vleuten C, Clarke M. Supervisor assessment of clinical and professional competence of medical trainees: A reliability study using workplace data and a focused analytical literature review. Adv Health Sci Educ. 2011;16:405-425.

7 Gingerich A, Regehr G, Eva KW. Rater-based assessments as social judgments: Rethinking the etiology of rater errors. Acad M ed. 2011;86(10 Suppl):S1-S7.

8 Kogan JR, Conforti L, Bernabeo E, lobst W, Holmboe E. Opening the black box of clinical skills assessment via observation: A conceptual model. Med Educ. 2011;45:1048-1060.

9 Govaerts MJB, Wiel M WJ, Schuwirth LWT, Vleuten CPM, M uijtjens AM M. Workplace-based assessment: Raters' performance theories and constructs. Adv Health Sci Educ. 2013;18:375-396.

10 Wood TJ. Exploring the role of first impressions in rater-based assessments. Adv Health Sci Educ. 2014 19:409-427.

11 Wittenbrink B, Park B, Judd CM, Sedikides C, Schopler J, Insko CA. The Role of Stereotypic Knowledge in the Construal of Person Models. Intergroup Cognition and Intergroup Behavior. Mahwah, NJ: Lawrence Erlbaum; 1998:177-202.

12 Mohr CD, Kenny DA. The how and why of disagreement among perceivers: An exploration of person models. J Exp Soc Psychol. 2006;42:337-349.

13 Park B, DeKay ML, Kraus S. Aggregating social behavior into person models: Perceiver-induced consistency. J Pers Soc Psychol. 1994;66:437-459.

14 Pennington N, Hastie R. Explanation-based decision making: Effects of memory structure on judgment. J Exp Psychol Learn. 1988;14:521-533.

15 Norcini JJ, Blank LL, Duffy FD, Fortna GS. The mini-CEX: A method for assessing clinical skills. Ann Intern Med. 2003;138:476.

16 Mohr CD. Consensus and Uniqueness in the Perception of M en and Women in General and in Particular. Ann Arbor, M I: University of Connecticut; 1999.

17 Wiley DE. Latent partition analysis. Psychometrika. 1967;32:183-193.

18 Miller DM, Wiley DE, Wolfe RG. Categorization methodology: An approach to the collection and analysis of certain classes of qualitative information. Multivariate Behavioral Research. 1986;21:135-167.

19 R Core Team. R: A Language and Environment for Statistical Computing. Vienna, Austria: R Foundation for Statistical Computing; 2013.

20 Kogan JR, Hess BJ, Conforti LN, Holmboe ES. What drives faculty ratings of residents' clinical skills? The impact of faculty's own clinical skills. Acad M ed. 2010;85(10 Suppl):S25-S28. 



\section{CHAPTER}

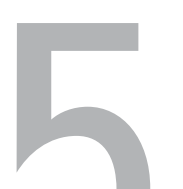

Comparing the ability of social judgment theories to explain rater variance in M ini-CEX assessments

Andrea Gingerich

Cees P.M . van der Vleuten

Glenn Regehr

Kevin W. Eva

Submitted for publication 


\section{ABSTRACT}

Given the breadth of competencies expected of medical professionals, clinical performance ratings are essential for assessing trainees. Variability of opinion is common whenever rater-based assessment formats are used, compelling us to better understand the cognitive processes used by raters. In recent research we found that seemingly idiosyncratic rater impressions of trainee performance contain a finite number of meaningful clusters of rater consensus. This study is an extension of that work in which we compare the relative capacity of three theories of categorization (Two-Dimensions, Person models, and Nominal labels) to determine which accounts for more variance in Mini-CEX ratings. For 7 video-recorded resident-patient encounters, 34-48 physicians completed a Mini-CEX and provided narrative responses to questions about the resident. 8-14 sorters per categorization theory then sorted the responses into piles based on the similarity of the content and latent partition analysis was used to aggregate the piles into categories. Next, category membership was used to explain variance in overall M ini-CEX ratings through a series of sequential multiple regressions. Similar proportions of variance (about one third) could be accounted for by all three theories of categorization although the Two-Dimensions theory accounted for significantly more unique variance. Examining the content of predictive categories allowed us to specify when differences in rater impressions reflected different emphasis on certain aspects of the performance, when they reflected disagreement about the same aspect of performance, and when they reflected differences in inferences being made regarding the residents' state of mind, personality traits and other social judgments. 


\section{BACKGROUND}

Given the breadth of competencies expected of medical professionals, clinical performance ratings are essential for assessing trainees. Variability of opinion is common whenever subjective assessment formats are used, leading researchers in medical education to investigate the cognitive processes used by raters to form assessment judgments. ${ }^{1}$ We have previously summarized the literature examining variability in the formation of everyday social judgments, and suggested that this work might serve as a good model for exploring how impressions of clinical performances are formed. ${ }^{2}$ This is important because there is ample evidence to indicate that when different people watch the same performance they often report different observations and make different assessments. ${ }^{3-7}$ This variability tends to be seen as detrimental for making sound assessment decisions ${ }^{8}$ and is often attributed to the biases or idiosyncrasies of the assessors. ${ }^{9}$ Better understanding the mechanism from which such variability arises will help determine if this is a reasonable assumption or if there is information to be gleaned from the differences of opinion commonly observed.

In recent work we have found that seemingly idiosyncratic rater impressions of trainee performance comprise a finite number of meaningful clusters of rater consensus. ${ }^{10}$ This work was conducted by conceptually replicating a study by Mohr and Kenny ${ }^{11}$ from the social cognition literature that aimed to explain variance in social impressions people formed about particular individuals. Consistent with Mohr and Kenny's findings, we found that although more than 34 physicians were asked to describe social judgments for seven different residents, their descriptions in each case could be categorized into as few as two and never more than five distinct clusters of opinion for any given resident. That is, the social judgments (e.g. inferences of the resident's personality traits, motives, feelings etc.) of physician raters revealed variations, and even contradictions, but these impressions were not entirely idiosyncratic. Rather, for each resident there were subgroups of raters who drew very similar social judgments that were often enmeshed with assessment judgments (even though membership of the subgroups was not consistent across residents). Consistent with our hypothesis, raters within a subgroup gave more similar M ini-CEX ratings than those from other subgroups describing different impressions. M ore specifically, we applied latent partition analysis (LPA) to the narrative descriptions raters provided to identify distinct categories of impressions formed by raters. Upon doing so we found that grouping raters according to these categories (which in many cases were based on social judgments) could explain significant variance in M ini-CEX ratings.

Mohr and Kenny's conceptualization of impression formation, ${ }^{11}$ however, represents just one of many theoretical conceptualizations that have been put forward to help us understand the processes through which people make social judgments. In our earlier 
review of the social judgment literature, we summarized three different theories about how impressions are formed in social categorization, each of which has strong empirical evidence: Person Models (PM), Two-Dimensions (TD) and Nominal Labels (NL) (e.g. stereotypes). Person Models is the term used to represent the idea that social impressions about an individual are formed by creating ad hoc stories describing what the person is like and why. The work of M ohr and Kenny ${ }^{11}$ and Park et al. ${ }^{12}$ has shown that a limited number of distinct person models can be used to capture all generated explanations for any given person's behaviour. The Two-Dimensions theory of categorization proposes that social judgments are made by determining in which of four possible quadrants a person belongs, with the four quadrants (warm-competent, warmincompetent, cold-competent and cold-incompetent) being defined by consideration of two dimensions: The 'warmth' dimension involves a judgment of how approachable and trustworthy the person seems to be based on perceived intentions; and the 'competence' dimension involves a judgment of how capable the person would be at carrying out his/her intentions. ${ }^{13}$ Finally, the Nominal Labels conceptualization encompasses the range of theories describing social categorization as stemming from the assignment of a person to a preconceived group. Commonly studied groups include those that have been labelled based on ethnicity, occupation and personality type. ${ }^{14}$ In the medical education context relevant nominal labels might include 'self-promoting', 'teachable', 'struggling', or 'trustworthy'. ${ }^{15}$

While our previous study ${ }^{10}$ provided an important proof of concept for the use of social judgment models to facilitate understanding of systematic rater variance in clinical assessments, it investigated only one theory of categorization (PM). Our attempt to replicate the methods of M ohr and Kenny helped to determine what aspects of social cognition methodologies need to be modified to translate that work into the medical education context. To take full advantage of the finding that forming impressions may be influential in rater-based assessments, it is important to determine the relative usefulness of the three theories for understanding rater cognition. To that end, this paper describes an extension of our previous study in which we compare the ability of the categories produced by each of the three theories to account for variance in opinion about clinical competence. More specifically, our main research question is "Does one theory of social categorization account for more variance in M ini-CEX clinical competence ratings relative to others?"

\section{METHODS}

Our ultimate aim was to better understand how raters make assessment judgments and whether or not there is meaningful information contained in the variability of such judgments. To do so, we used each theory of categorization (PM, NL, TD) to cluster 
rater narratives and used those clusters as nominal independent variables within multiple regression models. The proximate aim was to determine which accounted for the greatest proportion of variance in raters' Mini-CEX 'overall clinical competence' ratings. To accomplish these goals, data collection and analyses were divided into five phases as illustrated in Figure 1 and explained in more detail below. Briefly, in the first phase, we collected M ini-CEX ratings and responses to three separate open-ended text questions designed to elicit social judgments conducive to each theory of categorization reviewed above. To do so, raters viewed video-recorded clinical performances as described in our previous study. ${ }^{10}$ In the second phase, a new set of participants was recruited to sort the open text responses based on similarity of the content. In the third phase, latent partition analysis (LPA; as described in previous study ${ }^{10}$ ) was used to aggregate the new participants' sorts in a manner that identified the most parsimonious set of categories. In the fourth phase, we submitted the identified sets of latent categories as nominal independent variables to regression analyses to determine how much variance in Mini-CEX ratings could be explained by each theory. Finally, in the fifth phase, we examined the narrative content of the responses within the identified sets of latent categories to determine what defined and differentiated each category within a set.

This study was approved by the Behavioural Research Ethics Board at the University of British Columbia, the Health Sciences Research Ethics Board at the University of Toronto, and the Research Ethics Board at the University of Northern British Columbia. 


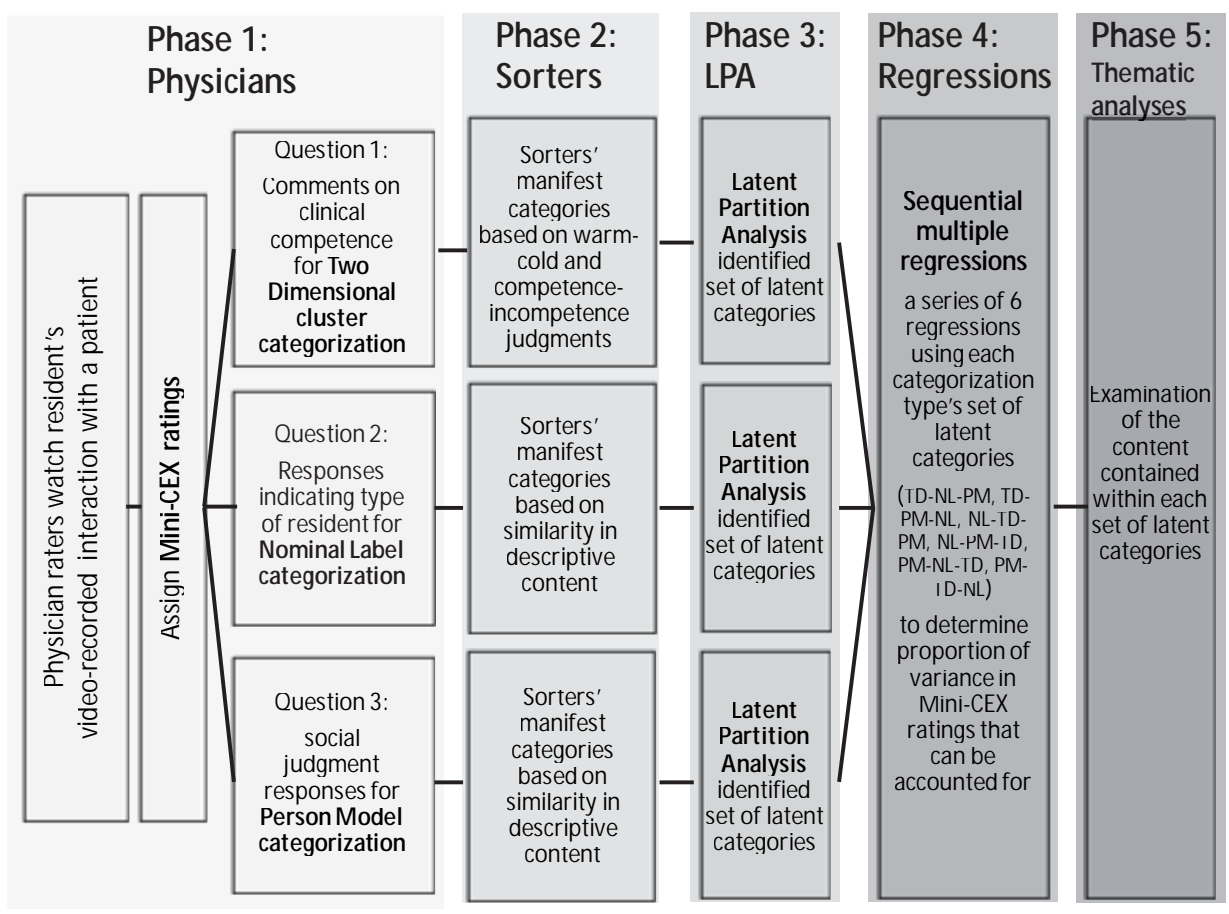

Figure 1: Schematic of study design ${ }^{\mathrm{a}}$

${ }^{a}$ This study had four phases and two different sets of participants. In phase 1 physician participants assessed a resident's video-recorded clinical encounter with a patient using M ini-CEX ratings and provided open text responses to three separate questions. The open text responses were sorted into manifest categories by new participants in phase 2 . In phase 3 the latent categories underlying the sorters' manifest categories were determined using latent partition analysis. In phase 4 the identified latent categories for each categorization theory were entered in every possible combination into sequential multiple regressions to determine the variance explained in the Mini-CEX ratings (provided by physician participants in phase 1) by each categorization theory. The content of the identified categories was examined during thematic analyses in phase 5.

\section{Phase 1: Narrative impressions and M ini-CEX ratings collected from physicians}

Participants. Emergency, internal, and family medicine physicians associated with the University of British Columbia and the University of Toronto Faculties of M edicine who had experience assessing residents were invited to participate. These participants received (or had donated to a charity on their behalf) a $\$ 100$ honorarium.

Materials. Seven video-recorded resident-patient encounters were selected based on pilot testing described in our 2014 paper. ${ }^{10}$ Each video depicted a different second year internal medicine resident and the set of videos represented various competency and interpersonal skill levels. ${ }^{10}$ 
Procedure. Recruitment invitations directed physicians to the online data collection system. After they provided informed consent to participate, they received this prompt before the presentation of each video:

In the following video you will be shown a portion of a clinical encounter between a second-year internal medicine resident and a patient. Please watch the video a single time and, based on the information it contains, answer the questions that follow.

After viewing each video, physicians completed a M ini-CEX rating form ${ }^{16}$ consisting of 7-dimensions (medical interviewing skills, physical exam skills, humanistic qualities/professionalism, clinical judgment, counselling skills, organization/efficiency, and overall clinical competence) using 9-point scales (1-2-3 unsatisfactory; 4-5-6 satisfactory; 7-8-9 superior). This was followed by three open-ended questions designed to elicit narrative responses that would allow assessors' impressions to be sorted using each of the three social categorization theories outlined above. Question 1 was designed to collect responses containing judgments of both competence-incompetence and warmth-coldness for use in the Two-Dimensions categorizations in a manner that is typical of M ini-CEX form questions:

1 Please comment on this resident's clinical competence (about 1 paragraph). Include any specific behaviours, clinical skills, errors, omissions or other criteria that influenced your ratings.

Question 2 was designed to collect information that could be used to assign Nominal Labels.

2 Based on your experience, how would you complete this statement? "Oh, I know this type of resident. They're the type that [fill in the blank]..."

Question 3 was designed to collect social judgment narratives that could be incorporated into Person Model categorizations.

3 Now we would like you to be subjective and speculate about what type of person this resident may be. Please take a moment to imagine how someone might perceive this resident's personality, state of mind, intentions, or beliefs. Feel free to include your own first impressions in this description.

The responses to each question served as the material to be used in the subsequent sorting phase of the study. 


\section{Phase 2: New participants sort the responses}

In preparation for subsequent regression analyses, we needed to determine how to optimally sort physicians' responses into categories based on content similarity. The specific process presented to sorters was customized for each theory of categorization and is described in detail below.

Participants. We posted notices in the medical building at the University of Northern British Columbia to recruit 36 research participants. Participants were required to be over the age of 18 and fluent in English, but clinical knowledge was not necessary as the sorting task required only reading comprehension skill. Sorting tasks were completed independently with participants being blinded to the M ini-CEX ratings offered by the physician participants. Sorters received an honorarium of $\$ 25$ per hour.

Procedure. To categorize based on Two-Dimensions theory, we provided eight sorters with a three-column chart in which all physician responses to Question 1 appeared in the first column. The responses were grouped by video and the order of the videos varied across the sorters. After reading each response, sorters were asked to make two separate sorting decisions. In the second column, the sorter was asked to record whether the content of the response described a warm person, a cold person or neither/cannot tell: "Warm" when the resident was described as approachable or sociable and 'cold' for a contrary description. The third column was used to record whether the response described a competent person (i.e. someone who knew what they were doing and did it well), an incompetent person or neither/cannot tell. Sorters were encouraged to indicate the intensity of the warmth-coldness and competenceincompetence being described (e.g. slightly cold, very cold).

To categorize based on Nominal Label theory, we asked 14 different sorters to read through the responses to Question 2 and to sort responses into piles based on similarity of the content. Each sorter was given a stack of responses for a single video, with each response printed on a separate piece of paper, accompanied by the following instruction:

Take a slip of paper from the stack, read the description, and place it on the table. Now read the description on the next slip of paper. If this description is describing the same type of person as that first description, then place it in the same pile. If this description is describing a different type of person, then start a new pile. (By "type" we mean a group name that can define a person's identity-think back to groups in high school.) Continue doing this for all the descriptions. You can use as many piles as you like and you can rearrange them as often as you'd like. 
After forming the piles, sorters were asked to label each in the manner that best summarized the type of the person included in that pile. This process, referred to as an Fsort in LPA methodology, was repeated for each video. Sorters met in groups of 2-5 people but worked independently with minimal conversation. To counteract learning and order effects, half of the sorters worked through videos 1 to 7 and the other half worked through videos 7 to 1 .

To categorize based on Person Model theory, we asked another 14 sorters to read through the responses to question 3 and sort them into piles based on the similarity of the content. The same F-sort process as described for question 2 was used except the sorting instruction emphasized the story being told about the residents rather than emphasizing identity types:

Take a slip of paper from the stack, read the description, and place it on the table. Now read the description on the next slip of paper. If this description is part of the same story about the resident as that first description, then place it in the same pile. If this description is part of a different story about the resident, then start a new pile. Continue doing this for all the descriptions. You can use as many piles as you like and you can rearrange them as often as you'd like.

After forming the piles, sorters were asked to provide a narrative summary of the story being told about the resident that determined membership in each pile.

\section{Phase 3: 'Clustering' Participant Sorts through Latent Partition Analysis}

To synthesize the data provided by our sorters we performed latent partition analysis on each of the 3 categorization theories for each of the 7 videos (i.e., 21 LPAs were performed). As described more fully in Gingerich et al., ${ }^{10}$ the mathematical technique of LPA has some computational similarities to factor analysis. It allowed us to aggregate across individual sorters' unique set of piles (i.e. manifest categories) and extract the underlying (i.e., latent) set of categories represented by the group. ${ }^{17,18}$ LPA was chosen because it allows empirical investigation of the elements, number, and size of the latent categories, as well as providing quantification of the relationships among the latent categories. ${ }^{17,18}$ We used the same procedures as described in our previous paper $^{10}$ to determine the best fitting sets of categories. RStudio (Boston, Massachusetts) was used to interface with $R$ version 3.0.1 to conduct the LPA. ${ }^{19}$

Given that LPA can result in multiple solutions that fit the data reasonably well (similar to factor analysis), and knowing that the regression equations into which this output would be placed (see phase 4 ) are sensitive to differences in the number of predictors that are entered into the model, it was necessary to select a final categorization struc- 
ture for each video that had the same number of categories across each of the three categorization theories. For each video, we therefore, examined the number of categories in every well-fitting solution and selected the lowest number of categories that was common across the three categorization types as the nominal structure to be used in the regression equation. This judgment task was completed with the researchers blinded to the M ini-CEX ratings provided by the physician participants in phase 1 .

\section{Phase 4: Sequential Multiple Regressions}

To determine the relative capacity of each categorization theory to predict M ini-CEX scores, we used sequential multiple regression (SMR, also known as hierarchical multiple regression). ${ }^{20}$ We chose SMR because it allowed us to determine both how much variance each of the three theories of categorization could explain and if they were explaining the same or different proportions of variance. The set of categories from each theory of categorization was used as predictors of 'overall clinical competence' Mini-CEX ratings. Separate analyses were performed for each of the seven videos. The categories were dummy coded in the regression models by using the largest category resulting from the LPA as the reference category. Thus, for the dummy coded dependent variables in the regression, each rater was assigned a 1 or 0 depending on his or her LPA determined category membership for each of the three theory-based sets of categories.

To determine the proportions of variance each theory of categorization could uniquely explain and what proportions of variance could be explained by more than one theory of categorization, we ran a series of six regressions for each video by altering the sequence in which each categorization theory was entered into the model. More specifically, for each of the seven videos, six regression analyses were performed by entering the categories generated through the LPAs in every possible combination: TD-NL-PM, TD-PM -NL, NL-TD-PM, NL-PM -TD, PM -NL-TD and PM-TD-NL. Doing so provided us with estimates of how much variance in M ini-CEX ratings was explained by each categorization theory independently (by examining $R^{2}$ for the first categorization theory entered in each regression - denoted as " $\mathrm{R}^{2}$ M odel 1 " in Table 2). It also provided us with estimates of how much additional variance could be explained by layering additional categorization theories onto the theory entered into the SMR first (by examining " $\Delta R^{2 \text { " for }}$ the second and third categorization types entered into each regression - denoted "Model 2" and "M odel 3" in Table 2).

To determine if one of the theories of categorization robustly explained significantly more variance across the different videos, we performed repeated measures ANOVAs with video and theory of categorization as independent variables and the amount of variance explained (using " $\mathrm{R}^{2}$ Model 1 " and " $\Delta \mathrm{R}^{2}$ Model 3 ") in M ini-CEX overall clinical 
competence ratings as the dependent variable. IBM SPSS Statistics 21 (Armonk, NY) was used for the calculations.

\section{Phase 5: Thematic interpretation of the latent categories}

Finally, after identifying which categories (again, for each video) were significant predictors of M ini-CEX ratings we compared and contrasted the content of the narrative responses generated in phase 1 . The aim here was to explore what defined each category that provided statistical prediction and what differentiated it from the other categories within the same set.

\section{RESULTS}

Phase 1: Narrative impressions and M ini-CEX ratings collected from physicians

From October 2013 to March 2014, a total of 48 physicians reviewed, scored, and commented on at least one video. 34 of those physicians completed these tasks for all seven videos. 16 questions were left blank and could not be used in the F-sort, but there was no obvious pattern to the missing data. There was considerable variability in the Mini-CEX ratings (See Table 1).

Table 1: Descriptive Statistics for the M ini-CEX Overall Clinical Competence Ratings of Residents Featured in Seven Videos, Made by 48 Physician Participants from Two Canadian M edical Schools, $2013^{\text {a }}$

\begin{tabular}{|c|c|c|c|c|c|c|c|c|c|c|}
\hline \multirow[t]{2}{*}{ Video } & \multirow{2}{*}{$\begin{array}{l}\text { Number of } \\
\text { physician } \\
\text { participants }\end{array}$} & \multirow[t]{2}{*}{$\begin{array}{l}\text { Lowest } \\
\text { rating }\end{array}$} & \multirow[t]{2}{*}{$\begin{array}{l}\text { Highest } \\
\text { rating }\end{array}$} & \multirow[t]{2}{*}{$\begin{array}{l}\text { Mean of } \\
\text { ratings }\end{array}$} & \multicolumn{2}{|c|}{$\begin{array}{l}\text { Question } 1 \\
\text { Two Dimensions }\end{array}$} & \multicolumn{2}{|c|}{$\begin{array}{l}\text { Question } 2 \\
\text { Nominal Labels }\end{array}$} & \multicolumn{2}{|c|}{$\begin{array}{l}\text { Question } 3 \\
\text { Person M odels }\end{array}$} \\
\hline & & & & & $\begin{array}{l}\text { Number of } \\
\text { responses } \\
\text { used in sort }\end{array}$ & $\begin{array}{l}\text { Mean of } \\
\text { ratings } \\
\text { associated } \\
\text { with } \\
\text { responses } \\
\text { used in sort }\end{array}$ & $\begin{array}{l}\text { Number o } \\
\text { responses } \\
\text { used in } \\
\text { F-sort }\end{array}$ & $\begin{array}{l}f \text { M ean of } \\
\text { ratings } \\
\text { associated } \\
\text { with } \\
\text { responses } \\
\text { used in } \\
\text { F-sort }\end{array}$ & $\begin{array}{l}\text { Number of } \\
\text { responses } \\
\text { used in } \\
\text { F-sort }\end{array}$ & $\begin{array}{l}\text { M ean of } \\
\text { ratings } \\
\text { associated } \\
\text { with } \\
\text { responses } \\
\text { used in } \\
\text { F-sort }\end{array}$ \\
\hline 1 & 48 & 1 & 7 & 3.98 & 47 & 3.98 & 46 & 3.96 & 46 & 4.00 \\
\hline 2 & 44 & 3 & 9 & 6.41 & 44 & 6.41 & 43 & 6.42 & 43 & 6.42 \\
\hline 3 & 39 & 4 & 9 & 6.85 & 39 & 6.85 & 38 & 6.84 & 38 & 6.81 \\
\hline 4 & 39 & 2 & 7 & 4.64 & 38 & 4.58 & 36 & 4.58 & 37 & 4.59 \\
\hline 5 & 36 & 2 & 6 & 3.61 & 36 & 3.61 & 36 & 3.61 & 36 & 3.61 \\
\hline 6 & 34 & 1 & 8 & 2.77 & 34 & 2.76 & 34 & 2.77 & 34 & 2.77 \\
\hline 7 & 35 & 1 & 9 & 4.77 & 35 & 4.77 & 35 & 4.77 & 34 & 4.79 \\
\hline
\end{tabular}


a Each video portrayed a resident's encounter with a patient. The overall clinical competence Mini-CEX ratings are shown for all physicians and for each of the subsets of physicians who contributed responses to the three stimulus questions that were subsequently used the sorting phase (F-sort) of latent partition analysis. As the table indicates, the ratings for each video showed considerable variability and the descriptive statistics for the ratings associated with the sorted responses for each stimulus question were comparable.

\section{Phase 2: Sorting outcomes}

The 36 sorter roles were filled by 31 individuals with diverse backgrounds including university employees, assorted students (undergraduate, graduate, medical) and members of the general public. Five participants performed sorts for both question 1 and question 3 (as the tasks were considered sufficiently different to minimize contamination). Sorters typically created $2-5$ piles for each video, with $68 \%$ of sorts $(208 / 308)$ resulting in 3-4 piles (range=1-11 piles).

\section{Phase 3: LPA outcomes}

The LPAs, conducted on each video for each categorization theory, clustered the sorting decisions into models that included 2 to 15 latent partitions (i.e., category solutions). Our interpretation of the output (the process for which was previously described ${ }^{10}$ ) combined with the requirement to select a well-fitting partition number that was common to all three categorization theories within a single video (see methods), resulted in between 2 and 4 category solutions providing the most meaningful aggregation of responses for each video. Importantly, all three theories of categorization identified a different set of categories for each video (i.e., each sorting strategy yielded different solutions). Table 2 provides an overview of the best fitting solutions including a summary of the content and number of responses included in each category. As was found in our previous paper, the narrative responses provided for each video easily collapsed into a finite number of categories that seem to represent clusters of consensus within the apparent diversity of impressions. ${ }^{10}$ Each category resembled a reasonably cohesive impression of the resident and/or their performance.

\section{Phase 4: Sequential M ultiple Regressions}

When the sets of categories from all three theories of categorization were entered into a regression model, together they explained an average of $53.7 \%$ of rating variance across the 7 videos (range=32-78\%). For 6 of the 7 videos, at least one of the categorization theories explained a significant proportion of variance in the ratings upon first entry into the regression model (i.e. $\mathrm{R}^{2} \mathrm{M}$ odel 1 ). As shown in Table 2, the proportion of variance explained by each categorization theory when entered first into the regression model averaged 37\% (range=21-57\%) for the Two-Dimensions theory, 33\% (range $=14-55 \%$ ) for the Nominal Labels theory, and 31\% (range=9-57\%) for the Person 
Models theory. Repeated measures ANOVA indicated no significant difference between the proportions of the variance explained by each categorization theory when entered in isolation $[F(2,12)=.964, p>05]$. In other words, each of the three theories of categorization produced a set of categories that could account for similar proportions (roughly one third) of variance in the overall clinical competence Mini-CEX ratings when they were the only predictor in the regression model.

When a predictor is entered last into a sequential regression model, all of the shared or overlapping variance will have already been claimed by the previously entered predictors, leaving only the variance that is unique to that final predictor available to be claimed. ${ }^{20}$ Two-Dimensions were capable of explaining significantly more variance above and beyond the other two categorization theories $\left(\Delta R^{2}\right.$ Model 3$)$ for four of the seven videos; Person M odels could explain a significant amount of unique variance for two videos; Nominal Labels never explained a significant amount of unique variance. Across the seven videos, repeated measures ANOVA and post-hoc pairwise Bonferronicorrected comparisons revealed that Two-Dimensions theory accounted for significantly more unique variance $[F(2,12)=8.47, p<05]$ than either Person Models $(p=.007)$ or Nominal Labels $(p=049)$. 


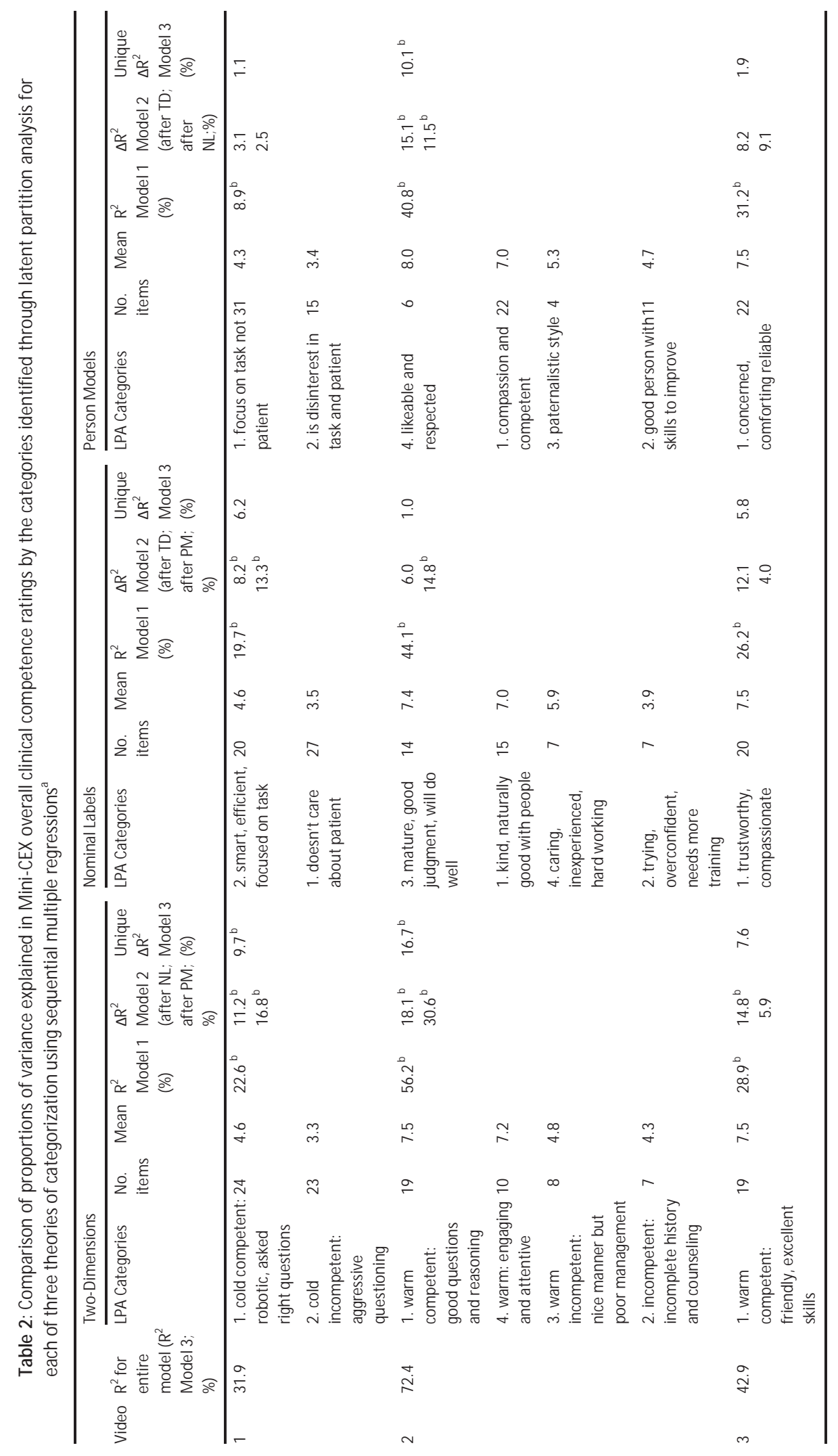




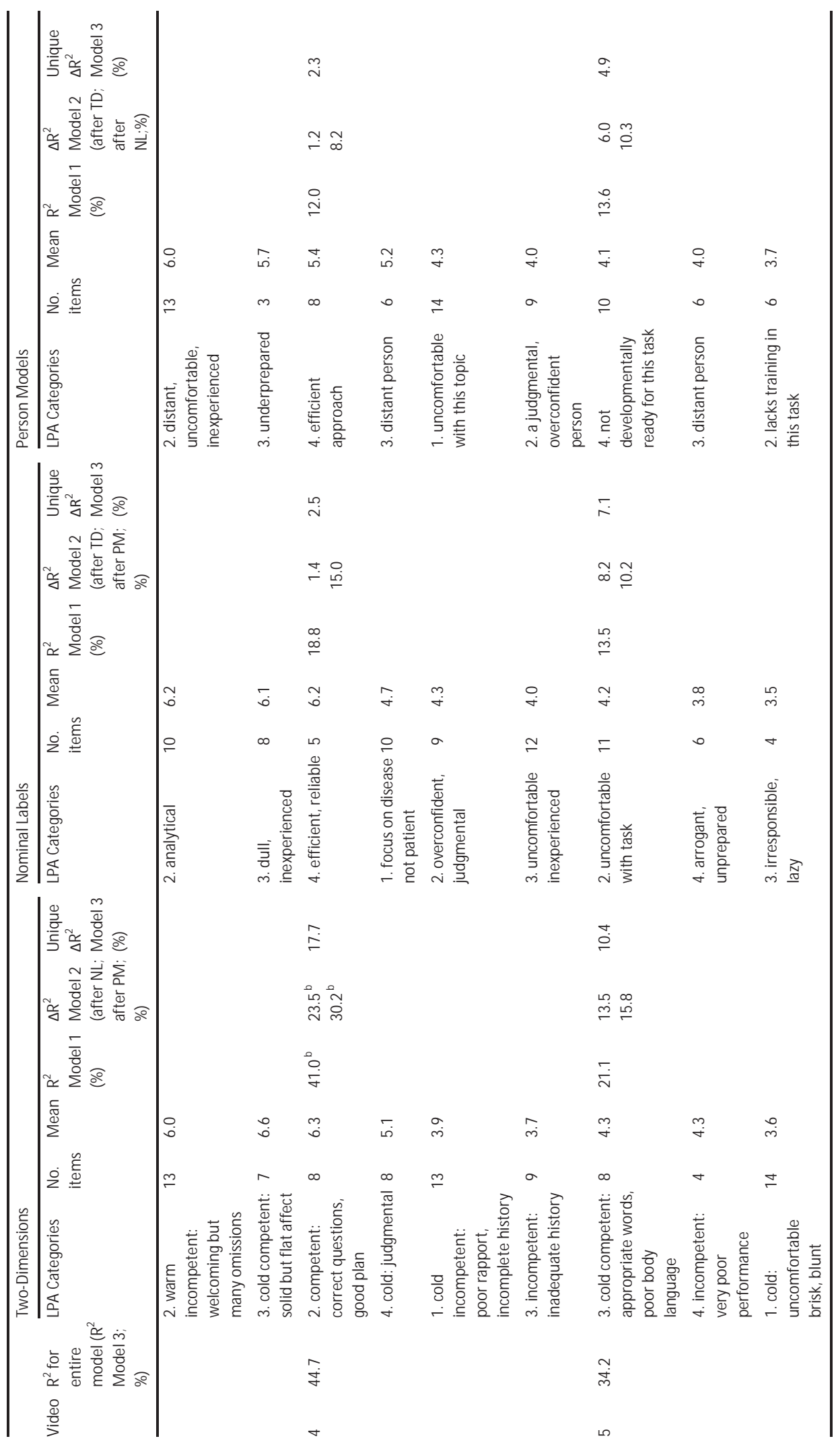




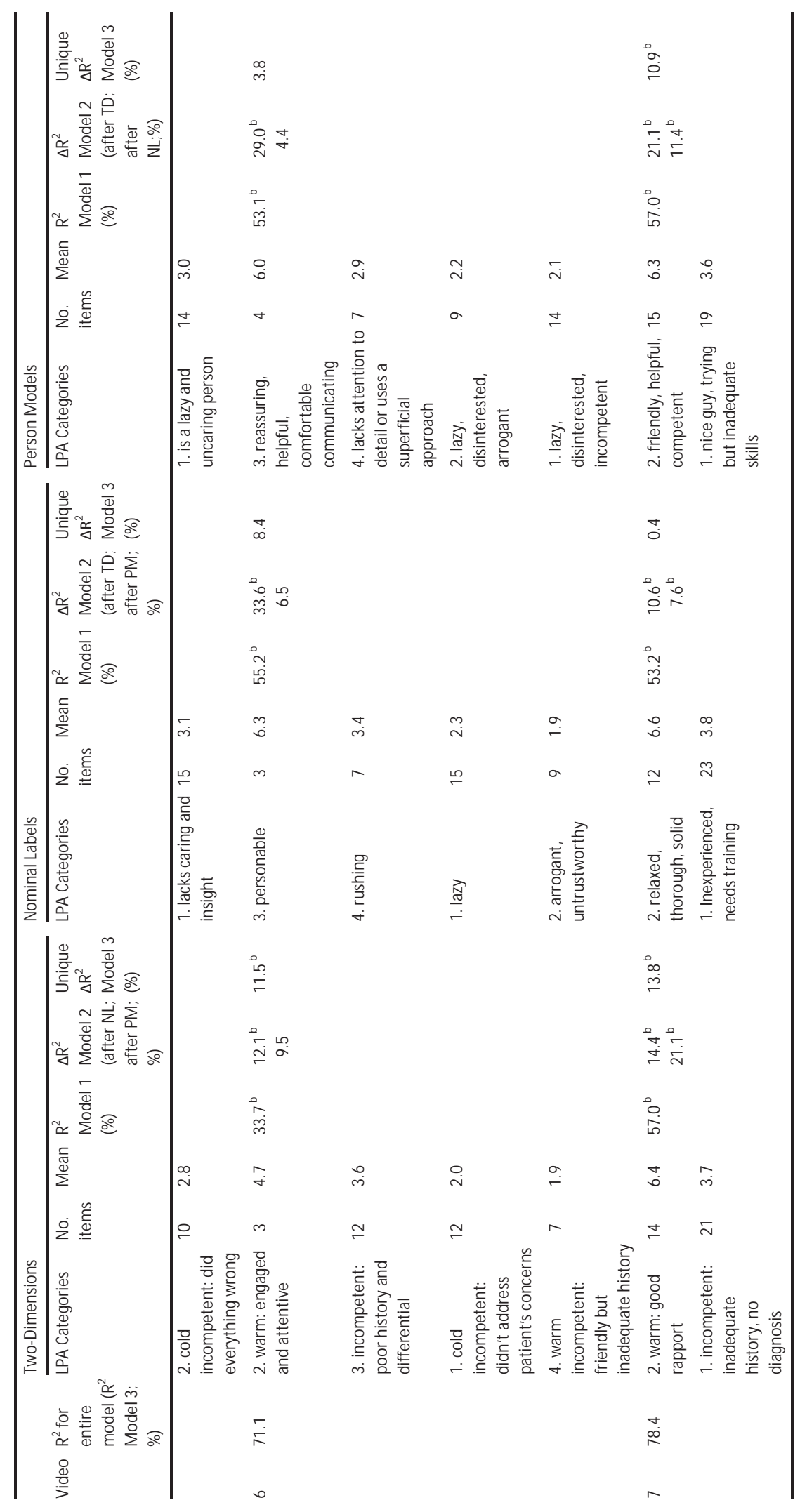


${ }^{a}$ Each video portrayed a different resident's clinical encounter with a patient. The variance explained by the entire regression model ( $R^{2}$ Model 3 ) is given in the second column. For each theory of categorization: TwoDimensions, Nominal Labels and Person Models, the same four columns are repeated for comparative purposes. The LPA categories column briefly summarizes the set of categories identified through latent partition analysis. This is followed by columns indicating the number of responses assigned to each category and the mean of the 'overall clinical competence' Mini-CEX ratings associated with those responses. The categories are listed in order of highest to lowest mean values. The next three columns display the proportions of variance explained in each sequence of the regression models. A series of six regressions were performed for each video with each set of LPA categories (one for each categorization theory) being entered into the model in every possible combination of blocks (TD-NL-PM, TD-PM -NL, NL-TD-PM, NL-PM-TD, PM-NLTD and PM-TD-NL). The $\mathrm{R}^{2}$ Model 1 column shows the variance explained by the categories for a particular theory of categorization when they are entered as the only predictors in the regression model (TD; NL; PM). The $\Delta R^{2}$ M odel 2 column shows the variance explained when the categorization theory's set of categories is entered into the regression model in the second block of predictors. Two values are given because the categories for a particular categorization theory were entered after each of the other two categorization theories (NL-TD, PM-TD; TD-NL, PM-NL; TD-PM, NL-PM, respectively). The final column Unique $\Delta R^{2}$ M odel 3 shows the proportion of variance that can only be explained by that categorization theory's set of categories as indicated by its entry into the third and final block of the regression model (NL-PM-TD; PM-TD-NL; TD-NL$P M$, respectively).

${ }^{\mathrm{b}} \mathrm{P}<05$

Also of note, for four videos, at least two categorization theories were included as significant unique predictors in the regression. In each of these four videos, the TD categorizations provided significant prediction. In addition, for two of these videos (1 and 6) the NL categorizations provided additional predictive power and for two (2 and 7) the PM categorizations provided additional predictive power.

\section{Phase 5: Thematic interpretation of the latent categories}

To further understand what aspects of physician narratives explained rating variance we examined the content of the responses from categories that were determined analytically to be significant predictors of M ini-CEX ratings. Using the LPA fit parameters, we were directed to the responses that loaded exclusively and strongly on the target category, and thus might be considered "quintessential" representations of that category. In this way we were able to identify the content that was distinct to each category.

When examining the TD categories, differences in narrative content between categories could be summarized as arising from one of two types of rater discrepancy: 1) differential salience in the importance of what was observed, and 2) disagreement in what actually happened. That is, in some cases there was general agreement about what had been observed, but subgroups of raters placed different emphasis on different aspects of the resident's performance. In other cases, there was clear disagree- 
ment in raters' interpretations of the events that occurred. Below we provide examples of each of these phenomena.

Differential salience. In videos 2, 4 and 6, in response to the question evoking TD narrative responses, raters seemed to generally agree about what was observed in the video, but each category created by the LPA emphasized a different aspect of the clinical performance observed. For example, in video 2, TD category 1 focused on how the resident successfully used the interview process to build rapport with the patient:

She introduced herself, sat down and engaged with the patient from the beginning. She allowed the patient to elaborate on her questions but kept the interview moving along. She made good eye contact and appeared to be listening to the patient. She was organized in her interview.

In contrast, TD category 2 focused on the incomplete content of the interview and inadequate counselling skills:

The resident has collected very little data that would allow one to determine why this patient might be depressed...we know nothing about the context of this person's life or what he is experiencing in response to it...She would not be able to determine if he was better after the meds as she doesn't know his baseline.

Category 3 included both the establishment of rapport and the failure to establish an adequate baseline while also emphasizing aspects of the residents' clinical management of depression:

I liked that she introduced herself, made contact with the patient and developed a therapeutic relationship.. She probably should have done a Beck or equivalent depression scale before making a decision to use medication and as comparison at future visit. She did not explore any non-medication treatment options and did not even mention counselling or lifestyle issues...

The content of the descriptions in each of the three categories demonstrate some agreement in what the resident did and how it was performed, yet each category emphasized a different aspect of the performance. Similarly in video 4, one category focused on a lack of rapport, inappropriate assumptions and poor management (TD category 1: cold incompetent) whereas another category focused on the resident asking the right questions in an organized way (TD category 2: competent).

Rater disagreement. In videos 1 and 7, the categories within the sets represented opposing interpretations of the same aspect of the clinical performance observed. For 
example in video 7, TD category 2 focused on the positive aspects of the resident's interviewing style and described his interview questions as thorough and efficient:

He asked most of the right questions, in the right order, connected well with the patient, had good eye contact, and generally did a good job.

This contradicts the descriptions in TD category 1 where several deficiencies in his interviewing skill were described:

He started off by asking questions about the pain but then did not focus on the correct systems review, asking too much about lower Gl symptoms and nothing about cardiorespiratory or musculoskeletal things.

Similarly for video 1 , TD category 1 described the resident's interview as including pertinent questions that worked through a broad differential whereas TD category 2 described the interview as a disjointed and incomplete checklist. Such differences could arise because subgroups of raters perceived, remembered and/or evaluated the same things differently.

For the four videos where either PM or NL categories explained a significant proportion of variance in addition to the proportion explained by TD categories, comparison of the relevant categories revealed that they contained different social judgments (often enmeshed with different assessment judgments). For example, within the set of statistically predictive NL categories, for video 6 each category described a different social inference about the resident including 'personable', 'rushing', or 'lazy'. For video 1 , one category contained inferences that the resident was 'smart, efficient, focused on the task' and the other category suggested that she 'doesn't care about the patient'. Social inferences included attributing personality traits, inferring current or future patients' reactions and inferring the residents' state of mind and intentions.

\section{DISCUSSION}

Consistent with our previous study, ${ }^{10}$ latent partition analysis identified clusters of consensus within physicians' variable narrative descriptions of residents that accounted for significant amounts of variance in M ini-CEX ratings. This suggests that there may be useful information embedded in seemingly idiosyncratic rater impressions. In this study we compared the capacity of three different theories of social categorization to explain variance in Mini-CEX ratings. When entered into the regression model first, significant associations that were comparable in magnitude were observed using the sets of categories produced by Two-Dimensions, Person Models, and Nominal Labels 
for the majority of the seven videos. When entered last into the sequential regression model, categories created using Two-Dimensions theory were found to explain the most unique variance. Examining the defining content of categories that were statistically predictive of $\mathrm{M}$ ini-CEX ratings suggested that distinguishing characteristics mainly reflected raters' emphasis being placed on different aspects of the performance for three videos and that subgroups of raters disagreed with one another regarding the same aspect of the performance for two videos.

This finding echoes those of medical education researchers ${ }^{6,7}$ and researchers outside our field of study. ${ }^{21,22}$ Park and colleagues, for example, have reported 'eye of the beholder' effects. They found raters made different impressions of the same person because they selected different acts as the central feature of an impression around which additional pieces of information were added to make a coherent story; to a lesser extent they disagreed on how to interpret the same acts. Importantly, this was the mechanism they proposed to explain the Person M odel theory of categorization. ${ }^{12}$ We are thus encouraged by the congruence in these diverse sets of findings and consider it worth continuing to draw upon social judgment and impression formation research to further understanding of rater cognition in health professional education.

While the instructions given to the TD group asked explicitly for competence-focused comments, it is interesting that the narratives that included social descriptions of the residents could explain as much variance in M ini-CEX ratings as did the TD narratives when each was entered into a regression model in isolation. Further, the Person M odel and Nominal Label categories were able to explain an additional significant proportion of variance on top of what could be explained by the TD-generated categories in four of the seven videos. The narratives that led to categories being generated using PM and NL theories contained performance-extraneous information regarding the residents' intentions for the encounter, personality traits and current state of mind. This subjective information is generally considered inappropriate data on which to base assessment ratings ${ }^{4}$ and such information tended not to be offered spontaneously in responses to question 1 . In social cognition research, such inferences have been found to be fundamental in helping us understand others. ${ }^{23}$ The findings that the number of social categorizations was small, that many raters described the same social judgments, and that those social judgments were enmeshed with assessment judgments, sum to suggest that such inferences may reflect subtleties in the clinical performance that were noted by some of the physicians. Perhaps these are important nuances that could be documented and used for clinical training purposes. ${ }^{24}$

Regardless of whether or not that is the case, the finding that the three different stimulus questions generated three qualitatively different responses, each of which could be used to group raters into different subgroups using different categorization theo- 
ries, has important implications. It suggests that how we attempt to access raters' assessment judgments has an impact on what judgments are revealed. In other words, asking different questions based on different theories can lead to different inferences being exposed. For researchers, this means that we must be intentional about what we ask raters because the stimulus question is not neutral in terms of the information it could extract. For faculty development and assessment administrators, an implication is that we need to dig deeply into raters' judgments because what could appear to be agreement when approached from one angle could be disagreement when approached from another angle and vice versa.

With regards to limitations, the use of non-clinicians as sorters could be considered a limitation, but we saw this as an advantage in that these participants could focus on the semantic nature of the responses rather than infer any implied meanings from assessment lingo ${ }^{25}$ Further, we are aware that sequential multiple regression is not typically used in the way it was applied here, but this approach fit our intended purposes. For example, while the sample size was not ideal for multiple regressions (or LPA for that matter), it was these analyses that were useful in helping us filter through the physicians' narrative responses, find statistically significant relationships with the assigned ratings and gain some insight into potential sources of variability in assessors' judgments. We were not oblivious in conducting these analyses to the statistical limitations and proceeded while monitoring for adverse effects on the outputs because this was an exploratory study with which we were searching for leads regarding where to investigate next.

Our goal was to better understand how raters make variable assessment judgments and we uncovered some tantalizing possibilities worth further investigation. Future research needs to focus on specifying the mechanism underlying the generation of different narratives and their impact on assessment. Research is needed to determine how much of the variation in categories is related to looking at different things within the performance and how much is related to seeing the same things differently as well as whether or not there is any practical way of telling the difference between the two situations in live time. By quantifying the influence, and better understanding the mechanism through which assessment judgments vary we could uncover if variations in social judgments (e.g. inferences) cause, or are caused by, variations in assessment judgments, thereby providing better guidance for further development in this area.

In conclusion, it was possible to identify clusters of consensus amidst physician raters' highly variable descriptions of competence and social judgments for a given clinical performance. Accounting for there being more than one point of consensus (i.e., physicians within a subgroup providing similar interpretations to one another but different interpretations relative to those of other subgroups) frequently explained variance in 


\section{CHAPTER 5}

clinical performance ratings. Of the three categorization theories, Two-Dimensions theory (warm-cold versus competent-incompetent) explained the most unique variance, with Person Models and Nominal Labels sometimes making important complementary contributions. The content that differentiated between categories included differing descriptions of competency as well as differing inferences regarding personality traits, the residents' state of mind and/or intentions during the encounter. Further investigation is needed to determine if there are any relationships between variations in social judgments and variations in assessment judgments.

Acknowledgements: The authors wish to thank Dr. Richard Wolfe for sharing his LPA program for R, Dr. Scott Allen for his instructions on how to use R and Dr. Jimmie Leppink for his consultation regarding methodology; Dr. Shiphra Ginsburg for her assistance with participant recruitment in Toronto; the Survey Research Lab at the University of Northern British Columbia for developing the online data collection system; and everyone who shared their video-recorded clinical performances including Dr. Jennifer Kogan.

Funding: This study was funded by a National Board of Medical Examiners ${ }^{\circledR}\left(\mathrm{NBME}^{\circledR}\right)$ Edward J. Stemmler, M D M edical Education Research Fund Grant. The project does not necessarily reflect NBME policy, and NBME support provides no official endorsement. 


\section{REFERENCES}

1 Gingerich A, Kogan J, Yeates P, Govaerts M, Holmboe E. Seeing the 'black box' differently: Assessor cognition from three research perspectives. M edical Education 2014;48 (11):1055-68.

2 Gingerich A, Regehr G, Eva KW. Rater-based assessments as social judgments: Rethinking the etiology of rater errors. Academic M edicine 2011;86 (10):S1-S7

3 LaMantia J, Rennie W, Risucci DA, Cydulka R, Spillane L, Graff L et al. Interobserver variability among faculty in evaluations of residents clinical skills. Academic Emergency M edicine 1999;6 (1):38-44.

4 Kogan JR, Conforti L, Bernabeo E, lobst W, Holmboe E. Opening the black box of clinical skills assessment via observation: A conceptual model. Medical Education 2011;45 (10):1048-60.

5 Govaerts MJB, Wiel MWJ, Schuwirth LWT, Vleuten CPM, Muijtjens AM M. Workplace-based assessment: Raters' performance theories and constructs. Advances in Health Sciences Education 2013;18 (3):375-96.

6 Mazor KM, Zanetti ML, Alper EJ, Hatem D, Barrett SV, M eterko V et al. Assessing professionalism in the context of an objective structured clinical examination: An in-depth study of the rating process. Medical Education 2007;41 (4):331-40.

7 Yeates P, O'Neill P, Mann K, Eva K. Seeing the same thing differently: Mechanisms that contribute to assessor differences in directly-observed performance assessments. Advances in Health Sciences Education 2013;18 (3):325-41.

8 Downing SM. Reliability: On the reproducibility of assessment data. Medical Education 2004;38 (9):1006-12.

9 Downing SM. Threats to the validity of clinical teaching assessments: What about rater error? Medical Education 2005;39 (4):353-5.

10 Gingerich A, van der Vleuten CP, Eva KW, Regehr G. More consensus than idiosyncrasy: Categorizing social judgments to examine variability in mini-cex ratings. Academic M edicine 2014;89 (11):1510-9.

11 Mohr CD, Kenny DA. The how and why of disagreement among perceivers: An exploration of person models. Journal of Experimental Social Psychology 2006;42 (3):337-49.

12 Park B, DeKay ML, Kraus S. Aggregating social behavior into person models: Perceiver-induced consistency. Journal of Personality and Social Psychology 1994;66 (3):437-59.

13 Fiske ST, Cuddy AJC, Glick P. Universal dimensions of social cognition: Warmth and competence. Trends in Cognitive Sciences 2007;11 (2):77-83.

14 Macrae CN, Bodenhausen GV. Social cognition: Thinking categorically about others. Annual Review of Psychology 2000;51 (1):93-120.

15 Lavine E, Regehr G, Garwood K, Ginsburg S. The role of attribution to clerk factors and contextual factors in supervisors' perceptions of clerks' behaviors. Teaching and Learning in Medicine 2004;16 (4):317-22.

16 Norcini JJ, Blank LL, Duffy FD, Fortna GS. The Mini-CEX: A method for assessing clinical skills. Annals of Internal Medicine 2003;138 (6):476.

17 Wiley DE. Latent partition analysis. Psychometrika 1967;32 (2):183-93.

18 Miller DM, Wiley DE, Wolfe RG. Categorization methodology: An approach to the collection and analysis of certain classes of qualitative information. Multivariate Behavioral Research 1986;21 (2):135.

19 R_Core_Team. R: A language and environment for statistical computing. Vienna, Austria: R Foundation for Statistical Computing; 2013.

20 Tabachnick BG, Fidell LS. Using multivariate statistics. 6th ed. Toronto: Pearson Education, Inc.; 2013. 983 pages.

21 Weber DE, Mavin TJ, Roth W-M, Henriqson E, Dekker SW. Exploring the use of categories in the assessment of airline pilots' performance as a potential source of examiners' disagreement. Journal of Cognitive Engineering and Decision Making 2014;8 (3):248-64.

22 Weber DE, Roth W-M, Mavin TJ, Dekker SW. Should we pursue inter-rater reliability or diversity? An empirical study of pilot perfor-mance assessment. Aviation in Focus-Journal of Aeronautical Sciences 2014;4 (2):34-58. 


\section{CHAPTER 5}

23 Malle BF. Time to give up the dogmas of attribution: An alternative theory of behavior explanation. In: Zanna M P, Olson JM, editors. Advances in experimental social psychology: Elsevier Inc.; 2011. p. 297311.

24 van den Eertwegh V, van Dalen J, van Dulmen S, van der Vleuten C, Scherpbier A. Residents' perceived barriers to communication skills learning: Comparing two medical working contexts in postgraduate training. Patient Education and Counseling 2014;95 (1):91-7.

25 Ginsburg S, Regehr G, Lingard L, Eva KW. Reading between the lines: Faculty interpretations of narrative evaluation comments. M edical Education 2015;49 (3):296-306. 


\section{CHAPTER}

Consistently variable

Multiple points of view for a

clinical performance predict ratings

Andrea Gingerich

Susan E. Ramlo

Cees P.M. van der Vleuten

Kevin W. Eva

Glenn Regehr

Submitted for publication 


\section{ABSTRACT}

Objectives Human judgment has been considered indispensable to programs of assessment but whenever multiple observers provide ratings, inter-rater variation is prevalent. Limitations of human cognition have been studied as a possible source of variable ratings. In recent research, we have found rater judgments may not be as idiosyncratic as they have often been characterized by discovering multiple clusters of consensus within the responses provided by physician raters for a single clinical performance.

Methods For the purpose of testing and extending these findings we chose to study this issue using $\mathrm{Q}$ methodology, a mixed methods technique that allows different points of view on the same topic to be uncovered. Participants watched a video, assigned $\mathrm{M}$ ini-CEX ratings, and then shared their impressions of the resident and his/her performance by sorting the statements provided to them. Subsequent factor analysis of the Q-sorts grouped participants with similar impressions together into a point of view.

Results 46 participants submitted 128 complete responses for 1-4 video-recorded clinical encounters previously studied. Two factors representing two or three points of view were identified for all four performances and the content of the points of view was consistent with the previously identified clusters of consensus. M embership in one point of view compared to the other could be used in regression analyses to predict ratings and accounting for there being multiple points of view explained, on average, $37 \%$ of the variance in the M ini-CEX ratings ( $\left.R^{2}: 21-53 \%\right)$ across the four videos.

Conclusions Given that finding multiple assessment judgments for a single performance has been replicated using a new set of participants and different methodology, we need to consider what features would be required for an assessment system to accommodate constructivist raters. 


\section{INTRODUCTION}

Human judgment has been considered indispensable to programs of assessment ${ }^{1}$ but whenever multiple observers provide ratings, inter-rater variation is prevalent. ${ }^{2}$ Reviews of the medical education literature have suggested that innate human cognition may contribute to variability in ratings ${ }^{3,4}$ such as when the demands of rating tasks exceed the limits of a finite mental workload ${ }^{5}$ or through the influence of social judgment processes ${ }^{6}$ including first impressions ${ }^{7}$. Variation in ratings for the same observed performance is often understood to be the result of raters making mistakes, committing omissions or being biased. ${ }^{4,8}{ }^{8}$ Regardless of its cause, this 'idiosyncratic rater variance' is considered to be unusable 'error' of measurement. ${ }^{10}$

In previous research, we have studied inter-rater variation and discovered patterns in raters' responses that could suggest their judgments are not as idiosyncratic as they have been characterized. ${ }^{11,12}$ M ore specifically, we used an exploratory data reduction technique called latent partition analysis ${ }^{12-14}$ (LPA) and discovered multiple clusters of consensus, each containing several raters, which represented subsets of impressions (or interpretations of the performance) that often varied widely with regard to the content and valence of the impression described. The differences in the various clusters sometimes stemmed from raters emphasizing different aspects of the performance (i.e. seeing different aspects as most important), and other times resulted from raters outright disagreeing on the same aspects of the performance (i.e. seeing the same aspect differently). From a functional perspective, our findings were consistent with other medical education studies reporting differential salience and rater disagreement regarding observed behaviours and/or inferred social judgments in performance assessment. ${ }^{15-19}$ From a theoretical perspective, the findings were also consistent with research from the social cognition literature which suggests that in social interactions, people will tend to categorize those they are observing based on social inferences they make about the performer. ${ }^{20-22}$

However, there are several theories in the social cognition literature regarding the mechanisms underlying these inference-based categorizations. ${ }^{6}$ The Two-Dimensions (TD) theory posits that social judgments are made by categorizing a person into one of four quadrants based on judgments of the person's warmth-coldness (i.e. sociability and trustworthiness) and competence-incompetence (i.e. ability to carry out his/her intentions). ${ }^{20}$ The Nominal Labels (NL) theory posits that impressions are formed by assigning a person to a pre-conceived group (such as stereotypes). ${ }^{21}$ The Person M odel theory posits that impressions are formed by creating an ad hoc story about the person in the moment of observation. ${ }^{22,23}$ Thus, in a subsequent study ${ }^{11}$ we applied the LPA analysis that generated these clusters of consensus separately for three different theories of social categorization and utilized multiple regression to predict Mini-CEX 
ratings for 7 different video-recorded clinical performances in order to determine which theory (or theories) of social categorization best predicted ratings. For 6 of the 7 studied videos, ratings were significantly predicted by the categorizations based on at least one of the three theories, and for four of the videos, the categorizations from two theories predicted greater variance than could be predicted by any single theory.

Given that accounting for these clusters of consensus using any one theory explained about one third of the variance in M ini-CEX ratings (and that consideration of all three together explained about half of the variance), we were encouraged that the results were meaningful, but their exploratory nature makes it important to replicate and challenge the findings. The previous investigations used latent partition analysis (LPA) to look for patterns within raters' responses. LPA is similar to exploratory factor analysis, but unlike exploratory factor analysis, LPA does not appear to have an associated confirmatory version. For the purpose of testing and extending our previous findings, therefore, we chose to study this issue using $\mathrm{Q}$ methodology. Q methodology is a mixed methods technique that allows different points of view on the same topic to be uncovered by having participants order a set of predetermined statements from those most consistent with their opinion to those most contrary to their opinion. ${ }^{24-26}$ For our purposes, we used statements extracted from raters who represented the various LPA categories in the previous study, and had new raters view the same videos and order those predetermined statements in a $\mathrm{Q}$ sort. $\mathrm{Q}$ analysis could then be used to determine the extent to which the multiplicity of perspectives identified previously replicated when the statements from others are made available to new raters.

Our ultimate goal for the larger line of research is to discover new ways to improve rater-based assessments by better understanding the variability in ratings introduced by raters. The specific aim of this study was to determine the stability of our finding that clusters of consensus exist within raters' variable assessment judgments. Through methodological triangulation, we address the main research question of "Can the multiple clusters of consensus finding be confirmed by identifying multiple points of view on the same clinical performances using a different methodology and a new dataset?" We address this question by testing the following hypotheses:

1 There will be more than one point of view for each video as indicated by the extraction of more than one "Q-factor" in the $\mathrm{Q}$ analysis.

2 The content of the different points of view (i.e. the different Q-factors) will match the content of the previously identified clusters of consensus (i.e. the impressions identified through latent partition analysis).

3 The different points of view (i.e. belonging to one Q-factor compared to another) will explain a significant amount of variance in the M ini-CEX ratings. 


\section{METHODS}

\section{Selection of videos}

For this study we selected four of the videos from our previous work. These four were selected based on the fact that the LPA categories derived from two different theoretical frameworks independently contributed significantly to predicting variance in $\mathrm{M}$ iniCEX ratings in the regression analyses. For all four videos, the TD categories were predictive. For two videos ( 1 and 6 from Gingerich et al, forthcoming) the NL categories added significant predictive power and for two videos (2 and 7 from Gingerich et al, forthcoming) the PM categories added significant predictive power.

\section{Description of Q methodology}

Q methodology provides a mixed methods approach to determine the number and composition of the points of view expressed for each performance. $Q$ consists of a philosophy, a theory and a set of procedures that focus on describing a population of viewpoints rather than describing a population of people. ${ }^{24,}{ }^{27}$ William Stephenson developed Q methodology after becoming dissatisfied with behaviorism's focus on the study of objective behavior to the exclusion of individuals' subjective perspective and experience. ${ }^{26,28} \mathrm{Q}$ methodology consists of four important steps: 1) concourse development and Q-sample selection, 2) the Q-sort, 3) a by-person factor analysis and 4) interpretation of the factors.

\section{1) Concourse development and Q-sample selection.}

The first step in the design of a Q-study is identifying a set of statements that will be sorted by participants. It begins with gathering a large array of statements that are broadly representative of the topic of interest, known as the concourse. ${ }^{25}$ Our concourse consisted of every open text response grouped into one of the clusters of consensus identified in our prior work. In total, 317 complete responses were collected from a total of 24 LPA clusters spread across the 4 videos. This concourse was reduced to the 195 most representative open text responses as indicated by the fit parameters of the latent partition analysis (i.e. only responses belonging to a single cluster of consensus were selected). The complete responses were then parsed into single idea statements, duplicates were removed and semantically similar statements were combined, resulting in 211 short statements.

From the concourse of possible statements, a subset of statements, the Q-sample, is then selected for presentation to participants for sorting. The Q-sample should be a reasonable size for participants to work with but remain representative of the concourse and be balanced across the possible points of view that could be found during 
analysis. ${ }^{25}$ We used the most formal approach to developing a structured Q-sample, known as Fisher's balanced-block approach. ${ }^{25,26}$ The most distinctive statements for each of the 24 clusters of consensus were identified. From these 71 statements, 60 were selected in a way that balanced the number of statements referring to each of the subscales on the Mini-CEX and different types of social judgments (e.g. naming personality traits, inferring state of mind etc.). Further review of the wording of the statements revealed redundancies across the videos (e.g. a distinctive statement for one cluster could also apply to a cluster for a different video). We then considered factors associated with the mechanics of the Q-sort process (e.g. recognizing that the score sheet used enables one statement to be positioned in different sorts to convey opposing opinions- see Figure 1 ). This combination of variables allowed the reduction of the number of statements to 44 while still maintaining balance and representation. Through two rounds of pilot testing, the phrasing of the statements was refined in response to participants' expressions of uncertainty, but the original phrasing was maintained as much as possible. The final list of 44 statements is presented in Table 1.

\section{2) Q-sort process.}

During a Q-sort, each participant's point of view on the specified topic (the performance of the resident in this case) is collected by having them sort the statements in the Q-sample using a forced quasi-normal distribution ranging from most consistent with their perspective to most inconsistent with their perspective. ${ }^{25}$ By differentially valuing the set of statements, the completed Q-sort allows the participant's subjectivity to be actively expressed in the first person perspective. ${ }^{29,}{ }^{30}$ Because people with similar points of view typically sort the statements in a similar way, factor analysis can then be used to group the shared perspectives by identifying high correlations between participants' Q-sorts. ${ }^{25,26}$

To operationalize this process, an invitation email was sent to participants that included a link to the website developed for facilitating data collection at a distance, QSortOnline. After giving consent to participate, watching a randomly presented video and completing the M ini-CEX ratings, participants were asked to complete a Q-sort using the following instructions:

We would like you to share your honest and unfiltered impressions of this resident and ask that you rank the statements from 'M OST consistent with my impressions of this resident and their performance' to 'MOST contrary to my impressions of this resident and their performance'.

The aim was to collect each physician's impression of the performance and the resident. FlashQ software was used to facilitate the Q-sort online, which was completed in multiple stages as suggested ${ }^{24}$ for face-to-face sorting. First, participants were asked to 
divide the 44 randomly presented statements into three piles: 'consistent with my impression', 'contrary to my impression' and 'not relevant'. Next, they were presented with a grid of boxes in a fixed quasi-normal distribution (see figure 1) called a score sheet. They were to read through all the statements in their 'consistent with my impression' pile, select the two statements that were MOST consistent with their impression and place them on the score sheet in the two ' +4 ' boxes. From the remaining 'consistent' pile, they were then asked to select the three remaining statements that were most consistent with their impression and to place them in the three ' +3 ' boxes on the score sheet. They continued placing the remaining 'consistent' statements in appropriate boxes until all of the statements in the consistent pile had been placed on the score sheet. They then repeated the process for the 'contrary to my impression' pile using the left-hand side of the score sheet, starting with the '-4' boxes, moving to the '- 3 ' boxes and so on. The statements in the 'not relevant' pile were then placed in the remaining boxes on the score sheet. Participants were given the opportunity to review and rearrange the statements, if necessary, to ensure the distribution on the score sheet best represented their impressions. They were then prompted to explain (a) why they selected the two statements in the -4 boxes as being most contrary to their impression, (b) why they selected the two statements in the +4 boxes as being most consistent with their impression, and (c) any problems they encountered with performing the sorting task. Finally they were asked to complete a short demographics questionnaire.

\begin{tabular}{|c|c|c|c|c|c|c|c|c|}
\hline-4 & -3 & -2 & -1 & 0 & +1 & +2 & +3 & +4 \\
\hline 口 & $\square$ & $\square$ & $\square$ & $\square$ & $\square$ & $\square$ & $\square$ & $\square$ \\
\hline \multirow[t]{9}{*}{ 口 } & 口 & 口 & $\square$ & $\square$ & $\square$ & $\square$ & 口 & $\square$ \\
\hline & 口 & $\square$ & 口 & $\square$ & 口 & $\square$ & $\square$ & \\
\hline & & 口 & 口 & 口 & $\square$ & $\square$ & & \\
\hline & & & 口 & $\square$ & $\square$ & & & \\
\hline & & & 口 & 口 & $\square$ & & & \\
\hline & & & 口 & $\square$ & $\square$ & & & \\
\hline & & & 口 & $\square$ & 口 & & & \\
\hline & & & & $\square$ & & & & \\
\hline & & & . & $\square$ & & & & \\
\hline
\end{tabular}

Figure 1: Q-Sorting Score Sheet

Participants rank-ordered 44 statements by placing them on a quasi-normal distribution scoring sheet. They had previously sorted the statements into three piles. When presented with the scoring sheet they were instructed to select from the 'consistent' pile the 2 statements that were most consistent with their impression and place them under +4 . The next three statements that were most consistent with their impression were placed under the +3 and so on. The same process was used to rank the statements from the 'contrary' pile. The statements in the 'not relevant' pile were then placed in the remaining spots on the score sheet. 
3) Q-Analysis.

We analyzed the sorting data using free custom software PQM ethod $2.35 .{ }^{31}$ In conventional factor analysis a 'by-item' matrix would be used but in Q methodology a 'byperson' matrix is used. The assumption is that participants with a similar point of view will construct a similar Q-sort and hence their sorts will be highly correlated. As such, the by-person factor analysis groups together participants with highly correlated Qsorts into a factor. ${ }^{25,}{ }^{26}$ We used the classic Centroid technique for factor extraction followed by varimax rotation of the factors. In considering how many factors to extract, we paid special attention to those with eigenvalues greater than $1 ;{ }^{25}$ those exceeding Humphrey's rule (i.e. those for which the cross-product of the two highest loadings for a factor in the unrotated matrix exceeded twice the standard error) $;_{i}^{25}$ or those with at least two sorts that loaded significantly $(p<01) .{ }^{25,32}$ Each factor solution was examined for fit and interpretability with the best solution selected. ${ }^{32}$

\section{4) Factor interpretation.}

Factor interpretation was accomplished by using the factor arrays to construct the narrative content of the factors based on procedures described by Watts and Stenner. ${ }^{25}$ For each video, we subsequently compared the interpretations of the narrative content of the Q-sort factors with those of the clusters of consensus derived from the latent partition analysis (generated and reported in Gingerich et al, forthcoming). Each video was analyzed separately with researchers blind to the corresponding M ini-CEX ratings.

\section{Predicting and explaining variance in M ini-CEX ratings}

The factor loadings, which indicate how strongly each participant's Q-sort belonged with each of the identified factors, were used to group participants as belonging to categories represented by the factors. That is, participants were assigned to the category with which their Q-sort had the highest factor loading. The factors were dummy coded using Factor 1 as the reference category and entered as predictors in a linear regression model. ${ }^{33}$ Regression analyses were performed separately for each video to determine both the ability of the Q-factors to predict M ini-CEX ratings (unstandardized coefficient B) and the amount of variance that could be explained (R square) in 'overall clinical competence'.

\section{Participants}

In Q methodology, each participant is considered to be a variable and, as such, participants should be intentionally selected to cover all possible viewpoints on the topic. ${ }^{25}$ To achieve this strategic approach to recruitment, we asked an array of colleagues to invite physicians who were known to them to be good assessors of residents to partic- 
ipate in our study. To be eligible, assessors must have been licensed to practice medicine in North America at some point in their career. In addition, they must have been trained in emergency, family or internal medicine because those were the specialties deemed relevant to the content of the cases presented on video. Informants were encouraged to include physicians who were known to use specific approaches to assessments (e.g. hawk or dove, focus on patient-centredness etc.) so that a diversity of assessment styles could be included in the study. Experts in assessment who are widely known for their contributions to assessment research, rater training, or assessment policy (and who met the inclusion criteria) were individually invited to participate.

To determine the number (and representation) of participants to be included for the study, Q-analyses were performed periodically throughout data collection. To help promote representation of all possible points of view, whenever a strong but small factor started to emerge, additional participants who matched the demographics of participants grouped into that factor were invited to participate. Recruitment was stopped once the factors became established and the number of gathered Q-sorts was between half and the total number of statements in the Q-sample (i.e., 22-44 participants per video). ${ }^{25}$

This study was approved by the Behavioural Research Ethics Board at the University of British Columbia and the Research Ethics Board at the University of Northern British Columbia.

\section{RESULTS}

Between November 2014 to February 2015 we received 128 complete responses submitted by 46 participants ( 23 female) from 19 different cities in 5 provinces in Canada and 5 states in the USA. $24(52 \%)$ were from internal medicine, $13(28 \%)$ were from emergency medicine and 9 (20\%) were from family medicine. Each participant completed the tasks for 1-4 videos. 


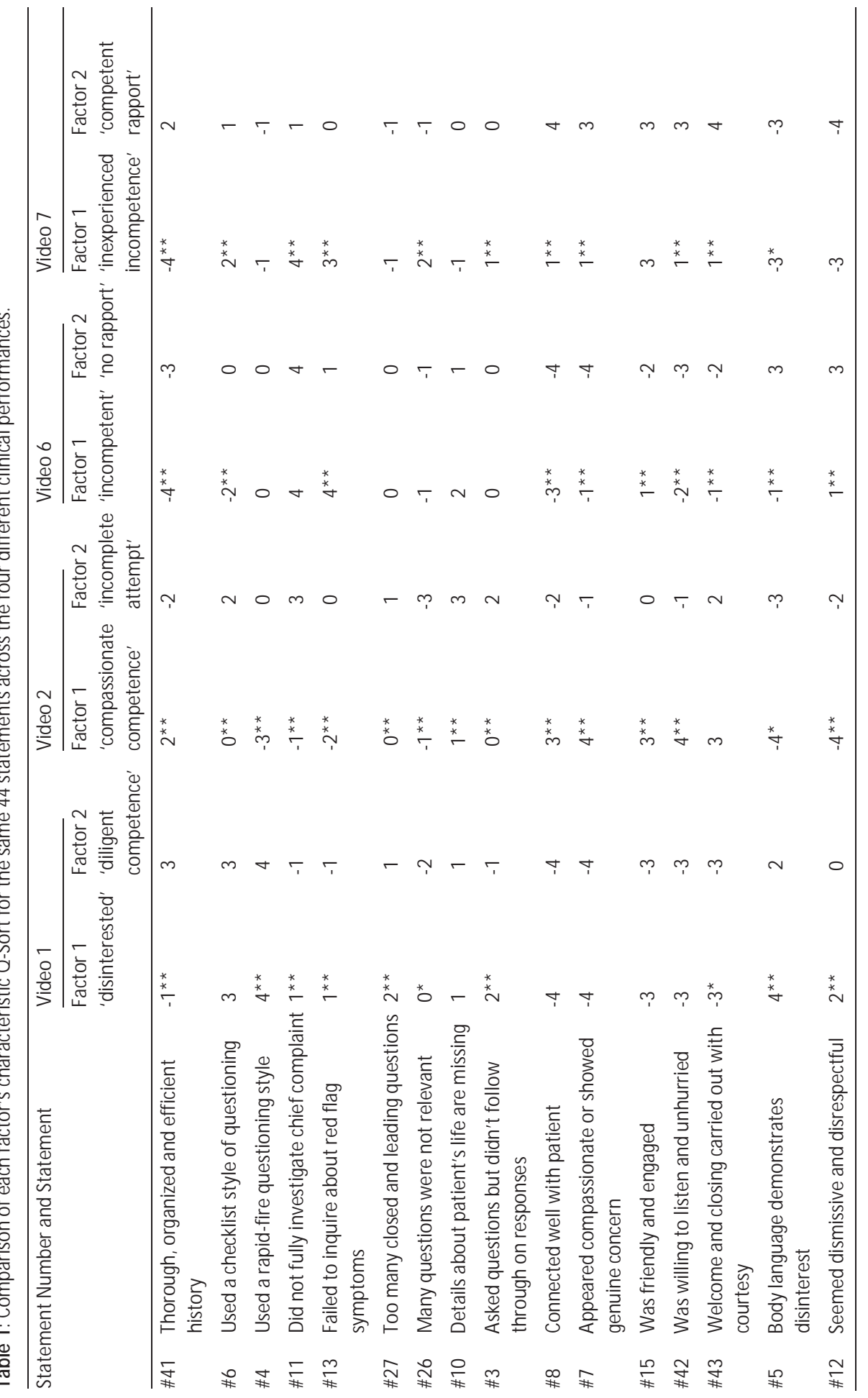


CONSISTENTLY VARIABLE

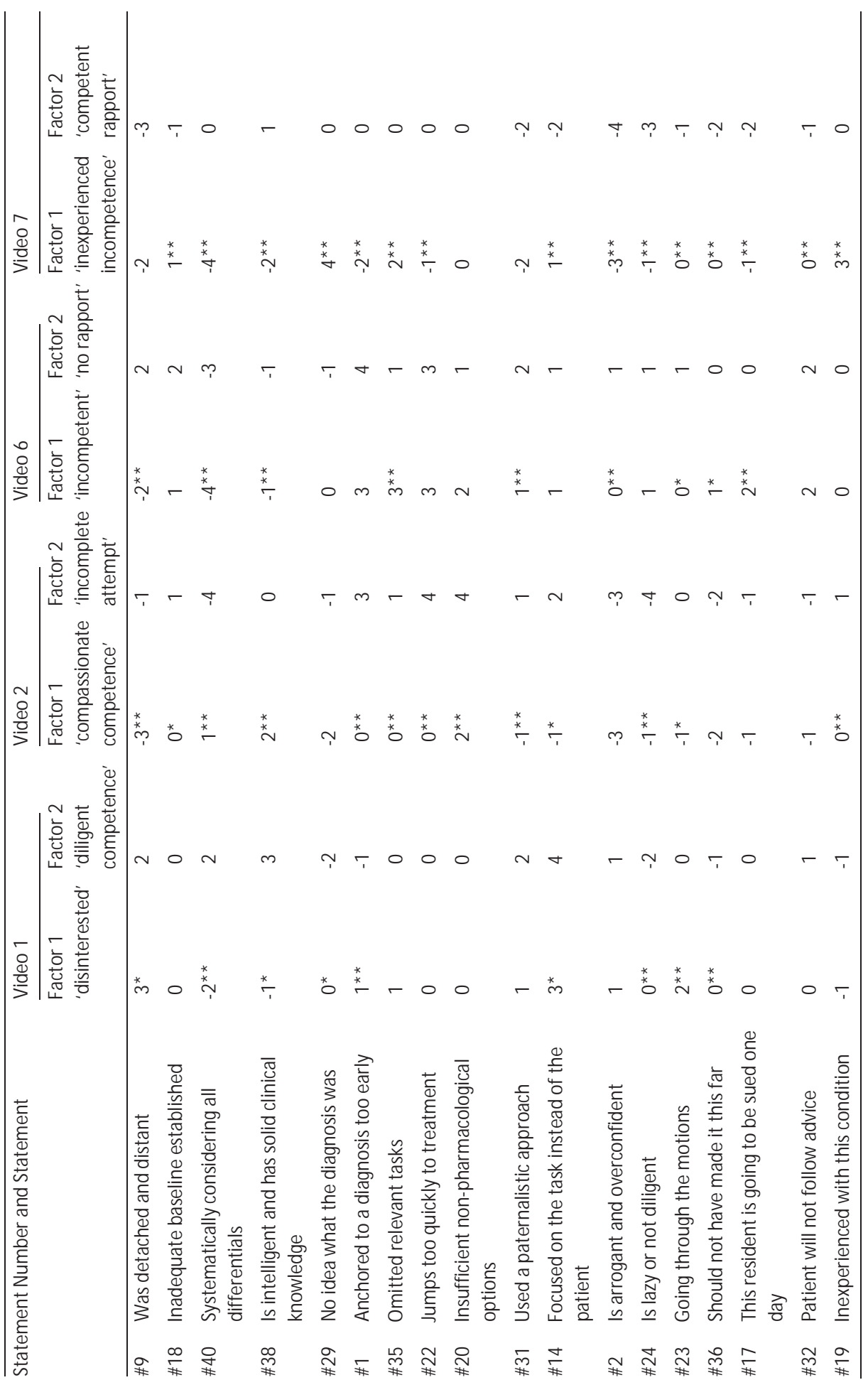




\section{CHAPTER 6}

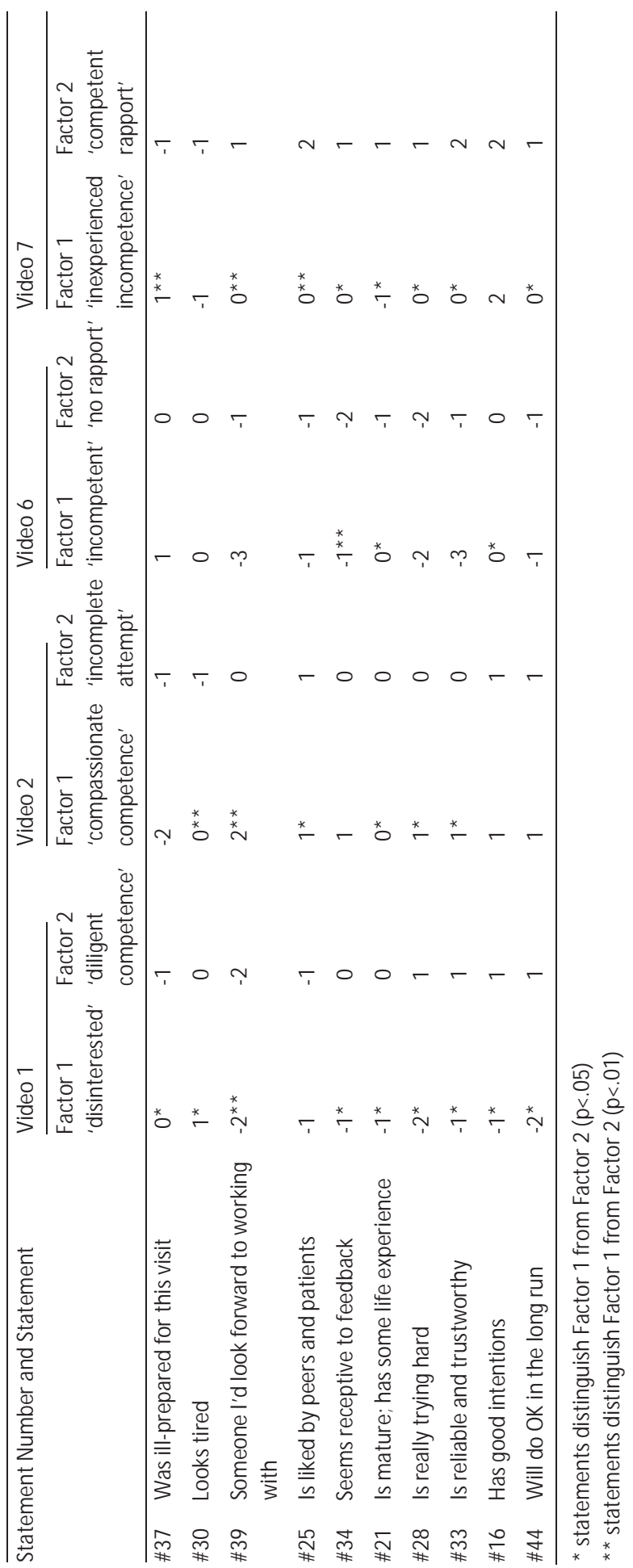


Table 1. 46 physicians viewed 1-4 video-recorded clinical performances of different second-year internal medicine residents. The same 44 statements were used by participants to represent their impressions of the resident and his/her performance in Videos 1, 2, 6 and/or 7. Q-factor analysis grouped highly correlated Qsorts into factors. Separate analyses extracted two factors for each of the four videos and each factor represented a unique point of view (although Video 2 Factor 1 and Video 7 Factor 2 are very similar). The different points of view for each video are represented in this table by its characteristic Q-Sort. The characteristic QSort is the analytically derived Q-sort that best represents the overall point of view of the participants grouped within that factor. As such, it is unlikely that the participants grouped into a point of view submitted exactly the same Q-sort as the characteristic Q-sort. The statements are ordered in the table roughly based on the subscales of the M ini-CEX rating form followed by various social judgments. To provide some orientation for interpreting this table, some key statements are briefly discussed. Statements describing the residents' interviewing, humanism, clinical judgment and other Mini-CEX subscale related skills were often ranked as most representative of participants' impressions by being placed at the extreme end of the score sheet as either (+4) 'most consistent' or (-4) 'most contrary' to participants' impressions. All four videos depicted a clinical encounter requiring a patient history and the interviewing skills statements were highly representative of participants' impressions. For example, statement \#41 'thorough, organized and efficient history' was a particularly representative and differentiating statement for the points of view for videos 1,2 and 7. Participants did not just differently emphasize this key feature of the same history-taking clinical encounter; they placed it on opposite sides of the score card which likely represents disagreement between the two points of view. Several statements corresponding to humanism and counseling skills were also highly representative of participants' impressions for all four performances. Statement \#8 'connected well with patient' depicts examples of agreement between the two points of view for video 1 , disagreement regarding this particular aspect between the points of view for video 2 , and the two points of view differently emphasizing it for video 7. Statements referring to clinical judgment skills such as \#40 'systematically considering all differentials' and \#1 'anchored to a diagnosis too early' were also highly representative of participants impressions' of performances or differentiated points of view for a given video.

\section{Hypothesis 1}

A 2-factor solution was the best for each of the four videos (see Appendix A for details) indicating there was more than one point of view for each clinical performance. For three videos $(1,2,7)$, raters' factor loadings were all positive. This resulted in the identification of two groupings to represent the raters' perspectives for these videos, one representing raters with a stronger positive loading on the first factor and one representing raters with a stronger positive loading on the second factor. For video 6 , however, one of the factors demonstrated both positive and negative loadings. Thus, three groupings were created, one representing raters with a stronger positive loading on the first factor, one representing raters with a stronger positive loading on the second factor, and one representing raters with a stronger negative loading on the second factor. All nine unique points of view are represented in Table 1 using their characteristic Q-sort. The content and the distinctiveness of the two points of view varied for each performance. For example, the two points of view for video 1 and two of the three points of view for video 6 shared similar opinions on several aspects whereas there was almost no agreement between the two points of view within videos 2 or 7 (as seen by the sortings in Table 1 and as described in Appendix A). 


\section{Hypothesis 2}

When comparing the content of the $\mathrm{Q}$ derived points of view to the previously identified ${ }^{11}$ clusters of consensus derived from LPA, there was a simple and direct alignment for videos 1 and 7. For example, the video 1 'diligent competence' point of view aligns both with the two-dimensions cluster of consensus describing the resident as robotic and asking the right questions as well as the nominal label cluster of consensus describing her as smart, efficient and focused on the task.

For videos 2 and 6, the content of the clusters of consensus presented in Gingerich et al (forthcoming) could be reasonably aligned with the $\mathrm{Q}$ points of view by combining two LPA clusters together (see Figure 2). In our previous work, videos 2 and 6 were each determined to have four clusters of consensus and this does not match the number of points of view identified in this study. Based on the content of the points of view, along with reviewing the comments participants made about how their impressions were represented by the Q-sort, it was possible to align two clusters of consensus to one point of view (as shown in Figure 2). For example, for video 2 matching a Two-Dimensions cluster of consensus describing the resident as warm and engaging along with another one describing her as warm and competent aligns with the point of view 'compassionate competence'. The alignment of clusters of consensus to points of view was important in determining how to proceed with the analysis of video 6 . The single negatively correlated Q-sort that solely composed the third point of view would have been downplayed in the interpretation of the Q-factors, and especially in the regression analysis, if this was not a follow-up study. However, its contrary point of view that the resident was friendly, engaged and took his time with the interview exactly matches a two-dimensional and a nominal label cluster of consensus from our previous investigations. The reproducibility strengthened the credibility of this seemingly idiosyncratic point of view and led to it being kept in subsequent analyses.

It is also worth noting that there is another dimension of alignment between the current data set and that of the previous LPA analyses. That is, the discrepancies between the points of view were sometimes differential salience and sometimes disagreements in performance. For example, both points of view for Video 1 included impressions that the resident's body language demonstrated disinterest but it was one of the most important aspects of Factor 1's point of view and much less so for those grouped into Factor 2 (statement \#5: +4; +2). By contrast, for Video 7 the two points of view disagreed on whether the history was thorough, organized and efficient or not by placing this statement on opposite sides of the score sheet (statement \#41: $+4 ;-2$ ). There are many more examples of both as presented in Table 1 and Appendix A. 


\begin{tabular}{|c|c|c|}
\hline $\begin{array}{l}\text { Two-dimensions' clusters of } \\
\text { consensus }\end{array}$ & Q-factors & $\begin{array}{l}\text { Other theories of categorization } \\
\text { clusters of consensus }\end{array}$ \\
\hline $\begin{array}{l}\text { TD2. cold incompetent: aggressive } \\
\text { questioning }\end{array}$ & $\rightarrow \quad$ Q-Factor 1 'disinterested' & -NL1. doesn't care about patient \\
\hline $\begin{array}{l}\text { TD 1. cold competent: robotic, } \\
\text { asked right questions }\end{array}$ & $\rightarrow$ Q-Factor 2 'diligent competence' & -NL2. smart, efficient, focused on task \\
\hline $\begin{array}{l}\text { TD 1. warm competent: good } \\
\text { questions and reasoning }\end{array}$ & Video 2 & PM 1. compassionate and competent \\
\hline TD 4. warm: engaging and attentive & Q-Factor 1 'compassionate competence' & PM 4. likeable and respected \\
\hline $\begin{array}{l}\text { TD 3. warm incompetent: nice } \\
\text { manner but poor management }\end{array}$ & & $\begin{array}{l}\text { PM 2. good person with skills to } \\
\text { improve }\end{array}$ \\
\hline $\begin{array}{l}\text { TD 2. incompetent: incomplete } \\
\text { history and counseling }\end{array}$ & Q-Factor 2 'incomplete attempt' & PM 3. paternalistic style \\
\hline $\begin{array}{l}\text { TD 4. warm incompetent: friendly } \\
\text { but inadequate history }\end{array}$ & $\begin{array}{c}\text { Video } 6 \\
\text { Q-Factor } 1 \text { 'incompetent' }\end{array}$ & -NL4. rushing \\
\hline $\begin{array}{l}\text { TD 1. cold incompetent: didn't } \\
\text { address patient's concerns }\end{array}$ & & NL1. lazy \\
\hline $\begin{array}{l}\text { TD 3. incompetent: poor history } \\
\text { and differential }\end{array}$ & Q-Factor 2 (positive) 'no rapport' & NL2. arrogant, untrustworthy \\
\hline TD 2. warm: engaged and attentive & $\begin{array}{c}\rightarrow \text { Q-Factor } 2 \text { (negative) 'friendly } \\
\text { competent' }\end{array}$ & -NL3. personable \\
\hline $\begin{array}{l}\text { TD 1. incompetent: inadequate } \\
\text { history, no diagnosis }\end{array}$ & $\begin{array}{c}\text { Video } 7 \\
\text { Q-Factor } 1 \text { 'inexperienced } \\
\text { incompetence' }\end{array}$ & $\begin{array}{l}\text { PM 1. nice guy, trying but inadequate } \\
\text { skills }\end{array}$ \\
\hline TD 2. warm: good rapport & $\rightarrow$ Q-Factor 2 'competent rapport' $\quad \leftarrow$ & -PM 2. friendly, helpful, competent \\
\hline
\end{tabular}

Figure 2: Comparison of Q-factor points of view to latent partition analysis clusters of consensus

Shared points of view were identified using Q methodology by grouping 128 impressions from 46 physician raters into Q-factors for 1-4 video-recorded clinical performances of different second-year internal medicine residents. Previous investigations used latent partition analysis to aggregate open-text responses provided by physician raters according to three different theories of social categorization. For each video, the narrative content of the Q-factor points of view (shown in the centre) is aligned with the content of the TwoDimensional theory of social categorization (TD) clusters of consensus (on the left); and either the Nominal Labels (NL) or Person M odels (PM) theories of social categorization (on the right).

\section{Hypothesis 3}

Accounting for raters' category membership based on the Q-analysis factor loadings predicted overall clinical competence ratings and explained an average (across videos) of $37.3 \%$ of the variance in Mini-CEX ratings $\left(R^{2}: 21-53 \%\right)$. See Table 2 for specific regression values. 
Table 2: Q-factors identified through Q methodology explain rating variance and predict overall clinical competence $\mathrm{M}$ ini-CEX ratings in multiple regression models, separately for four videos

\begin{tabular}{|c|c|c|c|c|c|c|c|}
\hline Video & Q-factors & $\begin{array}{l}\text { Number of } \\
\text { Q-sorts }\end{array}$ & Mean & $\begin{array}{l}\text { R square } \\
(\%)\end{array}$ & $\begin{array}{l}\text { Unstandardized } \\
\text { coefficient B } \\
\text { value } \\
\text { (standard error) }\end{array}$ & t value & $P$ value \\
\hline \multirow[t]{2}{*}{1} & Factor 1 'disinterested' & 18 & 3.2 & $39.5^{b}$ & \multirow{2}{*}{$\begin{array}{l}1.56 \\
(.35)\end{array}$} & \multirow[t]{2}{*}{4.43} & \multirow[t]{2}{*}{.000} \\
\hline & $\begin{array}{l}\text { Factor } 2 \\
\text { 'diligent competence' }\end{array}$ & 14 & 4.8 & & & & \\
\hline \multirow[t]{2}{*}{2} & $\begin{array}{l}\text { Factor } 1 \\
\text { 'compassionate competence' }\end{array}$ & 28 & 6.8 & $35.4^{b}$ & \multirow[t]{2}{*}{$\begin{array}{r}-1.79 \\
(.43)\end{array}$} & \multirow[t]{2}{*}{-4.19} & \multirow[t]{2}{*}{.000} \\
\hline & Factor 2 'incomplete attempt' & 6 & 5.0 & & & & \\
\hline \multirow[t]{3}{*}{6} & Factor 1 'incompetent' & 17 & 2.4 & $21.3^{b}$ & \multirow{2}{*}{$\begin{array}{l}.004 \\
(.34)\end{array}$} & \multirow[t]{2}{*}{.013} & \multirow[t]{2}{*}{.990} \\
\hline & $\begin{array}{l}\text { Factor } 2 \text { (positive) } \\
\text { 'no rapport' }\end{array}$ & 14 & 2.4 & & & & \\
\hline & $\begin{array}{l}\text { Factor } 2 \text { (negative) } \\
\text { 'friendly competent' }\end{array}$ & 1 & $5.0^{\mathrm{a}}$ & & $\begin{array}{l}2.65 \\
(.96)\end{array}$ & 2.77 & .010 \\
\hline \multirow[t]{2}{*}{7} & $\begin{array}{l}\text { Factor } 1 \\
\text { 'inexperienced incompetence' }\end{array}$ & 17 & 3.7 & $53.0^{b}$ & \multirow[t]{2}{*}{$\begin{array}{l}2.45 \\
(.44)\end{array}$} & \multirow[t]{2}{*}{5.61} & \multirow[t]{2}{*}{.000} \\
\hline & Factor 2 'competent rapport' & 13 & 6.2 & & & & \\
\hline
\end{tabular}

${ }^{a}$ the single overall clinical competence rating corresponding with the Q-sort

${ }^{b} p<05$

Table 2. 46 physicians viewed 1-4 video-recorded clinical performances of different second-year internal medicine residents and provided a Q-sort and Mini-CEX ratings in response. Q methodology was used to group the Q-sorts into Q-factors separately for each video. Participants were assigned to the Q-factor with which their Q-sort had the highest factor loading value. The Q-factors plus a label to summarize their content is provided in the second column. The number of Q-sorts grouped into each factor and mean of the 'overall clinical competence' Mini-CEX ratings is provided in the following two columns. The Q-factors were dummy-coded using Factor 1 as the reference category and entered as predictors in a linear regression model. Regressions were conducted separately for each video. Values from the regression model are presented in the last four columns starting with the variance explained ( $R$ square) expressed as a percentage. This is followed by the unstandardized coefficient $B$ value with the corresponding standard error in parentheses and the $t$ and $p$ values for the predictors.

\section{DISCUSSION}

The findings from the current triangulation study support all three of our hypotheses. First, multiple points of view for the same clinical performances were identified in a new dataset using $\mathrm{Q}$ methodology, with two factors (each representing two or three points of view) being identified for all four performances. Second, the content of the points of view reasonably matched the previously identified ${ }^{11}$ clusters of consensus derived from an LPA analysis of spontaneously generated statements by raters viewing the same performances. Finally, membership in one point of view compared to the other could be used to predict ratings, explaining on average over one third of the variance in the M ini-CEX ratings. 
Also consistent with our earlier findings, the points of view for a given video seemed to differ sometimes due to differential salience, such that different aspects of the performance were emphasized or the same aspect was given different emphasis within impressions, and sometimes due to rater disagreement, such that opposing impressions were formed regarding the same aspect of the performance. In prior medical education studies of inter-rater variation that had reported similar findings, open text responses or interviews were used to collect participants' assessment judgments. ${ }^{15-19}$ Therefore, a reasonable explanation for differences in the interpretations could have been that participants simply did not mention certain aspects of the performance. The design of Q methodology studies presents every participant with the same possibly relevant aspects of the performance and requires them to sort these aspects in relation to all others. As such, participants were explicitly presented with all the pertinent aspects of the performance. Even under these circumstances, we found rater variations in salience and interpretation regarding these aspects of performance. This is an important distinction because participants in Herbers and colleagues study ${ }^{16}$ provided less detailed responses when using an open text format than when they were prompted to provide more structured responses. The differences in how the same statements were ranked in this study support the explanation that participants differently emphasized or differently interpreted the same aspects of the performance. Moreover, the design of this study was able to more explicitly demonstrate that there can be clear disagreements amongst participants on certain aspects of the same performance. This was indicated when different participants placed the same statement on opposing sides of the score sheet giving it the opposite valence for the same performance.

We also found, consistent with our earlier work, that the factors or points of view generated by Q methodology in this study varied across videos. That is, there was not a small number of performance 'types' that raters seemed to be using to classify all of the performances in the videos. This variability is striking because we chose to have participants sort the same 44 statements for each of four different clinical performances. This design could have easily resulted in a small set of generic impressions being identified across performances. Instead, we continued to find two or three different points of view for each performance that were unique to each performance (with only one clear overlap as one point of view for Video 2 was similar to another for Video 7). In looking broadly at the nine different points of view that were created, they could be summarized in terms of differing judgments on interpersonal skills (IP) and clinical skills (CS) as the following: (low IP-low CS) or (low IP-HIGH CS) for video 1; (HIGH IP-HIGH CS) or (low IP-low CS) for videos 2 and 6; and (HIGH IP-low CS) or (HIGH IP-HIGH CS) for video 7. The finding of two dimensions underlying performance assessment judgments is consistent with prior medical education research. ${ }^{34-36}$ It also aligns well with the two-dimensional theory of social categorization which posits social judgments are made based on judgments of warmth-coldness versus competence- 
incompetence. ${ }^{20}$ However, it appears that each of the dimensions can be interpreted differently depending on the specifics of the encounter. For example, interpersonal skills could refer to counseling skills, humanism, or professionalism skills, but could also involve more inferential social judgments such as arrogant, lazy or likeable. Clinical skills could refer to interviewing skills, clinical judgment and/or clinical management but could also include inferences such as intelligent. This contextual variability in the aspects of performance that seem to comprise each of these two dimensions could account for the presence of contrasting factors that emerge for a given performance. Additionally, it suggests that two performances that might be identified as belonging in the same quadrant might have very different qualities. Thus, while the raters' interpretations of the performances might be mapped onto the two dimensional structure, whether this effort is of any great value remains in question, and the person model and nominal label frameworks might continue to be worth investigating.

This study adds important evidence to our line of research which suggests that rater variation may be more than simple idiosyncratic error. However, important questions remain. To date we have only looked at a small number of performances, and have only observed one performance for each trainee. Thus, we do not know whether each rater has a limited number of "categories" that he or she invokes repeatedly to interpret performances (and performers), nor the extent to which such sets of categories overlap across raters. Further, we have not explored the extent to which a given performer tends to evoke the same small subset of inferential categories across multiple performances. Such knowledge could have important implications for rater training and for learner feedback. Moreover, such knowledge could importantly inform our models of assessment and our models for determining the quality of that assessment. We need to seriously consider the idea that clinical performance is a complex social act; that assessments of such acts require many inferences to be made; and that the resulting assessment judgments are inherently interpretative and unlikely to meaningfully converge onto a single interpretation across observers. Given the multiplicity of possible assessment judgments, we are left to determine how we might reasonably compile and draw legitimate conclusions from them. This ultimately leads us to ponder, what features would be required for an assessment system to accommodate constructivist raters?

Contributors: This study was a component of AG's doctoral studies supervised by CPM vdV, KWE and GR. AG, CPM vdV, KWE and GR contributed to the conception of the study. All authors contributed to the design of the study. AG and SER analyzed the data and all authors contributed to interpretations of the findings. AG wrote the first draft of the paper and all authors substantially contributed to critical revision of subsequent drafts before approving the final manuscript. 
Acknowledgements: The authors wish to thank everyone who assisted with recruiting participants and especially those who took the time to participate in this study. We also wish to thank Rick Hoodenpyle for designing the online data collection system and hosting it on QSortOnline.

Funding: This study was funded by a National Board of Medical Examiners ${ }^{\circledR}\left(\right.$ NBME $\left.^{\circledR}\right)$ Edward J. Stemmler, M D M edical Education Research Fund Grant. The project does not necessarily reflect NBM E policy, and NBM E support provides no official endorsement.

Conflicts of Interest: none

Ethical approval: This study was approved by the Behavioural Research Ethics Board at the University of British Columbia and the Research Ethics Board at the University of Northern British Columbia. 


\section{REFERENCE}

1 Schuwirth LWT, Van der Vleuten CPM. Programmatic assessment: From assessment of learning to assessment for learning. M ed Teach 2011;33 (6):478-85.

2 Crossley J, Jolly B. Making sense of work-based assessment: Ask the right questions, in the right way, about the right things, of the right people. Med Educ 2012;46 (1):28-37.

3 Gingerich A, Kogan J, Yeates P, Govaerts M, Holmboe E. Seeing the 'black box' differently: Assessor cognition from three research perspectives. Med Educ 2014;48 (11):1055-68.

4 Williams RG, Klamen DA, McGaghie WC. Cognitive, social and environmental sources of bias in clinical performance ratings. Teach Learn M ed 2003;15 (4):270-92.

5 Tavares W, Eva KW. Exploring the impact of mental workload on rater-based assessments. Adv Health Sci Educ 2013;18 (2):291-303.

6 Gingerich A, Regehr G, Eva KW. Rater-based assessments as social judgments: Rethinking the etiology of rater errors. Acad M ed 2011;86 (10):S1-S7

7 Wood T. Exploring the role of first impressions in rater-based assessments. Adv Health Sci Educ 2014;19 (3):409-27.

8 Downing SM. Threats to the validity of clinical teaching assessments: What about rater error? Med Educ 2005;39 (4):353-5.

9 Albanese M. Challenges in using rater judgements in medical education. J Eval Clin Pract 2000;6 (3):305-19.

10 O'Neill TA, M LLarnon MJ, Carswell JJ. Variance components of job performance ratings. Human Performance 2015;28 (1):66-91.

11 Gingerich A, van der Vleuten CPM, Regehr G, Eva KW. Comparing the ability of social judgment theories to explain rater variance in $\mathrm{M}$ ini-CEX assessments. Forthcoming.

12 Gingerich A, van der Vleuten CP, Eva KW, Regehr G. More consensus than idiosyncrasy: Categorizing social judgments to examine variability in M ini-CEX ratings. Acad M ed 2014;89 (11):1510-9.

13 Miller DM, Wiley DE, Wolfe RG. Categorization methodology: An approach to the collection and analysis of certain classes of qualitative information. Multivar Behav Res 1986;21 (2):135.

14 Wiley DE. Latent partition analysis. Psychometrika 1967;32 (2):183-93.

15 Yeates P, O'Neill P, Mann K, Eva K. Seeing the same thing differently: Mechanisms that contribute to assessor differences in directly-observed performance assessments. Adv Health Sci Educ 2013;18 (3):325-41.

16 Herbers JE, Jr., Noel GL, Cooper GS, Harvey J, Pangaro LN, Weaver MJ. How accurate are faculty evaluations of clinical competence? J Gen Intern M ed 1989;4 (3):202-8.

17 Mazor KM, Zanetti M L, Alper EJ et al. Assessing professionalism in the context of an objective structured clinical examination: An in-depth study of the rating process. M ed Educ 2007;41 (4):331-40.

18 Kogan JR, Conforti L, Bernabeo E, lobst W, Holmboe E. Opening the black box of clinical skills assessment via observation: A conceptual model. Med Educ 2011;45 (10):1048-60.

19 Govaerts MJB, Wiel M WJ, Schuwirth LWT, Vleuten CPM, M uijtjens AM M. Workplace-based assessment: Raters' performance theories and constructs. Adv Health Sci Educ 2013;18 (3):375-96.

20 Fiske ST, Cuddy AJC, Glick P. Universal dimensions of social cognition: Warmth and competence. Trends in Cogn Sci 2007;11 (2):77-83.

21 Macrae CN, Bodenhausen GV. Social cognition: Thinking categorically about others. Annu Rev Psychol 2000;51 (1):93-120.

22 Mohr CD, Kenny DA. The how and why of disagreement among perceivers: An exploration of person models. J Exp Soc Psychol 2006;42 (3):337-49.

23 Park B, DeKay ML, Kraus S. Aggregating social behavior into person models: Perceiver-induced consistency. J Pers Soc Psychol 1994;66 (3):437-59.

24 Newman I, Ramlo S. Using Q methodology and q factor analysis in mixed methods research. In: Tashakkori A, Teddlie C, editors. Sage handbook of mixed methods in social and behavioral research: Second edition. Los Angeles and London: Sage Publications; 2010. p. 505-30. 
25 Watts S, Stenner P. Doing Q methodological research: Theory, method and interpretation. Thousand Oaks, California: Sage; 2012. 238 p.

26 Stephenson W. The study of behavior: Q-technique and its methodology. Chicago, Illinois: University of Chicago Press; 1953. $376 \mathrm{p}$.

27 Risdon A, Eccleston C, Crombez G, McCracken L. How can we learn to live with pain? A Qmethodological analysis of the diverse understandings of acceptance of chronic pain. Soc Sci Med 2003;56 (2):375-86.

28 Ramlo SE, Newman I. Q methodology and its position in the mixed methods continuum. Operant Subjectivity 2011;34 (3):173-92.

29 Watts S, Stenner P. Doing Q methodology: Theory, method and interpretation. Qual Res Psychol 2005;2 (1):67-91.

30 Watts S. Subjectivity as operant: A conceptual exploration and discussion. Operant Subjectivity 2011;35 (1):37-47.

31 Schmolck P. PQM ethod 2.35 software. adapted from Mainframe-Program QM ethod by John Atkinson at Kent State University; M ar 2014.

32 Brown SR. Political subjectivity: Applications of Q methodology in political science: Yale University Press; 1980. 355 p.

33 Field A. Discovering statistics using SPSS. Third ed. Thousand Oaks, California: Sage publications; 2009. $821 \mathrm{p}$.

34 Silber CG, Nasca TJ, Paskin DL, Eiger G, Robeson M, Veloski JJ. Do global rating forms enable program directors to assess the acgme competencies? Acad M ed 2004;79 (6):549-56.

35 Ramsey PG, Wenrich MD. Use of peer ratings to evaluate physician performance. JAMA 1993;269 (13):1655-60.

36 Nasca TJ, Gonnella JS, Hojat M Veloski J, Erdmann JB, Robeson M et al. Conceptualization and measurement of clinical competence of residents: A brief rating form and its psychometric properties.

MedTeach 2002;24 (3):299-303. 


\section{APPENDIX A}

\section{Video 1}

The Q sorts were submitted by 32 participants (14 male, 18 female; 16 internal medicine, 9 emergency medicine, 7 family medicine). In considering how many factors to extract, we noted 3 factors had eigenvalues greater than 1 (18.36, 2.55 and 1.04) but only a single factor exceeded Humphrey's rule. A 2 factor solution was chosen because it created two interpretable points of view and had 5 sorts that significantly loaded onto the second factor in the unrotated correlation matrix. Varimax rotation grouped 18 participants into factor 1 and 14 into factor 2 .

Although the 2 factors represent two distinct points of view of the resident and her performance, there were 22 consensus statements that did not differentiate the factors. Participants grouped into both factors agreed that she used a rapid-fire $(\# 4 ;+4$, $+4)$ checklist-type $(\# 6 ;+3,+3)$ questioning style that focused more on the task instead of the patient $(\# 14 ;+3,+4)$. She did not connect well with the patient $(\# 8 ;-4,-4)$ and the welcome and closing were not carried out with courtesy (\#43; $-3,-3)$. She came across as detached and distant (\#9; $+3,+2)$, hurried and not willing to listen, (\#42; -3; $3)$ not friendly or engaged ( $\# 15 ;-3,-3)$ or compassionate or genuinely concerned ( $\# 7$; $4,-4)$.

'Disinterested' Participants grouped into Factor 1 very much noticed that her body language was demonstrating disinterest $(\# 5 ; 4)$ and she seemed dismissive and disrespectful (\#12; +2) like she was just going through the motions (\#23; +2) and not trying very hard (\#28; -2). They had some concerns for how she will do in the long run (\#44; 2 ) as she asked too many closed and leading questions, $(\# 27 ;+2)$ didn't follow through on the responses $(\# 3 ;+2)$ and really didn't systematically consider all the differentials $(\# 40 ;-2)$.

The 18 participants ( 6 male and 12 female) sharing the Factor 1 point of view were from 11 different cities, 10 from internal medicine, 5 from emergency medicine and 3 from family medicine.

'Diligent competence' Participants grouped into Factor 2 had the impression that she was intelligent with solid clinical knowledge $(\# 38 ;+3)$ and performed a thorough, organized and efficient history $(\# 41 ;+3)$ while systematically considering all differentials $(\# 40 ;+2)$ to arrive at the diagnosis (\#29; -2). She seemed diligent and not lazy (\#24; -2) 
The 14 participants ( 8 male and 6 female) sharing the Factor 2 point of view were from 8 different cities, 6 from internal medicine, 4 from emergency medicine and 4 from family medicine.

There do not appear to be any appreciable differences in gender, location or type of medicine practiced between the participants grouped into the two factors.

\section{Video 2}

The Q sorts were submitted by 34 participants (18 male, 16 female; 18 internal medicine, 9 emergency medicine, 6 family medicine). In considering how many factors to extract, we noticed that 3 factors had eigenvalues greater than 1 (16.03, 3.91 and 1.60) but only 2 factors that exceeded Humphrey's rule and the third factor only had a single sort that loaded significantly in the unrotated matrix. We tried extracting and rotating the three factors and it resulted in nine sorts loading onto factor 3 but these sorts also loaded moderately well onto factor 1 . Examination of the content of Factor 3 found it to be very similar to the content of factor 1 and we determined it was not a distinct point of view. A 2 factor solution was chosen because two interpretable impressions were created. When the factors were rotated, Factor 1 grouped 28 participants and Factor 2 grouped 6.

These were two very distinct points of view. The only aspects the participants agreed on was that the resident carried out the welcome and closing with courtesy $(\# 44 ;+3$, +2 ) using body language that demonstrated interest $(\# 5 ;-4,-3)$ and she was not arrogant or overconfident $(\# 2 ;-3,-3)$.

'compassionate competence' Participants grouped into Factor 1 emphasized how the resident showed genuine concern and appeared to be compassionate $(\# 7+4)$ by the way she was willing to take time and listen $(\# 42 ;+4)$. She seemed friendly and engaged $(\# 15 ;+3)$ and connected well with the patient $(\# 8 ;+3)$ by not using a rapid-fire style of questioning (\#4; -3) or coming across as dismissive or disrespectful (\#12; -4). Her history was fairly thorough, organized and efficient $(\# 41 ;+2)$ and she seemed fairly intelligent with good clinical knowledge $(\# 38 ;+2)$ although she could have offered some non-pharmacological options ( $\# 20 ;+2)$.

The 28 participants ( 13 male, 15 female) sharing the Factor 1 point of view were from 15 different cities, 16 from internal medicine, 6 from emergency medicine and 6 from family medicine.

'incomplete attempt' Participants grouped into Factor 2 found many deficiencies in her performance. Of most concern, she jumped to treatment too quickly (\#22; +4$)$ and 
did not offer non-pharmacological options $(\# 20 ;+4)$. She did not fully investigate the chief complaint $(\# 11 ;+3)$ and although she asked relevant questions (\#26; -3) she did not ask enough of them so important details about the patient's life were missing (\#10; $+3)$. Her history was not thorough or organized or efficient (\#41; -2) and even though she used a somewhat checklist style of questioning $(\# 6 ;+2)$ questions were asked but not followed up on (\#3; +2$)$. She anchored to a diagnosis too early $(\# 1 ;+3)$ and did not work through all the differentials systematically (\#40; -4$)$. She did not connect well with the patient (\#8; -2) since she was more focused on the task than on him (\#14; +2)

The 6 participants ( 3 male, 3 female) sharing the Factor 2 point of view were from 5 different cities, 3 from internal medicine, 3 from emergency medicine and none from family medicine.

There do not appear to be any appreciable differences in gender, location or type of medicine practiced between the participants grouped into the two factors.

\section{Video 6}

The Q sorts were submitted by 32 participants (17 male 15 female; 17 internal medicine, 7 emergency medicine, 8 family medicine). In considering how many factors to extract, we noticed 3 factors had eigenvalues greater than $1(18.84,2.33,1.11)$ and all three had two or more significantly loading sorts but there were only two factors that barely met Humphrey's rule. A 3 factor solution was investigated and we discovered three sorts were confounded across the factors (i.e. did not load onto any factor). In addition, Factor 3 was a bipolar factor meaning that there were sorts that were both positively and negatively correlated with it. In fact, there was only a single sort that loaded onto each pole of the third factor. The content of the positively correlated sort was not sufficiently different from factor 1 to justify extracting Factor 3. A 2 factor solution was chosen because all the sorts loaded onto a factor and three interpretable points of view were created. The rotated 2 factor solution grouped 17 participants into Factor 1, 14 participants had sorts that positively correlated with Factor 2, and 1 participant's sort negatively correlated with Factor 2.

Factor 1 and the participants whose sorts were positively correlated with Factor 2 agreed that this resident anchored to a diagnosis too early $(\# 1 ;+3,+4)$ and jumped too quickly to treatment $(\# 22 ;+3,+3)$ without fully investigating the chief complaint ( $\# 11$; $+4,+4)$.

'incompetent' Participants grouped into Factor 1 thought the resident did not perform a thorough, organized or efficient history $(\# 41 ;-4)$ as he failed to inquire about the red flag symptoms $(13 ;+4)$ and did not systematically work through all the differential 
diagnoses (\#40; -4). He also omitted relevant tasks (\#35; +3) such as the physical exam and these deficiencies were significant enough that there was some concern he could be sued in the future $(\# 17 ;+2)$.

The 17 participants ( 9 male, 8 female) sharing the Factor 1 point of view were from 11 different cities, 10 from internal medicine, 5 from emergency medicine and 2 from family medicine.

'no rapport' Those participants whose Q sorts positively correlated with the Factor 2 view were especially concerned that he did not connect with the patient (\#8; -4) due to a lack of compassion and no display of genuine concern (\#7; -4). He came across as dismissive and disinterested $(\# 12 ;+3)$ and not willing to take the time to listen (\#42; 3 ) as well as somewhat detached and distant $(\# 9 ;+2)$.

The 14 participants ( 8 male, 6 female) sharing the Factor 2 point of view were from 12 different cities, 7 from internal medicine, 1 from emergency medicine and 6 from family medicine.

'friendly competent' The participant's point of view whose Q-sort negatively correlated with the Factor 2 could be represented as the opposite point of view of 'no rapport' described above. The point of view according to the participant's actual Q-sort and comments is that this resident should be fine in the future $(\# 44 ;+1)$ because he started with broad differentials (\#1; -4 ) and took his time with the questions $(\# 42 ;+3)$ so that he knew the diagnosis $(\# 29 ;+1)$ by the end of the interview. He showed genuine concern $(\# 7 ;+4)$, was friendly and engaged $(\# 15 ;+2)$ and not dismissive or disrespectful (\#12; -3). This participant completed all four videos; was female from emergency medicine with less than 5 years of extensive involvement with assessing residents.

There do not appear to be any appreciable differences in gender, location or type of medicine practiced between the participants grouped into the two factors.

\section{Video 7}

The Q sorts were submitted by 30 participants (16 male, 14 female; 15 internal medicine, 10 emergency medicine, 5 family medicine). In considering how many factors to extract, we noticed that 2 factors had eigenvalues greater than 1 (13.06 and 5.46), there were 2 factors that exceeded Humphrey's rule and 16 sorts significantly loaded onto Factor 2. Therefore, a 2 factor solution was chosen which when rotated grouped 17 participants into factor 1 and 13 into factor 2 . 


\section{CHAPTER 6}

The factors each represent a distinct point of view on the resident and his performance. Participants in both factors agreed he was friendly and engaged $(\# 15 ;+3,+3)$ with body language that demonstrated interest $(\# 5 ;-3,-3)$ and not at all dismissive or disrespectful $(\# 12 ;-3,-4)$ or arrogant or overconfident $(\# 2 ;-3,-4)$

'inexperienced incompetence' Participants grouped in Factor 1 did not believe the resident fully investigated the chief complaint $(\# 11 ;+4)$ because his history was unorganized, inefficient and not thorough (\#41; -4$)$, he did not systematically consider all the differentials (\#40; -4$)$ and had no idea what the diagnosis was $(\# 29 ;+4)$. He asked many questions that were not relevant $(\# 26 ;+2)$ while omitting relevant tasks (\#35; +2 ) such as inquiring about red flag symptoms $(\# 13 ;+3)$. He seemed inexperienced with this condition ( \#19; +3) and without solid clinical knowledge (\#38; -2).

The 17 participants ( 9 male, 8 female) sharing the Factor 1 point of view were from 10 different cities, 8 from internal medicine, 6 from emergency medicine and 3 from family medicine.

'competent rapport' Participants grouped in Factor 2 believed he performed a thorough, organized and efficient history $(\# 41 ;+2)$ while connecting well with the patient $(\# 8 ;+4)$ by being courteous with the welcome and closing (\#43; +4), appearing compassionate and showing genuine concern $(\# 7+3)$ and being willing to listen without hurrying (\#42; $+3)$. He came across as diligent ( $\# 24 ;-3)$, reliable and trustworthy $(\# 33 ;+2)$.

The 13 participants ( 7 male, 6 female) sharing the Factor 2 point of view were from 9 different cities, 7 from internal medicine, 4 from emergency medicine and 2 from family medicine.

There do not appear to be any appreciable differences in gender, location or type of medicine practiced between the participants grouped into the two factors. 
CHAPTER

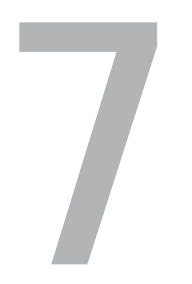

Discussion 

This dissertation described a program of research where the aim was to gain a different understanding of rater error by drawing on literatures and methodologies outside of medical education. Current understanding of rater error attributes variability in ratings to flawed rater judgments. Based on findings from social cognition research, we tentatively set aside the assumption that everyone should see and interpret the same things in the same way; and then we investigated the possibility that multiple raters of a single clinical performance may be able to share more than one legitimate interpretation, based on their different points of view. In other words, we began searching for-and contend we have found--more than one signal within the noise of variable ratings and assessment judgments.

Main research question 1:

\section{How have medical education researchers associated raters with "measurement error"?}

Psychometric models related to classical test theory are often used to analyze raterbased assessments in medical education. In these models rating variance can be attributed to the ratee, sources of systematic error variance and random measurement error. ${ }^{1-3}$ In classical test theory the ratee-related variance is referred to as "true score" variance, and although Generalizability theory has a unique conceptual framework, its universe score variance can be considered an analogue to true score variance. ${ }^{1,3-6}$ Both are essentially a type of consensus that is used to specify the legitimate component of rating variance, also known as the signal. ${ }^{7,8}$ It is not unusual for a higher proportion of error variance to be accounted for by rater judgments ${ }^{9-11}$ than by the true score variance of ratee performance ${ }^{12-14}$ for clinical performance assessments. This ratio has led to the rater-specific variance components being labeled "idiosyncratic rater effects" or "systematic rater bias" in occupational psychology research. ${ }^{15}$ These labels are also consistent with how rater error is conceptualized in medical education. ${ }^{16}$ Debate regarding how appropriate it is to attribute this variance to halo, bias and other mistakes of raters (and treat it as error of measurement) has initiated targeted investigations. ${ }^{2,17,18}$ For example, $\mathrm{O}^{\prime} \mathrm{Neill}$ and colleagues (2015) have found the rater component (i.e. hawk/severity or dove/leniency error) and rater $\mathrm{x}$ ratee component (i.e. relationship or person bias) are both equally large but they caution that, "Partitioning job performance ratings into reliable and idiosyncratic sources of variance is not analogous to partitioning performance-relevant and performance-irrelevant sources of variance." ${ }^{2(p .84)}$ This quotation warns against the common practice of equating statistically calculated rater error with evidence of rater generated mistakes. ${ }^{19,20}$

Regardless of the on-going debate, the defensibility of decisions based on clinical performance assessments is threatened when the true score variance is much less than the rater-specific variance. ${ }^{21}$ Therefore, our interest was piqued when in the social cognition literature Mohr and Kenny (2006) found that the rater $\mathrm{x}$ ratee component 
could be reduced (i.e. less error) and the ratee component increased (i.e. more signal) when it was taken into account that subgroups of raters had formed different impressions of the same ratee. ${ }^{22}$ These findings resonated with those of Govaerts and colleagues (2007) in medical education research who had raised the possibility for a plurality of true scores, rather than a single true score, due to the potential to have multiple legitimate interpretations of a performance. ${ }^{23}$ Taken together all of these findings demonstrate that raters have a large impact on the assigned ratings, sometimes larger than the ratee's performance, especially when it is assumed that all raters are trying to detect the one and only signal. However, if there was more than one signal to be found, then what looks like measurement noise under these assumptions may actually be construct relevant variance that is informative about the performance. In line with the sentiments of Lance and colleagues, "...we feel that some of their (implicit or explicit) assumptions have been too restrictive and have misled psychometric ratings researchers into painting the picture that performance ratings are routinely flawed, highly biased and in urgent need of repair. Rather, we suggest that performance ratings may not be as broken as they seem to be on the psychometric surface." $15(p .229)$

The program of research described in this dissertation investigated inter-rater variation and its findings did not support the explanation that rater error is the result of raters behaving idiosyncratically or being outliers. Rather, a very limited number of impressions for a single performance were uncovered because multiple raters described the same assessment information. Each cluster of consensus or shared point of view may indicate the presence of an identifiable "truth" or signal about the performance. However, there was always more than one impression identified for each performance because subgroups of raters described different aspects of the performance or differently described the same aspect of the performance. As such, each cluster of consensus represented a shared interpretation of the same performance and the presence of multiple impressions reflected variation in the interpretations for a single performance. To reiterate, when multiple people were asked to assess the same performance, there was definitely not a single global point of view; nor were there as many unique points of view as there were people making the judgments. If we use consensus as a proxy for signal, then we have found multiple signals.

Therefore, the main empirical finding of this dissertation, based on a proof of concept study and two investigations using different methodologies, can be summarized by a single equation: 


\section{E(signals $\mid n>30)=(1<$ clusters of consensus $<<n)$}

The expected value of signals, given that there were 30 or more raters, is estimated using clusters of consensus (which refers to both grouped social categorizations and/or points of view) to be greater than one and many fewer than the total number of raters. In other words, the number (and by proxy the number of signals) is much closer to one than it is to the number of people in the sample but it does not equal one.

This equation is offered to emphasize the overall finding of this entire program of research, to-date. There is nothing profound about the equation itself, and in fact, finding that there can be multiple perspectives on reality is not surprising to those with a constructivist stance. In constructivism, reality is not "true" in any absolute sense but instead is constructed through human intellect; therefore, there can be multiple realities that conflict with each other and be continuously revised. ${ }^{24}$ In terms of how we commonly analyze rater-based assessments, though, finding multiple clusters of consensus presents some troubling implications. Although this program of research did not empirically identify those implications or investigate possible options for accommodating them, we will offer our considered speculation on what they might be and how we might start to address them. First, we will critique the interpretation of this key finding.

The most critical limitation of this program of research, as with the broader psychometric tradition that this program of research is meant to address, is that we have used consensus of opinion as a proxy for signal; but, consensus does not guarantee accuracy in the judgments. The investigations described in this dissertation cannot empirically determine if the clusters of consensus represent multiple equally legitimate interpretations or signals, or not. This does not represent an oversight on our part but directly reflects the ongoing methodological debate in the psychology literature of what criterion to use as a comparison to determine rater judgment accuracy (and rating quality) as well as difficulties in how to construct the criterion itself. ${ }^{19,25,26}$ These difficulties are based in the paradox of trying to determine the accuracy of human judgment (and subsequently measure the quality of assigned ratings) when the concepts that are being judged can only be assessed through human judgment. This leads to research designs where human judgment of questionable accuracy is used as the gold standard from which to measure the quality of human judgment of unknown accuracy. In our studies, each cluster contained similar descriptions and evaluations of the performance made by multiple raters as well as similar social judgments that help to explain why the trainee is performing in that manner. The consensus may indicate that these features are important aspects of the performance to be assessed. This interpretation is supported with the finding that accounting for multiple impressions 
explains over one third of the rating variance, on average. This is a substantial amount of variance and reveals that, regardless of their relative legitimacy, clusters of consensus are associated with significantly different ratings.

Main research question 2:

\section{How well suited is human cognition for the tasks asked of raters in our current rater- based assessment designs?}

Inter-rater variability for a single performance results in measurement error that is often interpreted as evidence of faulty rater judgments. We propose a contrary interpretation based on our investigations. Classical test theory needs each rater to assess in exactly the same way, or be considered interchangeable, for measurement outcomes to be perfect. ${ }^{17}$ An important implication of finding multiple clusters of consensus for a single performance is that it is difficult to imagine raters belonging to a homogeneous population with each rater being randomly drawn from a pool of interchangeable raters. In general, it is difficult to imagine when human judgment could be considered interchangeable since humans do not perceive and remember the same things in the same way. ${ }^{27-32}$ As reviewed in Chapters 2 and 3, human cognition has limitations and propensities that will never allow it to be truly "objective" or replicable. Even more disappointing, by putting humans into a role that assumes their judgments are interchangeable, we are not making the best use of sophisticated human judgment. ${ }^{33-35} \mathrm{M}$ any of the limitations that prevent human cognition from being objective are also strengths that allow the highest priority features of an unpredictable and dynamic environment to be extracted from a sea of potentially important data points. ${ }^{36-}$ ${ }^{39}$ As such, it could be concluded that human cognition does not align well with the tasks specified for raters in current assessment designs.

In concordance with other concerns raised by researchers in the medical education community, ${ }^{40-45}$ finding clusters of consensus could be evidence that psychometric measurement models, based on theories of true score variance, are not ideal for analyzing rater judgments. This reversal in the interpretation of inter-rater variability no longer frames the problem as faulty raters who need to be trained to better perform their rating tasks. The problem now becomes what analysis to use if classical test theory cannot accommodate raters from two or more (unknown) populations with potentially irreconcilable interpretations of the object of measurement. Classical test theory is robust to assumption violations, ${ }^{46}$ and after re-evaluating the appropriateness of using it for rater-based assessments, we may decide its benefits outweigh its limitations. However, if we continue to use psychometrics then we should do so with the knowledge that using humans as raters does not fit the model's assumptions well and will likely result in high rater error. That being known, the presence of high rater error should not then be used as the evidence for flawed rater judgments. If we choose to 
use humans as raters then it is not fair to blame them for behaving like humans when they perform rating tasks.

Even if it were possible to train physicians to perfectly agree in their assessments and ratings of the performances, such that they were interchangeable raters, we cannot train patients in the same way. Thus, the required standardization and objectification needed to reduce inter-rater variation could eliminate relevant subjectivity in assessment judgments. ${ }^{42}$ Clinical work is a social activity that requires interactions with other humans. It may be that patients form a similar array of impressions to those represented by the clusters of consensus and this could be formally investigated in future research. If so, then trainees having the opportunity to learn about the multiple ways that their performances can be perceived could be useful assessment information as it might better prepare them for the diversity of real-world responses from patients. For feedback purposes, comments could be phrased to acknowledge that they reflect the individual rater's perception rather than phrased to be a statement of truth. This would make the subjective nature of the rater judgments more explicit and may better communicate conflicting rater judgments to trainees.

Main research question 3:

\section{How can the search for multiple signals within the noise of rating error variance be conducted when the commonly used statistics assume only one signal?}

This research required methodologies that would support each individual participant in the study to uniquely express their own opinion while providing ways to group similar opinions together into whatever number of groupings fit best. We needed to use lesser known methodologies, such as latent partition analysis and Q methodology, to accomplish this because they allowed for the possibility of multiple categorical answers to be identified. One methodology grouped free text responses and the other grouped more structured Q-sort responses but both objective assessment information and subjective social judgments could be grouped into clusters of consensus. These methodologies were borrowed from other fields but our findings are consistent with theirs. ${ }^{47-50}$

Finding multiple clusters of consensus within the responses for a single performance could reveal that raters are not as interchangeable as psychometric models may require, as previously discussed. A second major consideration is that it may reveal something about our conceptualization of competence. Competence is not directly observable so it must be inferred from observable behaviours and is considered a latent variable in psychometric models. ${ }^{51,52}$ Medical education tends to conceptualize competence as something that exists, has effects on the performance and can be measured. ${ }^{53-55}$ However, it has not been definitively determined what competence is, 
how it relates to cognitive models of learning or exactly how it should be connected to psychometric models. ${ }^{56}$ In fact, many aspects of competence are speculative. For example, changes in competence over time could be best characterized by continuous, monotonic increases in its growth; by it starting as something more basic and then differentiating into something that is highly specialized; or by it undergoing the qualitative changes needed to progress from novice to expert. ${ }^{51}$

A limitation of our methods is that we only assessed one performance per resident and consequently do not know if certain trainees tend to evoke similar impressions across different performances. If the same trainee did repeatedly receive the same set of varied assessment judgments for multiple performances, it could suggest competence itself can be differently perceived and/or that there are different types of competence to be perceived. The consistency of the varied judgments would add support for our assumption to use the clusters of consensus as a proxy for measurement signal. It could also add support to the conceptualization of competence as a latent variable that can be manifested in a performance and detected by raters. If, however, a given trainee were each to receive unique judgments across different performances, then either competence is not a stable latent construct that manifests through performance behaviours or raters are not able to detect indications of latent competence in a performance. This would be very problematic for rater-based assessments, especially those based on psychometric principles.

The clusters of consensus may also provide support for Marjan Govaerts' program of research (2007-13) that reported, "...multiple assessors will have multiple constructed realities ${ }^{\prime 17(p .1169)}$ when raters are seen as social perceivers through socio-cultural constructivist theories. ${ }^{23,58,59}$ If multiple realities reflect multiple true scores for any given performance then we may need to worry less about how well physicians perform the ratings tasks and more about the implications of treating ratings as noisy approximations of a single knowable truth. For example, when the assessment judgments of standardized patient (SP) raters were studied from a constructivist perspective, they were described as holistic representations of complex, nuanced and variable SPtrainee interactions. ${ }^{60}$ As such, the SP judgments and ratings reflected different realities and were complementary perspectives to the physician raters' perspectives. The description of SP judgments as being nuanced in response to the specific clinical encounter is reminiscent of context specificity in regards to the trainee's competence. In context specificity, there is something about the variations in context that enable a trainee's competence to manifest or not. ${ }^{61-63}$ This variability is considered measurement error, but notably, we do not tend to think of the context as being wrong or flawed or biased. ${ }^{64}$ There is some question, though, as to whether doing well in one context should be used to compensate for performing poorly in another context. ${ }^{44}$ 
If the clusters of consensus are thought of as representing multiple truths constructed by the physicians observing the performance, we would need to search for a model that could incorporate raters acting like constructivist assessment instruments. One place to start is by thinking about the clusters of consensus finding as comparable to the context specificity effect. ${ }^{65}$ If we were to think of raters as actively constructing a version of the reality, it might be reasonable to consider raters are part of the context for that performance. In this way, multiple raters observing the same performance would actually be part of different contexts. Our finding of consensus suggests they may not each create a unique construction of the reality but they are also unlikely to all converge on the same construction of truth. If this was considered analogous to context specificity then we could think of it as rater specificity rather than rater error. It may even be possible to combine a small sample of diverse assessment judgments into a composite score to make generalizable summative inferences ${ }^{66}$ This might mean we may need to consider how appropriate it is to average across differences in rater opinions to allow trainees rated poorly by one physician to compensate for that interpretation with a high rating from a different physician. Perhaps instead there may be some meaningful assessment information to be gleaned from trainees who tend to receive a wide spread of assessment judgments and ratings from different raters. ${ }^{67}$

Main research question 4:

\section{How could it be possible for conflicting or contradictory assessment judgments for the same performance to each contain legitimate assessment information?}

There appear to be at least two different mechanisms for the multiple clusters of consensus: differential salience, where the clusters represent emphasis on different aspects of the same performance; and rater disagreement, where the clusters represent opposing views of the same aspect of the performance. Since similar findings of differential salience and rater disagreement have been discussed by researchers in medical education, ${ }^{10,68-70}$ social cognition ${ }^{22}$ and aviation ${ }^{71}$ we believe the effect is prevalent even if it is not thoroughly understood. In terms of consensus being a reasonable proxy for signal, it is certainly easier to imagine differential salience representing multiple legitimate points of view than rater disagreement. In a clinical performance requiring the demonstration of numerous clinical skills and interactions with a patient, there are a multitude of different judgments that need to be made and combined to result in an assessment of the performance. It seems reasonable for subgroups of raters to find different aspects of the performance more important for their assessment judgments than other aspects of the performance and that this could lead to differential salience.

The mechanism of rater disagreement may be more difficult to imagine as representing multiple valid points of view. The assessment judgments contained within different clusters of consensus for a given performance frequently conflicted with each other. 
For example, one cluster of consensus could describe a thorough history and another that the history was incomplete. It is likely these types of disagreements that lead to rater judgments being viewed as flawed and requiring more rater training. ${ }^{69,70}$ We will spend some time contemplating how seemingly incompatible judgments could arise without being the result of raters' biases or mistakes. We offer an analogy as a way to conceptualize how rater disagreement could possibly reflect ratee-relevant information. There is a Cornsweet edge optical illusion ${ }^{72,73}$ on the back cover of this dissertation. When people are asked, "Are these two squares the same colour?" They say "NO". In reality, we perceive these two squares as different colours ${ }^{74}$ so answering that they are different colours is a valid and legitimate reflection of the way the stimulus can be perceived. However, also in reality, they are the same colour, the same wavelengths, the same pixel distribution. We can only see them as the same colour, though, if we eliminate the horizon and the angle in the picture. Go ahead and cover the middle of the picture where the two squares connect. Answering "YES" these squares are the same colour is also a valid and legitimate answer but it contradicts our previous correct answer and contradicts the phenomenology of the observed experience. Is the most valid answer the one that tells us about the picture under typical conditions or is it the one that tells us about the picture under specific conditions such as when the middle section is obscured? Analogously, as described in the previous section, if the rater was considered to be part of the context (e.g., given differences in their own past experiences), then which perception is the most valid?

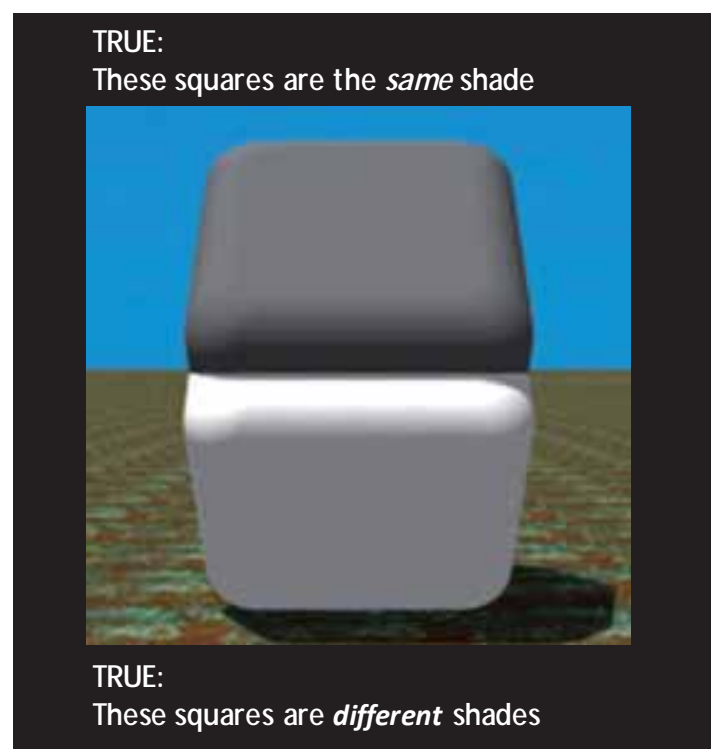

Figure 1 Cornsweet edge optical illusion Image courtesy of Purves, D. et al. (2002)."Why we see what we do." American Scientist 90(3): 236-243. 
Perceptual "errors" like these can be explained by a probabilistic theory of vision that proposes experiences from our past are used to decide how the object looks by choosing the best explanation for what would cause it to look that way. ${ }^{74,75}$ Or in other words, our perception can be described as sensory data being combined with prior beliefs to create a percept. ${ }^{75}$ In the Cornsweet illusion people make the same inferences and agree that the two squares are different shades of grey because we all have the same prior experiences with the horizon and edges and shadows. In real-world conditions, the lower grey square would be in shadow because we assume the sun shines from above. Therefore, we perceive the same shades of grey as different because our brain automatically compensates for the lower square being in shadow which implies its true shade must be lighter than the top square. ${ }^{76,77}$ We can be trained to recognize that this is an illusion, but even with this knowledge, we will still perceive the two squares as different shades of gray. We can speculate how this might translate into rater training situations. If we are asking physicians to ignore their subjective perceptions while observing a performance, in order to provide a more objective and decontextualized rating, it may be that they are responding with what they think might be the best response rather than what they experienced during the specific interaction. Trainees would then not have the opportunity to discuss how their interactions may be differently perceived by others, such as future patients and coworkers. Discussions regarding how competence manifests within a particular context may be as important for trainee learning and success, as are measurements of their latent competence. $^{18,78,79}$

The probabilistic explanation of perception also aligns with other social and psychological theories that suggest our own past experiences and current contexts influence what we perceive in a performance assessment. ${ }^{57,61,80,81}$ For example, in medical education research, assessment of the immediately preceding performance has been found to have an effect on how physicians assess the subsequent performance both under experimental conditions ${ }^{82,83}$ and with real-world assessment data. ${ }^{84}$ This appears to be an example where previous experiences may have an adverse effect on subsequent judgments by resulting in contrast effects in the ratings. It has been argued that our brains are inference machines, although the mechanism of how those inferences are generated (e.g. heuristics or Bayesian) is debated. ${ }^{85-88}$ Regardless of the mechanism, our findings support the theory that raters form inferences during performance assessments and can have opposing points of view on the same performance.

\section{Using physicians' judgments rather than ratings to assess competence}

Finding clusters of consensus within physicians' responses for a single clinical performance has led us to speculate about some of the implications for rater-based assessments. We have reasoned that physician raters may not be well-suited to provide a 
single cohesive judgment of competence. However, this does not mean they are incapable of providing important assessment information if we were to stop treating differences in their judgments as necessarily indicating error. These implications challenge us to try to find an assessment design that does not require averaging of ratings and can accommodate variable assessment judgments to make defensible decisions regarding trainee's ability to practice medicine. The psychometric model has provided the lens to see rater error so well and for so long that it is difficult to even consider what other lens might be available. We cannot provide the answer for a better assessment system to replace it, since this program of research did not empirically study assessment solutions. Nonetheless, we can provide an overview of a hypothetical model that could systematically codify physicians' judgments without the use of ratings. The examples that follow are used to illustrate possibilities for new directions rather than as answers of what future assessments should look like.

If we start with an oversimplified version of medical training, we could say that students enter medical school unable to think and perform as a doctor. The medical school and postgraduate programs offer them teaching and opportunities to practice their skills and at some point they become able to think and perform like a doctor. At the most fundamental level, what we need is an assessment system that can monitor each individual's progression towards becoming a doctor to help us make decisions about what learning opportunities they need and to identify what skills they have mastered. Ideally, we would be able to decide they are ready to practice autonomously as a doctor when enough evidence has been accumulated to prove that they are able to perform the majority of skills with the majority of patient types for the majority of conditions--like a doctor.

In the specific medical training example of workplace-based learning and assessment, physicians oversee trainees as they practice clinical skills. Ultimately, the supervising physician is responsible for the actions of the trainee but their oversight can take on many forms. ${ }^{89}$ Due to many constraints the supervising physician cannot directly observe the trainee at all times and needs to make decisions about how and when supervision is provided. They must also make decisions about what activities the trainee participates in and how they participate in them. For example, the trainee might observe, assist or take the lead in all or a portion of the encounter. Recent research has shown that physicians are willing and capable of making reports regarding their decisions on direct and indirect supervision of trainees. ${ }^{90}$ We are in need of an assessment system that can accommodate physicians forming variable judgments and making variable decisions regarding the same trainee. If we assume that physicians can recognize a clinical performance that resembles how a doctor would perform it and assume that there are many possible ways for how a doctor might perform it well ${ }^{91}$ then we 
can start to think about how we can take advantage of clinical oversight judgments for assessment purposes.

In continuing with an oversimplified version of assessment, we could ask supervising physicians a single question, "Is this trainee performing like a doctor in this encounter?" and think about how to use it to determine when the trainee had enough training to be a doctor. If competence was assumed to be a continual incremental progression then all of their answers would be "No" until a particular point in time when they all became "Yes". It is not that simple, of course, and we would need a model that could handle more complexity regarding competence and physician judgments. For one, as presented in the optical illusion analogy, we would expect physicians to form different judgments and comparisons based on their prior experiences. We would also expect the trainee to exhibit different levels of doctor-ness based on the difficulty of the clinical encounter and situation and the patient. Therefore, we would anticipate many No's mixed with many Yes's for many of the performances rather than a definite transition line from No to Yes.

The hypothetical dichotomous Yes-No response might be suitable for responding "No" for a performance that absolutely did not look doctor-like and "Yes" for a very doctorlike performance but there would be too many performances that would be better described as something like doctor-ish or doctor-esque or not-quite-like-a-doctor. If we were to acquire a very large dataset we could follow multiple physicians as they assessed multiple trainees over time. This would enable the total number of different clusters of consensus that are used by physicians to be determined. An infinite number would be problematic but given there was some similarity in two out of the nine points of view identified for four performances presented in Chapter 6, it is probable that there are a limited number of clusters of consensus. If clusters of consensus represent a way physicians categorize trainees with differing competence then it might be possible to align these classifications with corresponding learning opportunities that are aimed to improve their skill set. By asking physicians to report their assessment judgment by matching their impression to one of a limited number of 'diagnostic' trainee categories, it could remove the need for physicians to express their judgment as a rating.

It is likely reasonable to ask physicians to indicate which pre-defined cluster of consensus best represents their assessment impression of the trainee's performance for the clinical encounters they directly observe. ${ }^{92,93}$ But, of course, only a limited number of performances are or can be observed. This is where it might be useful to take advantage of the clinical oversight decisions as a supplement within the assessment design. It would require creating a database to document (nearly) every clinical encounter the trainee was involved in; whether they observed or participated in some way; 
and whether it was fully, partially or unobserved by a supervisor. A robust and efficient tracking system would be needed to compile the clinical oversight information but if created it could document the breadth and depth of coverage of clinical experiences for each trainee. This could be used to reveal gaps and inform mentors' and trainees' decisions regarding specific future clinical experiences. Ways to map the trainee's progression through the curriculum using supervisory decisions could be explored. An assessment system model, such as this, could accommodate different physicians making different supervisory decisions under similar conditions. In fact, it might enable investigations to determine if physicians have unique assessment patterns and what judgments tend to be made under different conditions. It would be interesting to see if these differences could be profiled and utilized as prior histories to predict their subsequent assessment decisions.

In an assessment system without ratings, faculty development would not need to include rater training and it could focus on updating physicians' clinical skills and best practices for patient care. In this way it would serve two purposes by improving physicians' skills and also enabling their judgments of trainees' performances to be compared with the latest performance expectations. The goal of faculty development would not be to help everyone agree on the one best way to perform within a particular clinical encounter. Rather, it could be to recognize possible ways of performing well within that clinical encounter. This might help facilitate a change in culture where physicians and trainees come to recognize that variability in the impressions formed are not necessarily wrong and needs to be considered as representative of possible ways in which their performance can be perceived by others. Sessions could also be used to show physicians the clinical oversight decisions made by their peers for the same trainees. This might help highly risk-averse supervisors to allow trainees to have more indirectly supervised opportunities. If a list of clusters of consensus or diagnostic trainee categorizations were to be used to help physicians to explicitly label the type of performance they observed, these could be introduced during a faculty development session as well.

Systematic analysis of non-rating related physician judgments would require a model different from classical test theory. For example, we could move away from inferring the trainee's latent competence based on between-trainee comparisons and try making personally relevant decisions for each trainee. We would need a model that could use simple clinical oversight decisions or diagnostic trainee categorizations to predict the trainee's future performance based on how they performed in the past. We could explore ways to use something like the yes-no comparison judgments to calculate the likelihood that the trainee will be perceived as performing like a doctor in unknown but relevant clinical encounters (with applicable patient types in specific situations). For example, it might be possible to build a dynamic model to answer a conditional 
statement like: Given that a particular physician is assessing this trainee's performance, what is the probability that a trainee with this pattern of past performances (in this specific clinical encounter that requires these skills with this type of patient) will be judged as performing like a doctor? It seems reasonable to decide that a trainee can perform like a doctor once the probability of them being perceived that way by a diversity of physicians reaches a certain threshold for a required set of patient types, clinical encounter types, et cetera. There are several examples of portfolios ${ }^{79,94}$ being used successfully within a programmatic assessment framework to robustly compile diverse assessment information and inform expert judgments to make high-stakes decisions. ${ }^{95,96}$ Competency assessment decisions based on conditional probability calculations (e.g. Bayesian models ${ }^{97-99}$ ) have been previously raised as a possibility for rater-based assessments in the medical education literature ${ }^{45,100}$ but to our knowledge have not yet been implemented.

\section{IN CONCLUSION}

Psychometric measurement models are commonly used to analyze rater-based assessments in medical education. In these models, "true score" variance can be considered as a type of consensus that is used to specify the legitimate component of rating variance, also known as the signal. We used consensus in raters' impressions as a proxy for measurement signal within their assessment judgments. However, such proxies are not guaranteed to be an accurate representation of the performance and determining their accuracy is hampered by methodological limitations. We were able to identify multiple clusters of consensus in the impressions for a given performance with content that was consistent across two samples of participants and two different methodologies. This finding may reveal something about how humans provide assessment judgments and ratings, the nature of rater judgments and/or the nature of competence. The finding of different, and even opposing, assessments of competence for the same performance could indicate that humans cannot function well as interchangeable raters in a psychometric model. The finding that raters can consistently form one of multiple impressions for the same performance could suggest that the latent construct of competence might be better conceptualized as having multiple "truths" constructed by the participants within a specific context rather than a single underlying truth. Finding contradictory judgements of the same performance within the clusters of consensus could suggest raters' judgments may be affected by prior experiences or intertwined with the context.

These findings pose challenges for designing an assessment system that can accommodate variable and subjective rater judgments to make robust decisions regarding trainee competence. Modern latent variable models or models using conditional prob- 


\section{CHAPTER 7}

abilities without ratings could be explored as possible alternative assessment systems. An overview of a hypothetical assessment design based on physicians' judgments and supervisory decisions, but not ratings, is given. In it, decisions would be based on conditional probabilities personalized for each trainee to make predictions of how they are likely to perform under specific, relevant future conditions. More thought and study is needed to fully understand what clusters of consensus represent and what they mean for rater-based assessments. 


\section{REFERENCES}

1 Crossley J, Davies H, Humphris G, Jolly B. Generalisability: A key to unlock professional assessment. Medical Education 2002;36 (10):972-8.

2 O'Neill TA, M cLarnon MJ, Carswell JJ. Variance components of job performance ratings. Human Performance 2015;28 (1):66-91.

3 Brennan RL. Generalizability theory. Educational M easurement: Issues and Practice 1992;11 (4):27-34.

4 Brennan RL. Generalizability theory and classical test theory. Applied Measurement in Education 2011;24:1-21.

5 M cGill D, van der Vleuten C, Clarke M. Supervisor assessment of clinical and professional competence of medical trainees: A reliability study using workplace data and a focused analytical literature review. Advances in Health Sciences Education 2011;16 (3):405-25.

6 Cronbach LJ, Shavelson RJ. My current thoughts on coefficient alpha and successor procedures. Educational and Psychological M easurement 2004;64 (3):391-418.

7 Murphy KR, De Shon R. Progress in psychometrics: Can industrial and organizational psychology catch up? Personnel Psychology 2000;53 (4):913-24.

8 Schmidt FL, Le H, Oh IS. Are true scores and construct scores the same? A critical examination of their substitutability and the implications for research results. International Journal of Selection and Assessment 2013;21 (4):339-54.

9 Elliot DL, Hickam DH. Evaluation of physical examination skills. Reliability of faculty observers and patient instructors. JAM A: The Journal Of The American Medical Association 1987;258 (23):3405-8.

10 Herbers JE, Jr., Noel GL, Cooper GS, Harvey J, Pangaro LN, Weaver MJ. How accurate are faculty evaluations of clinical competence? Journal Of General Internal M edicine 1989;4 (3):202-8.

11 Noel GL, Herbers JE, Caplow M P, Cooper GS, Pangaro LN, Harvey J. How well do internal medicine faculty members evaluate the clinical skills of residents? Annals of Internal M edicine 1992;117 (9):757-65.

12 Cook DA, Beckman TJ, Mandrekar JN, Pankratz VS. Internal structure of mini-cex scores for internal medicine residents: Factor analysis and generalizability. Advances in Health Sciences Education 2010;15 (5):633-45.

13 Margolis MJ, Clauser BE, Cuddy M M, Ciccone A, Mee J, Harik P et al. Use of the mini-clinical evaluation exercise to rate examinee performance on a multiple-station clinical skills examination: A validity study. Academic M edicine: Journal Of The Association Of American M edical Colleges 2006;81 (10 Suppl):S56-S60.

14 Hill F, Kendall K, Galbraith K, Crossley J. Implementing the undergraduate mini-cex: A tailored approach at southampton university. Medical Education 2009;43 (4):326-34.

15 Lance CE, Hoffman BJ, Gentry WA, Baranik LE. Rater source factors represent important subcomponents of the criterion construct space, not rater bias. Human Resource Management Review 2008;18 (4):223.

16 Downing SM. Threats to the validity of clinical teaching assessments: What about rater error? Medical Education 2005;39 (4):353-5.

17 Murphy KR, DeShon R. Interrater correlations do not estimate the reliability of job performance ratings. Personnel Psychology 2000;53 (4):873-900.

18 Berendonk C, Stalmeijer RE, Schuwirth LWT. Expertise in performance assessment: Assessors' perspectives. Advances In Health Sciences Education 2013;18 (4):559-71.

19 Funder DC. Errors and mistakes: Evaluating the accuracy of social judgment. Psychological Bulletin 1987;101 (1):75-90.

20 Murphy KR, Balzer WK. Rater errors and rating accuracy. Journal of Applied Psychology 1989;74 (4):619-24.

21 Downing SM. Reliability: On the reproducibility of assessment data. Medical Education 2004;38 (9):1006-12.

22 Mohr CD, Kenny DA. The how and why of disagreement among perceivers: An exploration of person models. Journal of Experimental Social Psychology 2006;42 (3):337-49. 
23 Govaerts MJB, van der Vleuten CPM, Schuwirth LWT, Muijtjens AMM. Broadening perspectives on clinical performance assessment: Rethinking the nature of in-training assessment. Advances in Health Sciences Education 2007;12 (2):239-60.

24 Guba EG, Lincoln YS. Competing paradigms in qualitative research. Handbook of qualitative research 1994. p. 105-17.

25 Sulsky LM, Balzer WK. M eaning and measurement of performance rating accuracy: Some methodological and theoretical concerns. Journal of Applied Psychology 1988;73 (3):497-506.

26 Kenny DA. A general model of consensus and accuracy in interpersonal perception. Psychological Review 1991;98 (2):155-63.

27 Quiroga RQ, Pedreira C. How do we see art: An eye-tracker study. Frontiers in human neuroscience 2011;5.

28 Markovic J, Anderson AK, Todd RM. Tuning to the significant: Neural and genetic processes underlying affective enhancement of visual perception and memory. Behavioural Brain Research 2014;259 (0):229-41.

29 Aditya S, Aloimonos Y, Baral C, Fermuller C, Yang Y. Visual common-sense for scene understanding using perception, semantic parsing and reasoning. Twelfth Commonsense Symposium 2014.

30 Milner AD, Goodale MA. Two visual systems re-viewed. Neuropsychologia 2008;46 (3):774-85.

31 Williams RG, Klamen DA, M cGaghie WC. Cognitive, social and environmental sources of bias in clinical performance ratings. Teaching \& Learning in M edicine 2003;15 (4):270-92.

32 Tavares W, Eva KW. Exploring the impact of mental workload on rater-based assessments. Advances in Health Sciences Education 2013;18 (2):291-303.

33 Corbetta M, Patel G, Shulman GL. The reorienting system of the human brain: From environment to theory of mind. Neuron 2008;58 (3):306-24.

34 Gigerenzer G, Brighton H. Homo heuristicus: Why biased minds make better inferences. Topics in Cognitive Science 2009;1 (1):107-43.

35 Rosset E, Rottman J. The big 'whoops!'in the study of intentional behavior: An appeal for a new framework in understanding human actions. Journal of Cognition and Culture 2014;14 (1-2):27-39.

36 Hofstadter D. I am a strange loop. New York, NY US: Basic Books; 2007.

37 Brighton H, Gigerenzer G. Homo heuristicus: Less-is-more effects in adaptive cognition. Malaysian Journal of Medical Sciences 2012;19 (4):6-16.

38 Kruglanski AW, Gigerenzer G. Intuitive and deliberate judgments are based on common principles. Psychological Review 2011;118 (1):97-109.

39 Klein G. Streetlights and shadows: Searching for the keys to adaptive decision making. Cambridge, MA: MIT Press; 2009.

40 Eva KW, Hodges BD. Scylla or charybdis? Can we navigate between objectification and judgement in assessment? Medical Education 2012;46 (9):914-9.

41 Hodges B. Assessment in the post-psychometric era: Learning to love the subjective and collective. Medical Teacher 2013;35 (7):564-8.

42 Hodges B. M edical education and the maintenance of incompetence. Medical Teacher 2006;28 (8):690-6.

43 Kuper A, Reeves S, Albert M, Hodges BD. Assessment: Do we need to broaden our methodological horizons? Medical Education 2007;41 (12):1121-3.

44 Schuwirth LW, van der Vleuten CP. Assessing competence. In: Hodges BD, Lingard LA, editors. The question of competence: Reconsidering medical education in the twenty-first century. First ed. Ithaca and London: ILR Press-Cornell University Press; 2012. p. 113-30.

45 Schuwirth LWT, van der Vleuten CPM. A plea for new psychometric models in educational assessment. Medical Education 2006;40 (4):296-300.

46 Suen $\mathrm{H}$, Lei P. Classical versus generalizability theory of measurement. Educational Measurement 2007:4:1-13.

47 Miller DM, Wiley DE, Wolfe RG. Categorization methodology: An approach to the collection and analysis of certain classes of qualitative information. Multivariate Behavioral Research 1986;21 (2):135.

48 Willson VL, Palmer DJ. Latent partition analysis of attributions for actual achievement. American Educational Research Journal 1983;20 (4):581-9. 
49 Watts S, Stenner P. Doing q methodology: Theory, method and interpretation. Qualitative Research in Psychology 2005;2 (1):67-91.

50 McKeown BF, Thomas DB. Q methodology (quantitative applications in the social sciences series, vol. 66). Thousand Oaks, CA: Sage; 1988.

51 Blömeke S, Gustafsson J-E, Shavelson RJ. Beyond dichotomies: Competence viewed as a continuum. Zeitschrift für Psychologie 2015;223 (1):3-13.

52 De Champlain AF. A primer on classical test theory and item response theory for assessments in medical education. Medical Education 2010;44 (1):109-17.

53 Borsboom D. Psychometric perspectives on diagnostic systems. Journal of Clinical Psychology 2008;64 (9):1089-108.

54 Borsboom D, Mellenbergh GJ, Van Heerden J. The theoretical status of latent variables. Psychological Review 2003;110 (2):203.

55 Schuwirth LWT, van der Vleuten CPM. General overview of the theories used in assessment: Amee guide no. 57. M edical Teacher 2011;33 (10):783-97.

56 Koeppen K, Hartig J, Klieme E, Leutner D. Current issues in competence modeling and assessment. Zeitschrift für Psychologie/Journal of Psychology 2008;216 (2):61-73.

57 Govaerts M, Vleuten CPM. Validity in work-based assessment: Expanding our horizons. M edical Education 2013;47 (12):1164-74.

58 Govaerts MJB, Schuwirth L, Van der Vleuten CP, Muijtjens AM M. Workplace-based assessment: Effects of rater expertise. Advances in Health Sciences Education 2011;16 (2):151-65.

59 Govaerts MJB, Wiel M WJ, Schuwirth LWT, Vleuten CPM, M uijtjens AM M. Workplace-based assessment: Raters' performance theories and constructs. Advances in Health Sciences Education 2013;18 (3):375-96.

60 Johnston JL, Lundy G, McCullough M, Gormley GJ. The view from over there: Reframing the osce through the experience of standardised patient raters. Medical Education 2013;47 (9):899-909.

61 Durning SJ, Artino AR. Situativity theory: A perspective on how participants and the environment can interact: AM EE Guide No. 52. Medical Teacher 2011;33 (3):188-99.

62 Durning SJ, Artino AR, Jr., Pangaro LN, van der Vleuten C, Schuwirth L. Redefining context in the clinical encounter: Implications for research and training in medical education. Academic Medicine 2010;85 (5):894-901.

63 Eva KW. On the generality of specificity. Medical Education 2003;37 (7):587-8.

64 Kreiter CD, Bergus GR. Case specificity: Empirical phenomenon or measurement artifact? Teaching \& Learning in Medicine 2007;19 (4):378-81.

65 Vleuten CPM. When I say ... Context specificity. M edical Education 2014;48 (3):234-5.

66 Moonen-van Loon J, Overeem K, Donkers H, Van der Vleuten C, Driessen E. Composite reliability of a workplace-based assessment toolbox for postgraduate medical education. Advances in Health Sciences Education 2013;18 (5):1087-102.

67 Crossley J. Validity and truth in assessment. M edical Education 2013;47 (12):1152-4.

68 Yeates P, O'Neill P, Mann K, Eva K. Seeing the same thing differently: Mechanisms that contribute to assessor differences in directly-observed performance assessments. Advances in Health Sciences Education 2013;18 (3):325-41.

69 Kogan JR, Conforti L, Bernabeo E, lobst W, Holmboe E. Opening the black box of clinical skills assessment via observation: A conceptual model. M edical Education 2011;45 (10):1048-60.

70 Mazor KM, Zanetti M L, Alper EJ, Hatem D, Barrett SV, M eterko V et al. Assessing professionalism in the context of an objective structured clinical examination: An in-depth study of the rating process. M edical Education 2007;41 (4):331-40.

71 Weber DE, Mavin TJ, Roth W-M, Henriqson E, Dekker SW. Exploring the use of categories in the assessment of airline pilots' performance as a potential source of examiners' disagreement. Journal of Cognitive Engineering and Decision Making 2014;8 (3):248-64.

72 Cornsweet TN. Visual perception. Oxford, England: Academic Press; 1970.

73 Purves D, Lotto RB, Nundy S. Why we see what we do. American Scientist 2002;90 (3):236-43. 
74 Purves D, Shimpi A, Lotto RB. An empirical explanation of the cornsweet effect. The Journal of Neuroscience 1999;19 (19):8542-51.

75 Brown H, Friston KJ. Free-energy and illusions: The cornsweet effect. Frontiers in Psychology 2012;3:43.

76 Adelson EH. Perceptual organization and the judgement of brightness. Science 1993;262:2042-4.

77 Todorović D. Lightness, illumination, and gradients. Spatial Vision 2006;19 (2-4):219-61.

78 Boud D, M olloy E. Rethinking models of feedback for learning: The challenge of design. Assessment \& Evaluation in Higher Education 2013;38 (6):698-712.

79 Bok HG, Teunissen PW, Favier RP, Rietbroek NJ, Theyse LF, Brommer H et al. Programmatic assessment of competency-based workplace learning: When theory meets practice. BM C M edical Education 2013;13 (1): 123.

80 Delandshere G, Petrosky AR. Assessment of complex performances: Limitations of key measurement assumptions. Educational Researcher 1998;27 (2):14-24.

81 Gipps C. Socio-cultural aspects of assessment. Revi Res Educ 1999;24:355-92.

82 Yeates P, O'Neill P, Mann K, Eva KW. Effect of exposure to good vs poor medical trainee performance on attending physician ratings of subsequent performances. JAM A 2012;308 (21):2226-32.

83 Yeates P, O'Neill P, Mann K, W Eva K. 'You're certainly relatively competent': Assessor bias due to recent experiences. Medical Education 2013;47 (9):910-22.

84 Yeates P, M oreau M, Eva K. Are examiners' judgments in osce-style assessments influenced by contrast effects? Academic M edicine 2015.

85 Marewski JN, Gaissmaier W, Gigerenzer G. Good judgments do not require complex cognition. Cognitive processing 2010;11 (2):103-21.

86 Bowers JS, Davis C). Bayesian just-so stories in psychology and neuroscience. Psychological Bulletin 2012;138 (3):389.

87 Moutoussis M, Fearon P, El-Deredy W, Dolan RJ, Friston KJ. Bayesian inferences about the self (and others): A review. Consciousness and Cognition 2014;25 (0):67-76.

88 Baker CL, Tenenbaum JB. M odeling human plan recognition using bayesian theory of mind. Plan, activity, and intent recognition: Theory and practice 2014:177-204.

89 Kennedy TJT, Lingard L, Baker GR, Kitchen L, Regehr G. Clinical oversight: Conceptualizing the relationship between supervision and safety. JGIM : Journal of General Internal Medicine 2007;22 (8):1080-5.

90 Weller J, Misur M, Nicolson S, Morris J, Ure S, Crossley J et al. Can i leave the theatre? A key to more reliable workplace-based assessment. British journal of anaesthesia 2014:aeu052.

91 Greco EF, Regehr G, Okrainec A. Identifying and classifying problem areas in laparoscopic skills acquisition: Can simulators help? Academic M edicine 2010;85 (10):S5-S8.

92 Regehr G, Bogo M, Regehr C, Power R. Can we build a better mousetrap? Improving the measures of practice performance in the field practicum. Journal of Social Work Education 2007;43 (2):327-43.

93 Regehr G, Ginsburg S, Herold J, Hatala R, Eva K, Oulanova O. Using "standardized narratives" to explore new ways to represent faculty opinions of resident performance. Academic M edicine 2012;87 (4):419-27.

94 Dannefer EF, Henson LC. The portfolio approach to competency-based assessment at the cleveland clinic lerner college of medicine. Academic M edicine 2007;82 (5):493-502.

95 Heeneman S, Oudkerk Pool A, Schuwirth LWT, van der Vleuten CPM, Driessen EW. The impact of programmatic assessment on student learning: Theory versus practice. in press.

96 Van der Vleuten C, Schuwirth L, Driessen E, Dijkstra J, Tigelaar D, Baartman L et al. A model for programmatic assessment fit for purpose. Medical Teacher 2012;34 (3):205-14.

97 Koenig A, Iseli M, Wainess R, Lee JJ. Assessment methodology for computer-based instructional simulations. Military M edicine 2013;178 10 (Suppl 1):47-54.

98 Di Pietro L, Guglielmetti Mugion R, Musella F, Renzi MF, Vicard P. Reconciling internal and external performance in a holistic approach: A bayesian network model in higher education. Expert Systems with Applications 2015;42 (5):2691-702.

99 Hoijtink H, Béland S, Vermeulen JA. Cognitive diagnostic assessment via bayesian evaluation of informative diagnostic hypotheses. Psychological M ethods 2014;19 (1):21-38. 
100 van der Vleuten CPM, Schuwirth LWT, Scheele F, Driessen EW, Hodges B. The assessment of professional competence: Building blocks for theory development. Best Practice \& Research Clinical Obstetrics \& Gynaecology 2010;24 (6):703-19. 

Summary 


\section{CHAPTER 1}

The program of research described in this dissertation was motivated by a desire to improve the utility of rater-based assessments. It germinated out of a curiosity of how multiple people could observe the same performance and make very different interpretations, judgments and assessments of that performance. We started to look for explanations for why it is so difficult to support raters to make consistent assessment judgments. This questioning led to the need to better understand how raters make judgments and prompted a journey into the psychology literatures to learn more about human judgment in social situations.

We searched for comparable circumstances where variability in judgments for the same performance had been studied and found an extensive research collection in the field of impression formation. In this literature it had been discovered that people form different impressions of the same target person but they were not idiosyncratic impressions. Instead, multiple people formed one of limited number of impressions for a person. This was intriguing because there was consensus of opinion but not one global point of consensus. Given the way our rater-based assessments are designed and analyzed, if something similar was occurring for clinical performance assessments, then these multiple points of consensus would be interpreted as measurement error. Hence, we were motivated to study the contribution of physicians' judgments to interrater variability for workplace-based assessments.

\section{CHAPTER 2}

This paper was written after Chapter 3 and it gives a broader review of the literature pertaining to inter-rater variation. It developed out of conversations with an international group of researchers sharing a common interest in rater cognition. Given the similar themes among our recent publications, Dr. Eric Holmboe had encouraged the group to meet, share ideas and discuss ways in which we could collaborate. During these discussions it became apparent that we were all thinking about the causes of inter-rater variation, and subsequently the solutions for it, in very different ways. The literature review is a result of us defining, comparing and contrasting our different perspectives in understanding variability in ratings and judgments. The three resulting perspectives are not mutually exclusive but they do represent some incompatible ideas. In the first two perspectives, variability is seen as the result of raters being under-trained or due to inherent limitations of human cognition. Either way, variability is not ideal, and as a result, is something to be minimized or compensated for. The third perspective better represents the philosophy of this dissertation in that variability is seen as potentially resulting from informed differences of opinion by experts judging a 
complex social interaction. It is this paper that provides the context in which our program of research exists; how it aligns with, and is differentiated from, other rater cognition investigations.

\section{CHAPTER 3}

This is the paper that marked the beginning of our program of research. It summarizes our understanding of the research investigating how social categorization and social judgment processes contribute to variability in the impressions we form of others. It is drawn from an expansive collection of literatures broadly considered social psychology but more specifically referred to as the domain of social cognition. Within the numerous research studies that were reviewed, there were findings of consensus and agreement amidst the very subjective and potentially idiosyncratic social judgments. We describe three overarching theories of social categorization that each propose different mechanisms for how impressions are formed. We, as humans, must have evolved to benefit from our skills in observation, perception, judgment and decision-making during social interactions. However, these processes may not align well with the tasks asked of raters in rater-based assessments and contribute to variability in ratings. These literatures provided us with the theoretical and methodological support to begin investigating rater cognition in clinical performance assessments.

\section{CHAPTER 4}

This article represents a proof of concept as we conceptually replicated a social cognition study by translating it into the medical education context. It also introduces the methodology of latent partition analysis used to search for multiple clusters of consensus within the opinions offered by physicians. Consistent with the social cognition literature, we were able to identify more than one impression, each described by multiple physicians, for every trainee. Despite the possibility for each physician to have provided a unique social impression of the trainee, we identified as few as two and no more than five distinct impressions for each trainee. The content across the set of impressions for a given trainee was not merely different but often contained conflicting judgments. We found that physicians describing similar social judgments also assigned more similar ratings. The findings suggested there may be multiple signals within the noise of inter-rater variability and set the way for further investigations.

\section{CHAPTER 5}

Having established a methodology for identifying clusters of consensus within physicians' comments regarding a clinical performance, we were able to extend the investi- 
gations to include all three theories of social categorization described in Chapter 3. In comparing their relative ability to explain variance in clinical performance ratings, we discovered each could account for significant rating variance. That is, each theory of categorization could be used to group physicians' comments pertaining to a single performance into 2-4 distinct categories. When we examined the content of the predictive categories, we observed that, consistent with other medical education research findings, the differences in raters' impressions reflected disagreement regarding the same aspect of performance as well as emphasis on different aspects of a single clinical performance. We had identified clusters of consensus that appeared to be meaningfully different interpretations of a single performance but the findings were exploratory and needed to be further tested.

\section{CHAPTER 6}

In this article we describe our efforts to triangulate the clusters of consensus finding using a new set of participants and a different methodology. Once again we find two or three different points of view for the same clinical performance, that when accounted for, explain a substantial proportion of variance. The content of the points of view was consistent with the content of the previously identified clusters of consensus and it confirmed that physicians can have opposing judgments of the same aspect of the performance. The consistency of these findings prompts us to seriously consider that we may need to conceptualize physicians functioning as constructivist raters rather than post-positivist assessment instruments.

\section{CHAPTER 7}

In the final chapter we further consider the implications of finding clusters of consensus within variable assessment judgments. Multiple points of consensus may reveal competence could be better conceptualized as having multiple signals or "truths". If so, our measurement models will need to be interpreted in terms of multiple "true scores". This finding presents challenges for designing an assessment system that can analyze variable and subjective assessment judgments to contribute to robust decision-making regarding trainee competence. We discuss possible non-psychometric approaches for systematic analysis of physicians' judgments regarding trainee competence in terms of a fictitious assessment system. Further investigations are needed to more fully understand what clusters of consensus represent and what the implications may be for rater-based assessments. 
Samenvatting (Summary in Dutch) 


\section{HOOFDSTUK 1}

Een wens om de bruikbaarheid van toetsen waarvan de beoordeling afhankelijk is van beoordelaars te verbeteren, vormde de aanleiding voor het onderzoeksprogramma dat in dit proefschrift beschreven wordt. Het onderzoek kwam voort uit een nieuwsgierigheid naar hoe meerdere mensen bij het observeren van dezelfde prestatie tot geheel verschillende interpretaties, oordelen en beoordelingen van die prestatie konden komen. We gingen op zoek naar aanwijzingen die konden verklaren waarom het zo moeilijk is consequentheid bij het toekennen van beoordelingen onder beoordelaars te bevorderen. Door deze vragen te stellen ontstond behoefte aan meer inzicht in de wijze waarop beoordelaars oordelen vormen, wat ons ertoe bracht de psychologische literatuur in te duiken om zo meer te weten te komen over menselijke oordeelvorming in sociale situaties.

Zoekend naar vergelijkbare situaties waarbij afwijkende beoordelingen van dezelfde prestatie waren onderzocht, vonden we een uitgebreide verzameling onderzoek op het gebied van indrukvorming. In deze literatuur was men tot de ontdekking gekomen dat mensen weliswaar verschillende indrukken vormden van dezelfde doelpersoon, maar deze indrukken bleken niet persoonsgebonden te zijn; in plaats daarvan werd steeds een beperkt aantal indrukken van een persoon gevormd waarbij meerdere mensen eenzelfde indruk deelden. Dit boeide ons, omdat er eensgezindheid bleek te bestaan, maar er tegelijkertijd geen algemeen gedeelde mening kon worden aangewezen. Als hier bij de beoordeling van klinisch handelen ook sprake van zou zijn, dan zouden deze verschillende punten van eensgezindheid, gezien de manier waarop onze beoordelaarsafhankelijke toetsen zijn ontworpen en worden geanalyseerd, worden aangemerkt als meetfouten. Dit inspireerde ons te onderzoeken hoe de werkplekbeoordelingen van artsen bijdroegen aan beoordelingsverschillen tussen beoordelaars.

\section{HOOFDSTUK 2}

In dit artikel dat na hoofdstuk 3 geschreven werd, wordt de literatuur over beoordelingsverschillen tussen beoordelaars in ruimere zin besproken. Het kreeg gestalte middels het voeren van een aantal gesprekken met een internationale groep onderzoekers die een belangstelling voor beoordelaarcognitie deelden. Aangezien een aantal van onze recente publicaties op ongeveer dezelfde thema's gestoeld waren, had Dr. Eric Holmboe de groep aangemoedigd bijeen te komen, ideeën uit te wisselen en samenwerkingsmogelijkheden te bespreken. Tijdens deze gesprekken werd duidelijk dat we allemaal heel anders dachten over de oorzaken van de verschillen tussen beoordelaars en bijgevolg ook over de betreffende oplossingen. Het literatuuronderzoek toont het resultaat van onze inspanning om onze verschillende perspectieven ten aanzien van waarderings- en beoordelingsverschillen, en ons begrip daarvan, te definiëren, verge- 
lijken en contrasteren. De drie perspectieven die hieruit voortvloeiden sluiten elkaar niet uit, doch zij vertegenwoordigen enkele tegenstrijdige ideeën. Bij de eerste twee perspectieven wordt variabiliteit toegeschreven aan een scholingstekort onder beoordelaars of aan natuurlijke beperkingen van de menselijke cognitie. Hoe het ook zij, variabiliteit is niet ideaal en dient dan ook zoveel mogelijk beperkt of ondervangen te worden. Het derde perspectief drukt de filosofie van dit proefschrift beter uit, in zoverre dat het variabiliteit beschouwt als iets dat mogelijk ontstaat doordat deskundigen die een ingewikkelde sociale interactie beoordelen op doordachte wijze van mening verschillen. Dit artikel biedt de context waarin ons onderzoeksprogramma ligt ingebed en laat zien waar de overeenkomsten en verschillen liggen met ander onderzoek dat toegespitst is op beoordelaarcognitie.

\section{HOOFDSTUK 3}

Met dit artikel werd het begin van ons onderzoeksprogramma ingeluid. Het vat samen hoe wij uitleg hebben gegeven aan het onderzoek naar de vraag hoe sociale categorisatie en sociale beoordelingsprocessen een verscheidenheid aan indrukken die we van anderen vormen in de hand werken. Het is ontleend aan een uitgebreide verzameling literatuur die onder de algemene noemer "sociale psychologie" te brengen valt, maar meer specifiek tot het domein van de sociale cognitie wordt gerekend. In de vele onderzoekstudies die we bestudeerd hebben, werden onder de erg subjectieve en mogelijk persoonsgebonden sociale beoordelingen signalen van consensus en overeenstemming onderscheiden. We beschrijven drie overkoepelende theorieën van sociale categorisatie die de manier waarop indrukken gevormd worden elk op een andere manier uitleggen. De mensheid heeft zich waarschijnlijk zo ontwikkeld dat ons vermogen te observeren, waarnemen, beoordelen en besluiten tijdens sociale interacties zo goed mogelijk wordt benut. Deze processen zouden echter wel eens in strijd kunnen zijn met de taken die bij beoordelaarsafhankelijke toetsen van beoordelaars verwacht worden en bijdragen aan de totstandkoming van afwijkende waarderingen. Deze literatuur leverde ons de theoretische en methodologische steun die nodig was om een onderzoek te kunnen instellen naar beoordelaarcognitie bij het beoordelen van klinisch handelen.

\section{HOOFDSTUK 4}

Dit artikel is niets minder dan een proof of concept, d.w.z. dat een bestaand principe werd bewezen door een studie over sociale cognitie opnieuw uit te voeren, maar dan in een nieuwe, medisch onderwijskundige context. Daarnaast wordt "latente klasse analyse" besproken, een methodologie die we gebruikt hebben om onder de menin- 
gen van artsen naar meerdere clusters van overeenstemming te zoeken. Net zoals beschreven in de literatuur over sociale cognitie, constateerden we dat er van elke aios* meer dan één indruk werd gevormd, die elk door meerdere artsen beschreven werd. Ondanks het feit dat elke arts een unieke sociale indruk van de aios had kunnen opgeven, vonden we toch slechts twee en niet meer dan vijf verschillende indrukken voor elke aios. De reeks indrukken voor een bepaalde aios varieerde niet alleen qua inhoud, maar ook qua oordeel dat gegeven werd. Onze bevinding was dat artsen die ongeveer dezelfde sociale oordelen gaven, vaak ook vergelijkbare waarderingen toekenden. Deze resultaten wezen erop dat er binnen het geruis van variabiliteit tussen beoordelaars ook meerdere signalen op te vangen waren die een aanknopingspunt vormden voor nader onderzoek.

\section{HOOFDSTUK 5}

Nu we een methodiek hadden gevonden waarmee we binnen de opmerkingen van artsen over klinisch handelen clusters van overeenstemming konden ontdekken, konden we het onderzoek verder uitbreiden zodat het alle drie de in hoofdstuk 3 beschreven theorieën van sociale categorisatie omspande. Toen we nagingen in hoeverre elk van deze theorieën in staat was om de verschillen tussen praktijkbeoordelingen te verklaren, kwamen we tot de ontdekking dat ze stuk voor stuk een aardige variatie aan waarderingen wisten uit te leggen. Anders gezegd, met elke categorisatietheorie konden we de opmerkingen van artsen m.b.t. het klinisch handelen van één aios in 2 tot 4 aparte categorieën onderverdelen. Bij het bestuderen van de inhoud van de voorspellende categorieën merkten we dat de indrukken van beoordelaars niet alleen per aspect konden afwijken, maar dat zij ook verschilden in de aspecten van klinisch handelen die benadrukt werden. Deze bevinding vindt zijn weerklank bij ander medisch onderwijskundig onderzoek. We hadden clusters van overeenstemming gevonden die inderdaad wezenlijke verschillen in de interpretatie van het handelen van één aios leken te weerspiegelen. Deze bevindingen waren echter slechts nog proefondervindelijk en behoefden nadere toetsing.

\section{HOOFDSTUK 6}

In dit artikel wordt beschreven hoe wij de bevinding dat er clusters van overeenstemming lijken te bestaan hebben getrianguleerd met behulp van een nieuwe groep deelnemers en door een andere methodologie toe te passen. Opnieuw vonden we dat er twee of drie verschillende meningen werden gegeven voor het klinisch handelen van dezelfde aios. Bij nadere inspectie bleken deze meningen behoorlijk wat verscheidenheid te vertegenwoordigen. De inhoud van deze meningen kwam overeen met die van 
de eerder benoemde clusters van overeenstemming en daarmee werd het gegeven bevestigd dat artsen eenzelfde aspect van het handelen op verschillende manieren kunnen beoordelen. Het feit dat deze resultaten zich steeds opnieuw bevestigd zien, maakt dat wij ons serieus afvragen of het niet verstandiger is artsen als constructivistische beoordelaars te beschouwen in plaats van ze als post-positivistische toetsinstrumenten te zien.

\section{HOOFDSTUK 7}

In het laatste hoofdstuk gaan we nader in op de gevolgen van de bevinding dat er onder wisselende beoordelingen clusters van overeenstemming te ontwaren zijn. Het feit dat er meerdere punten van overeenstemming bestaan zou erop kunnen wijzen dat een bepaalde competentie beter beschouwd kan worden als iets dat meerdere signalen of "waarheden" omsluit. Als dat zo is, dan moeten we onze meetmodellen zo aanpassen dat ze rekening houden met meerdere "ware scores". Deze bevinding maakt het een uitdaging een beoordelingssystematiek te ontwikkelen waarmee wisselende en subjectieve beoordelingen zo geanalyseerd kunnen worden dat ze bijdragen aan gedegen besluitvorming ten aanzien van aios-competenties. Op basis van een fictieve beoordelingssystematiek bespreken we niet-psychometrische methodes waarmee de beoordelingen van artsen ten aanzien van de competenties van aiossen mogelijk systematisch geanalyseerd zouden kunnen worden. Er is meer onderzoek nodig om nog vollediger te kunnen begrijpen wat clusters van overeenstemming betekenen en wat de gevolgen zijn voor beoordelaarsafhankelijke toetsen. 

Addendum

Valorization paragraph 
1. (Relevance) What is the social (and/or economic) relevance of your research results (i.e. in addition to the scientific relevance)?

Variability in ratings, human judgment, assessment and measurement were discussed within this dissertation. Rater-based assessments are an important component of programmatic assessment ${ }^{1}$ spanning all levels of medical training and requiring significant financial and human resources. However, the quality of our assessment systems affects more than just our medical training programs. Since training per student is expensive in terms of money and time, many medical schools are heavily funded through taxpayer money. As such, governments demand accountability from the educational institutions for those funds and taxpayers expect quality health care as a result of the expenditures. Assessment outcomes are one form of evidence medical training programs can use in their reporting their activities.

More critically, assessment functions as a gate-keeping mechanism to determine when students are sufficiently competent to progress to the next phase of training. This includes assessment being used to determine when trainees are competent enough to be considered autonomous practitioners who provide unsupervised health care to the general public. As emphasized by Kogan and colleagues, "To be professionally accountable and attain the public's trust, the onus is on us, as medical educators, to make good assessment decisions. The interrater variability of work-based assessments is not just an educational issue but also a patient care and safety issue. Medical education and health care delivery are intertwined.. ${ }^{2(p .725)}$ Our failure to adequately assess students and trainees could negatively impact health care delivery making assessment design and analysis relevant to societal needs.

This is especially important since there has been a world-wide shift to adopting outcomes-based medical education at all levels of training. ${ }^{3}$ The outcomes to be measured are complex, functionally relevant skills; skills which are vital for trainees to perform well within the labour market. ${ }^{4}$ Assessment of these complex skills requires human judgment, and therefore, understanding how humans make assessment judgments is important. If we fail to use human judgment well within our assessment programs, outcomes-based medical education will fail. This dissertation prompts further investigations into better understanding human judgment within assessment tasks.

2. (Target groups) To whom, in addition to the academic community, are your research results of interest and why?

The general public relies on our graduates to provide health care. They expect our assessments to determine if and when trainees are capable of providing quality care. ${ }^{5}$ As such, medical licensing examination boards may be interested in considering these 
results when making decisions regarding which measurement techniques to use. The need for National licensing examinations is debated ${ }^{6}$ and their role might change if more sound workplace-based assessments could be used to map the progression of trainee competence over time.

Additional target groups include program administrators who could use these results to re-consider how they collect and interpret assessments from supervisors. For example, these results suggest that administrators should expect multiple different assessment judgments to be collected from different supervisors for the same trainee. These different judgments are associated with different points of view but are not likely to be unique to each supervisor and do not necessarily reflect bias in the judgments. Similarly, clinical mentors could consider these results when meeting with trainees to discuss their clinical performance. Discussions could include reflections about why performance can be perceived differently than it was intended. Trainees could use these results to prepare themselves to receive differing judgments of their performance. Rather than dismissing them as mixed messages, these results might help encourage trainees to view different judgments as differing critiques.

3. (Activities/Products) Into which concrete products, services, processes, activities or commercial activities will your results be translated and shaped?

I believe it is premature to begin translating these results into assessment products. It is reassuring that a relatively limited number of variations between raters were found rather than idiosyncratic impressions and judgments. Although, these results do have some unsettling implications for how we conceptualize our current assessment designs and radical design changes would be required to accommodate them. However, these results are very preliminary and need to be extended and challenged before it would be reasonable to use them to inform design changes. I would be delighted if fellow researchers were motivated to test the limits of these findings and through their investigations, along with our own, we could determine the robustness of the effects.

4. (Innovation) To what degree can your results be called innovative in respect to the existing range of products, services, processes, activities and commercial activities?

This dissertation is innovative in presenting a new way to think about variability in ratings. It takes a novel approach to trying to understand rater cognition by assuming most raters are trying to provide useful assessment judgments and are capable of providing quality assessment judgments. Up until this point, researchers in favour of using ratings for performance assessments have viewed variability as something to minimize (as is discussed in more detail in Chapter 2). Researchers who have been 
more critical of using ratings for performance assessment have focused on the (mis)alignment of the psychometric assumptions to the purpose of the assessments. ${ }^{7,8}$ The focus has been at the conceptual or philosophical level. ${ }^{9}$ This program of research provides some initial evidence that physicians may be not interchangeable as raters, and therefore, violate the psychometric assumption for homogeneity of the rater population. These results could be used to challenge the use of psychometric measurement for performance assessment ratings, calling for new views on how to handle assessment information. ${ }^{10}$

These results are innovative in that they compel us to start thinking differently about the source of variability in ratings and what the variability reveals about rater cognition. If these results are found to be robust through further investigations, they could inspire a novel approach to assessment design and analysis. To be consistent with this dissertation's perspective, the novel approach could include first determining what assessment information supervisors can aptly provide and then designing a suitable assessment system to collect and analyze it. As an example of one possible direction for innovation in assessment design, we presented a hypothetical assessment design that does not use ratings. This dissertation changes what is seen as the problem with rater-based assessments, and subsequently, opens up a new potential for solutions.

5. (Schedule \& Implementation) How will this/these plans(s) for valorization be shaped? What is the schedule, are there risks involved, what market opportunities are there and what are the costs involved?

For the last several years, I have been discussing these questions and findings at academic conferences and asking other researchers for their reactions to them. This has been immensely helpful in refining and re-directing my thinking around rater cognition. It has also led to invitations to join research collaborations that will hopefully allow me to pursue multiple lines of research into assessment judgments, in parallel. As I transition from being a research associate to a faculty member, I believe I am wellpositioned to continue investigating variability in assessment judgments. This research will aim to contribute to the medical education community's current interests in using entrustable professional activities and competency-based assessments. Rater-based assessments are a key component of our apprenticeship-like clinical training models resulting in a strong need for improved assessment designs. Even though it is too early to specify when and how it will happen, as more is uncovered about rater cognition, I am confident the new findings will contribute to improving assessment designs and decisions regarding trainee competency. 


\section{REFERENCES}

1 Van der Vleuten C, Schuwirth L, Driessen E, Dijkstra J, Tigelaar D, Baartman L et al. A model for programmatic assessment fit for purpose. Medical Teacher 2012;34 (3):205-14.

2 Kogan JR, Conforti LN, lobst WF, Holmboe ES. Reconceptualizing variable rater assessments as both an educational and clinical care problem. Academic M edicine 2014;89 (5):721-7.

3 Tekian A, Hodges BD, Roberts TE, Schuwirth L, Norcini J. Assessing competencies using milestones along the way. Medical Teacher 2015;37 (4):399-402.

4 Ben-David MF. The role of assessment in expanding professional horizons. Medical Teacher 2000;22 (5):472-7.

5 Otaki J, Nagata-Kobayashi S, Takayashiki A. Aspects of clinical skills test demanded by the public for the national medical licensure examination in japan. Medical Teacher 2012;34 (5):423-.

6 Bajammal S, Zaini R, Abuznadah W, Al-Rukban M, Aly SM, Boker A et al. The need for national medical licensing examination in saudi arabia. BM C M edical Education 2008;8:53-.

7 Schuwirth LW, van der Vleuten CP. Assessing competence. In: Hodges BD, Lingard LA, editors. The question of competence: Reconsidering medical education in the twenty-first century. First Ed. Ithaca and London: ILR Press-Cornell University Press; 2012. p. 113-30.

8 Hodges B. Assessment in the post-psychometric era: Learning to love the subjective and collective. Medical Teacher 2013;35 (7):564-8.

9 Whitehead CR, Kuper A, Hodges B, Ellaway R. Conceptual and practical challenges in the assessment of physician competencies. Medical Teacher 2015;37 (3):245-51.

10 Govaerts M, Vleuten CPM . Validity in work-based assessment: Expanding our horizons. Medical Education 2013;47 (12):1164-74. 

Curriculum vitae 
Andrea Gingerich was born on March 28, 1976, in Huron County, an agricultural region in southwestern Ontario along the coast of Lake Huron. She lived in a rural setting near the hamlet of Walton before moving to the nearby small town of Seaforth in 1989 where she attended and graduated from the local high school.

After graduating from the University of Western Ontario with a bachelor degree in physiology and psychology in 1998, she attended the Canadian College of Naturopathic Medicine in Toronto. She graduated and was licensed as a naturopathic doctor in 2002, opened a multi-disciplinary clinic in her hometown of Seaforth and practiced for four years.

To pursue a passion for teaching and research, in 2006, she sold her practice and moved to the small remote city of Prince George which is considered the capital of northern British Columbia and is located in the interior of the province. There, she started as a problem-based learning tutor with the Northern Medical Program, a regional medical campus of the University of British Columbia's Faculty of Medicine. Enjoyment with this role led to the completion of a degree of master of medical education with distinction through Dundee University in 2010. During her studies, she was hired as a research associate with the Northern M edical Program, continued to tutor in problem-based learning as well as in other small group learning courses and helped with training, recruiting and organizing PBL tutors.

In addition to the support she received from the Northern Medical Program during her doctoral studies, she received a grant from the Society of Directors of Research in Medical Education to write the review paper, "Rater-based assessments as social judgments: Rethinking the etiology of rater errors" in 2010. In 2011, she was awarded the Thomas Hale Ham Award for New Investigators by the Research in M edical Education Conference Program Planning Committee of the Association of American M edical Colleges Group on Educational Affairs for that same paper. She received a Canadian Association of Medical Education Certificate of M erit Award in 2012 for making a valuable contribution to medical education at the UBC Faculty of Medicine. Her doctoral program of research was funded through a 2012 Edward J. Stemmler, MD Medical Education Research fund from the National Board of M edical Examiners.

Andrea is eager to continue studying rater cognition with this program of research. 


\section{SHE dissertations series}

The SHE Dissertation Series publishes dissertations of PhD candidates from the School of Health Professions Education (SHE) who defended their PhD theses at Maastricht University. The most recent ones are listed below. For more information go to: www.maastrichtuniversity.nl/she.

Al-Eraky, M. (21.05.15) Faculty development for medical professionalism in an Arabian context Wearne, S. (08.04.2015) Is it remotely possible? Remote supervision of general practice registrars Embo, M. (13.03.2015) Integrating workplace learning, assessment and supervision in health care education Zwanikken, P. (23.01.2015) Public health and international health educational programmes for low- and middle-income countries: questioning their outcomes and impact

Hill, E. (11-12-2014) A cutting culture: gender and identification in the figured world of surgery

Diemers, A. (03-10-2014) Learning from pre-clinical patient contacts

Tjiam, I. (17-09.2014) Learning in Urology. Designing simulator based skills Training \& Assessment

Berkenbosch, L. (30-06-2014) Management and leadership education for medical residents

Bergman, E.M . (30-06-2014) Dissecting anatomy education in the medical curriculum

Dijkstra, J. (25-06-2014) Guidelines for designing programmes of assessment

Van Loon, M.H. (08-05-2014) Fostering monitoring and regulation of learning

Frambach, J.M . (26-03-2014) The cultural complexity of problem-based learning across the world

Hommes, J.E. (26-02-2014) How relations, time \& size matter in medical education

Van der Zwet, J. (30-01-2014) Identity, Interaction and Power. Explaining the affordances of doctor-student interaction during clerkships

Watling, C.J. (22-01-2014) Cognition, Culture, and Credibility. Deconstructing Feedback in M edical Education Winston, K. (12-12-2013) Remediation Theory and Practice: Transforming At-Risk M edical Students

Kamp, R.J.A. (28-11-2013) Peer Feedback to Enhance Learning in Problem-Based Tutorial Groups

Junod Perron, N. (24-10-2013) Towards a learner-centered approach to postgraduate communications skills teaching

Pratidina Susilo, A. (24-10-2013) Learning to be the Patient Advocate The Development of a Communication Skills Course to Enhance Nurses' Contribution to the Informed Consent Process

Alves de Lima, A. (23-10-2013) Assessment of clinical competence: Reliability, Validity, Feasibility and Educational Impact of the mini-CEX

Sibbald, M. (09-10-2013) Is that your final answer? How doctors should check decisions

Ladhani, Z. (05-07-2013) Competency based education and professional competencies: a study of institutional structures, perspectives and practices in Pakistan

Jippes, M. (01-02-2013) Culture matters in medical schools: How values shape a successful curriculum change

Duvivier, R. J. (12-12-2012) Teaching and Learning Clinical Skills. Mastering the Art of Medicine

De Feijter, J.M. (09-11-2012) Learning from error to improve patient safety 
Prescott, L. (09-11-2012) Ensuring the Competence of Dental Practitioners through the Development of a Workplace-Based System of Assessment

Cilliers, F.J. (05-09-2012) The Pre-assessment Learning Effects of Consequential Assessment: Modelling how the Examination Game is Played

Spanjers, I. A.E. (05-07-2012) Segmentation of Animations: Explaining the Effects on the Learning Process and Learning Outcomes

Al-Kadri, H.M.F. (28-06-2012) Does Assessment Drive Students' Learning?

Leppink, J. (20-06-2012) Propositional manipulation for conceptual understanding of statistics

Van Zundert, M.J. (04-05-2012) Conditions of Peer Assessment for Complex Learning

Claramita, M. (30-03-2012) Doctor-patient communication in a culturally hierarchical context of Southeast Asia: A partnership approach

Kleijnen, J.C.B.M. (21-03-2012) Internal quality management and organizational values in higher education

Persoon, M.C. (19-01-2012) Learning in Urology; The influence of simulators and human factors

Pawlikowska, T.R.B. (21-12-2011) Patient Enablement; A Living Dialogue

Sok Ying Liaw, (14-12-2011) Rescuing A Patient In Deteriorating Situations (RAPIDS): A programmatic approach in developing and evaluating a simulation-based educational program

Singaram, V.S. (7-12-2011) Exploring the Impact of Diversity Factors on Problem-Based Collaborative Learning

Balslev, T. (24-11-2011) Learning to diagnose using patient video cases in paediatrics: Perceptive and cognitive processes

Widyandana, D. (19-10-2011) Integrating Pre-clinical skills training in skills laboratory and primary health care centers to prepare medical students for their clerkships

Durning, S.J. (09-09-2011) Exploring the Influence of Contextual Factors of the Clinical Encounter on Clinical Reasoning Success (Unraveling context specificity)

Govaerts, M. J.B. (08-09-2011) Climbing the Pyramid;Towards Understanding Performance Assessment

Stalmeijer, R. E. (07-07-2011) Evaluating Clinical Teaching through Cognitive Apprenticeship

Malling, B.V.G. (01-07-2011) M anaging word-based postgraduate medical education in clinical departments

Veldhuijzen, J.W. (17-06-2011) Challenging the patient-centred paradigm: designing feasible guidelines for doctor patient communication

Van Blankenstein, F. (18-05-2011) Elaboration during problem-based, small group discussion: A new approach to study collaborative learning

Van M ook, W. (13-05-2011) Teaching and assessment of professional behavior: Rhetoric and reality 


\section{TRUE:}

These squares are the same shade

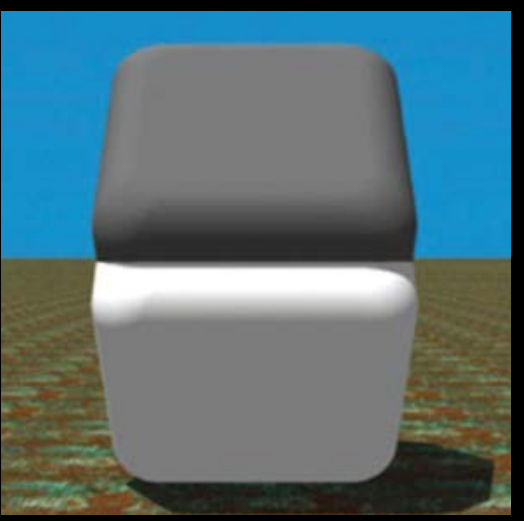

TRUE:

These squares are different shades 